\title{
Die Copepoden der Umgebung Basels von
}

\author{
Alb. GR $\approx$ T E R \\ Hiezu Tafel. 15. \\ 6 Tabellen und 1 Karte.
}

Die hier niedergelegten Ergebnisse faunistischer Untersuchungen bilden den ersten, erweiterten Teil einer von der philosophischen Fakultät der Universität Basel im Jahre 1896 preisgekrönten Arbeit über die Copepoden und Ostracoden der Umgebung Basels.

Es sei mir vergönnt, meinem verehrten Lehrer, Herrn Prof. F. ZschоккE, dessen Anregung mich auf dieses reiche Arbeitsfeld geführt hat, herzlich zu danken. Er ist mir bei der Beschaffung der Litteratur wirksam zur Seite gestanden und hat mir auch mit der eigenen Bibliothek ausgeholfen. Herr Prof. E. Hagenbach hat mit mir die physiologische Frage der Gleichgewichtsbedingungen der Genera Cyclops und Diaptomus besprochen, und von Herrn Prof. O. Funrmans in Neuenburg, damals Assistent der Basler Zoologischen Anstalt, der selbst schon 13 Cyclopsarten für unsere Umgebung nachgewiesen hatte, bin ich in die Geheimnisse der Crustaceenbestimmung eingeweiht worden. Es freut mich, beiden Herren an dieser Stelle für alle mir bewiesene Freundlichkeit danken zu dürfen. Verpflichtet bin ich auch den Herren Prof. R. BuRckнardt in Basel, Prof. Heuscher in Zürich, Bibliothekar Dr. STEck

Rev. Suisse de Zool. T. 11. 1903. 
in Bern und Dr. Jules RichaRd in Paris, die durch Ratschläge und durch Beschaffung von Büchern auch zum Erfolg dieser Arbeit beigetragen haben, und Herrn Dir. HAAck, der durch seine Gastfreundlichkeit mir die Untersuchung der vielen Weiher der Fischzuchtanstalt erleichtert hat.

\section{EINLEITUNG.}

Der Zweck der vorliegenden Untersuchungen war die Aufstellung einer mögliçst genauen und vollständigen Artenliste aller im Gebiete vorkommenden, freilebenden SüsswasserCopepoden. Die Untersuchungen erstrecken sich über einen Zeitraum von 5 Jahren, von 1895 bis 1900 . Sie umfassen die Gegend von Belfort bis Säckingen, mit Delsberg und dem Nordabhange des Jura als südlichster Grenze, und der Stadt Neuenburg am Rhein mit dem Feldberg als nördlichster Grenze. In diesem Gebiet wurden die verschiedenartigsten Gewässer, im Ganzen über 180, zu allen Jahreszeiten untersucht. Dabei ist der zoogeographische Zweck insofern erreicht worden, als Basel jetzt nicht nur die auf Copepoden bestuntersuchte Stadt ist, sondern auch als diejenige angesehen werden muss, deren Gebiet die grösste Zahl von Arten beherbergt. Die zweite Tatsache steht mit der ersten in mehr als bloss zufälligem Zusammenhang. Doch muss für sie auch eine Erklärung in der günstigen Lage Basels gesucht werden; vor allem in der reichen Gliederung der Umgebung, dem Zusammentreffen dreier Gebirgssysteme mit dem südlichen Teile der rheinischen Grabenversenkung.

Ich hege nicht die Ueberzeugung, dass das Verzeichnis vollständig sei, wurde es doch noch im letzten Jahre meiner Untersuchungen um zwei Arten vermehrt und befinden sich auf ihm nur drei Arten der unregelmässig und launenhaft auftretenden 
Harpacticiden. Hiezu kommt, dass ich den grossen Reichtum des Schwarzwaldes zu spät erkannt und sein Gebiet nicht so untersucht habe, wie zum Beispiel das der Rheinebene.

Um meinen Hauptzweck nicht von einem andern durchkreuzen zu lassen, habe ich, - wenn sie sich mir nicht durch ihre Auffälligkeit aufdrängten, - die periodischen Schwankungen im Auftreten der einzelnen Arten vernachlässigt. Da allein die Zählmethode zu sicheren Ergebnissen führt, in kleineren Gewässern aber, - wenigstens heute noch, - nur geschätzt und nicht gemessen werden kann, so sind diese auch nicht geeignete Orte für derartige Untersuchungen.

Immerhin erlauben mir meine, nicht auf relatives Seltenerwerden, sondern auf absolutes Verschwinden gestutzten Beobachtungen, eine Liste der eurythermen Formen, eine der Kaltwasser- und eine der Warmwasserformen des Genus Cyclops aufzustellen.

Es lag sehr nahe, die drei Listen mit der Zusammenstellung zu vergleichen, die Zschokke von den alpinen Cyclopsarten in der ,Tierwelt der Hochgebirgsseen" gemacht hat. Dieser Vergleich ergab, wenn auch nicht ganz unerwartete, so doch auffallend bestimmte Beziehungen. Ebenso lohnend war die Ausdehnung dieses Vergleichs auf die allgemeine geographische Verbreitung, über die heute eine umfangreiche, mehr oder minder zuverlässige Litteratur vorliegt.

In einer übersichtlichen Tabelle habe ich dann versucht, das Gesamtresultat zu kondensieren, um eine brauchbare Basis für weitere Vergleichungen zu schaffen. Es wird diese Tabelle im Einzelnen noch manche Korrektur erfahren; aber schon heute ergiebt sich aus ihr deutlich, welcher Natur die dem Kosmopolitismus der Cyclopiden gezogenen Grenzen sind.

Der kosmopolitische Charakter der Cyclopsarten bringt es mit sich, dass sie entweder gleichmässig oder dann ganz regellos über das Gebiet verstreut sind. Zu zoogeographischen 
Betrachtungen sind sie somit nicht gut zu verwerten. Hingegen sind es die Centropagiden, besonders die Arten des. Genus Diaptomus. Verglichen mit dem Genus Cyclops fanden sich ihrer nur wenige, von dem 67 Arten zählenden Genus Diaptomus nur 6. Aber die 6 Arten verteilen sich über das Gebiet in so charakteristischer Weise, dass sich dieses. darnach in Bezirke auflösen lässt. Es wird das Vorkommen dieser wenigen Arten einen brauchbaren Beitrag zur Förderungder so eifrig studierten Frage der Verbreitung der Diaptomusarten bilden.

Der Gegensatz im Auftreten dieser beiden bekanntesten und verbreitetsten Genera der Süsswasser-Copepoden geht. Hand in Hand mit einem Gegensatz in der Lebensweise und Organisation und kann sogar mit grosser Wahrscheinlichkeit aus ihm erklärt werden. Das Genus Diaptomus ist einseitigpelagisch, und seine 67 Arten stimmen in der Körperorganisation bis auf die biologisch unwichtigen Differentialcharaktere überein. Gegenüber dieser Eintönigkeit in dem grossen Genus sticht die Mannigfaltigkeit ab, die in dem viel kleineren Genus Cyclops $\mathrm{zu}$ finden ist. Von der pelagischen zur littoralen und von dieser zur kriechenden Lebensweise finden sich alle Uebergänge, und mit der Lebensweise wandelt auch die Körperform. Das Studium der Cyclopiden gewinnt dadurch eine besondere Bedeutung; denn, wenn irgendwo, so müssen bei ihnen die Beziehungen zwischen Lebensweise und Körperbau zu Tage treten. Der Umstand, dass die 22 Cyclopsarten Deutschlands alle bei Basel vorkommen und ich deshalb alle lebend untersuchen konnte, hat mir erlaubt, mich mit beidem vertraut zu machen. Das Resultat meiner so gewonnenen Anschauung ist der Versuch, einen Stammbaum des Genus zu entwerfen, sowie die Einteilung des Genus, in der dieser Stammbaum seinen praktischen Ausdruck gefunden hat. In den Spezialdiagnosen ist die Stellung der einzelnen Arten im Stammbaum und im System jeweilen ausführlich be- 
sprochen worden. Einen Zweck hätten die Diagnosen nach den methodischen und erschöpfenden Beschreibungen ScHMEILS sonst nicht gehabt. Für die Arten der Centropagiden und Harpacticiden gebe ich keine solchen Einzelbeschreibungen; dafür habe ich der geographischen Verbreitung der beiden Familien je ein besonderes Kapitel gewidmet.

\section{Verzeichniss DER GEFUNDENEN ARTEN.}

Die Zahl der von mir bei Basel gefundenen Copepoden beziffert sich auf 34, wovon 8 auf die Centropagiden, 23 auf das Genus Cyclops und 3 auf das Genus Canthocamptus entfallen. Die Arten heissen:

1. Heterocope saliens.

2. $\gg$ appendiculata.

3. Diaptomus castor.

4. $\gg$ laciniatus.

5. $\quad$ gracilis.

6. $\quad$ transylvanicus.

7. $\gg$ vulgaris.

$8 . \quad$ denticornis.

9. Cyclops fuscus.

10. » albidus.

12. " prasinus.

13a. " serrulatus forma typica.

13b. » serrulatus nov. var. denticulata.

14. » macrurus.

15. " affinis.

16. 》 phaleratus.

17. $\gg$ poppei.

18. " fimbriatus.

19. " leuckarti. 
20. Cyclops hyalinus var. von oithonoides.

21. » dybowskii.

22. 》 gracilis.

23. $\gg$ strenuus.

24. $\gg$ viridis.

25. $\gg$ insignis.

26. » varicans.

27 . $\gg$ vernalis.

28. $\gg$ bicuspidatus.

29. » bisetosus.

30. 》 languidus.

31. » diaphanoides nov. var. von diaphanus.

32. Canthocamptus staphylinus,

$33 . \quad$ minutus.

34. 》 northumbricus.

Die Ausbeute, die für die Centropagiden und die Harpacticiden gut ausgefallen ist, muss für das Genus Cyclops geradezu überraschend genannt werden. Die 22 Arten, die als Frucht der Arbeit des vergangenen Jahrhunderts in dem bestuntersuchten Lande, in Deutschland, gefunden worden sind, kommen alle samt und sonders bei Basel vor. Die Theorie von der gleichmässigen Verbreitung der Cyclopiden, die gerade in letzter Zeit von MrazeK und STEuER angegriffen worden ist, erhält hier eine neue Stütze.

Die 17 bis jetzt für Frankreich konstatierten Arten habe ich durch den Fund von Cyclops varicans bei Faverois um eine Art vermehrt.

Die Liste der schweizerischen Tiere wird durch die Arten Cyclops varicans (Bonfol), Cyclops insignis (Bonfol) und Cyclops languidus (Allschwyl) vermehrt.

Deutschland wird um den Diaptomus transylvanicus und verschiedene neue Fundorte wie die des Diaptomus denticornis bereichert. 
Ueberhaupt neu sind die beiden prägnanten Varietäten $C y$ clops serrulatus nov. var. denticulata (Frankreich, Deutschland, Schweiz), und Cyclops diaphanus nov. var. diaphanoides (Schwarzwald: Jungholz und Nonnenmattweiher).

Einige Formen verschwanden im Sommer vollständig oder teilweise, wenigstens in einer Anzahl von Weihern und traten das folgende Jahr wieder auf. Ich habe darnach folgende Liste von Kaltwassertieren zusammengestellt:

Cyclops strenuus, C. vernalis, C. bicuspidatus.

Andere verschwanden umgekehrt im Winter, sind also Warmwassertiere :

Cyclops prasinus, C. macrurus, C. poppei, C. levickarti (erwachsene Exemplare), C. oithonoides var. hyalina, C.dybowskii, C. gracilis, C. bicolor.

Interessant ist es nun zu sehen, dass in der von ZschokKE aufgestellten Liste von alpinen Cyclopsarten die Kaltwasserformen alle und von Warmwasserformen keine einzige enthalten ist. Interessant ist auch, dass die drei Kaltwasserformen nahe Verwandte sind, von den Warmwasserformen die drei ersten unter sich eine Gruppe bilden, und die vier letzten die Subsectio der Chatophora in ihrer Gesammtheit ausmachen. Am besten wird die geographische Verteilung auf den nun folgenden Tabellen ersichtlich. Die letzte enthält zum Vergleich noch einige Resultate gut untersuchter schweizerischer Gewässer. Teils nach Steck (Moosseedorfsee), Zschokke (Lac des Brenets), AvBerg (Katzensee), teils von mir untersucht (Lohweiher, Bieler-, Neuenburger- und Walensee), sind es bloss Gewässer, bei denen neben dem Plankton auch die littorale Fauna berücksichtigt wurde. Die Verhältnisse der verschiedenen Bezirke zu einander werden am besten der beigefügten Karte entnommen. Diese soll im Besonderen dazu dienen, von der Verteilung der Diaptomusarten ein anschauliches Bild zu geben. 
Da die periodischen, jahreszeitlichen Schwankungen der Cyclopiden, wie sie mir ohne quantitive Messungen nur durch das Verschwinden und Wiederauftreten der einzelnen Arten aufgefallen sind, auf den Tabellen nicht ausgedrückt werden, soll die folgende Liste der Cyclopsarten das Vorkommen und das Nichtvorkommen dieser Schwankungen, sowie ihre Natur, ob sommerlich oder winterlich, übersichtlich darstellen, und in Verbindung damit die geographische Verbreitung in der Richtung des Meridians und das Auftreten im Hochgebirge. Als stenotherme Formen habe ich auch solche bezeichnet, die nur ausnahmsweise

- aus einem Gewässer, sei es zur heissen oder zur kalten Jahreszeit, periodisch verschwanden und dafür in andern das ganze Jahr hindurch ausharrten. Wie sehr diese Auffassung richtig ist, beweist, dass sogar Cyclops strenuus in diesem Falle ist und in seiner pelagischen Form sehr oft den Sommer überdauert. Da dieser Umstand sein südliches Vorkommen erklären dürfte, habe ich ihn auf der Tabelle zweimal, $d . h$. noch besonders als pelagische Art aufgeführt. Unter Norden und Süden ist zu verstehen, jenseits des 55sten Grades, respective des 35sten.

\section{DAS JAHRESZEITLICHE AUFTRETEN DER CYCLOPSARTEN VERGLICHEN}

MIT IHRER HORIZONTALEN UND VERTIKALEN VERBREITUNG.

Stenotherme Kaltwasser-

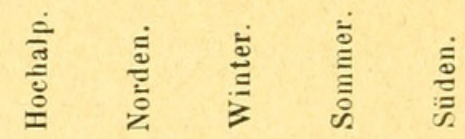

formen, die den Hochalpen fehlen.

Stenotherme Kaltwasser-

Cyclops insignis . . . $-++\ldots$

formen, die auf den Hochalpen vorkommen.

Cyclops strenuus (pelagische sowohl als littorale Form

\section{Cyclops oithonoides. .}

") bicuspidatus.

" strenuus (nur die

pelagische Form). . $.++-(+)+$ Homs $=35^{\circ}$.

Cyclops vernalis . . ++++ Neusibirien, Canaren und

" viridis . . . $++\quad+\quad+$ Azoren $=37^{\circ}$ 
Eurytherme Formen, die dem

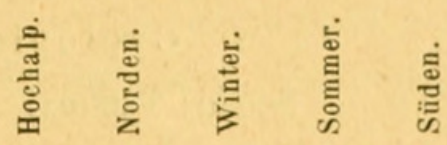

Sïiden fehlen, auf den Hochalpen vorkommen.

$$
\text { Cyclops fuscus . . . . }++++-\begin{aligned}
& \text { Janaland. } \\
& \text { Grönland. }
\end{aligned}
$$

Eurytherme Formen, mit siidlichem und alpinem Vorkommen.

$$
\begin{aligned}
& \text { Cyclops diaphanus . . }++++ \text { Biskra, Cairo. } \\
& \text { ) albidus. . + }+++ \text { Südamerika, Cairo. } \\
& \text { ) serrulatus... }++++ \\
& \text { ") affinis. . }+++++
\end{aligned}
$$

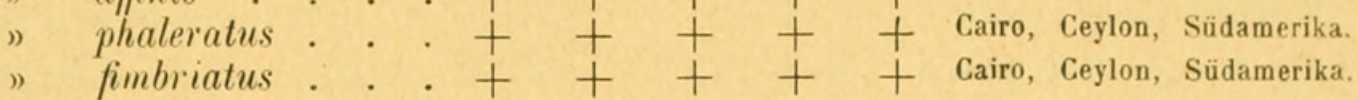

Eurvtherme Formen, mit siidlichem aber nicht alpinem Vorkommen.

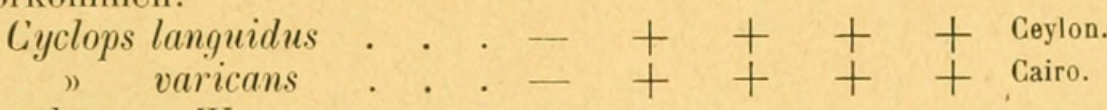

Stenotherme Warmwasserformen mit schwach ausgeprägtem nordischem Charakter.

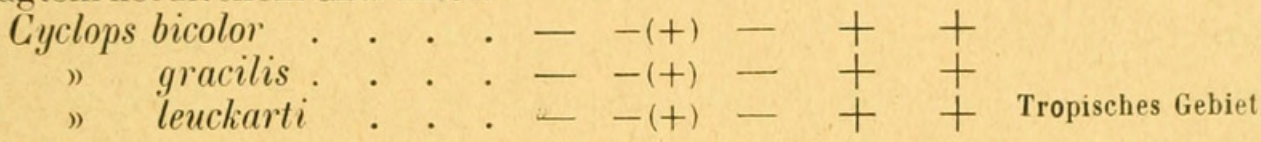

Stenotherme Warmwasser-

formen, die dem Norden

fehlen.

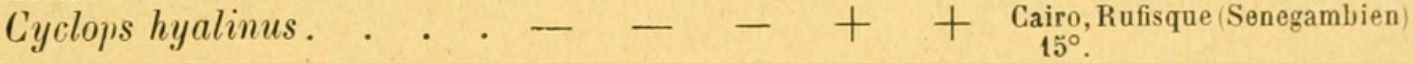

$$
\begin{aligned}
& \text { ") prasinus . . - - }-++ \text { Tropisches Gebiet. } \\
& \text { ") } \\
& \text { ") dybowskii . . - - + + Cairo. }
\end{aligned}
$$

Anmerkung. - - = nicht nachgewiesen.

$+\quad=$ sicher nachgewiesen.

$-(+)=$ nur ausnahmsweise oder im Grenzgebiete vorkommend. 
Cyclopidæ: Genus Crciops.

\author{
Sectio: Trifida. Sectio : BIfIDA.
}

Chætophora. Acanthophora_

Rhein.

Kleinhüningen-Klibeck.

Kleinhüningen-Holzschleife.

Kleinhüningen-Obere Schanze.

Kleinhüningen-Untere Schanze.

Märkt.

Istein.

Felsmühle.

Kleinkems (oberhalb des Dorfes).

Kleinkems (Dorfweiher).

Rheinweiler.

Steinenstadt.

Bucht oberh. d. Eisenbahnbrücke.

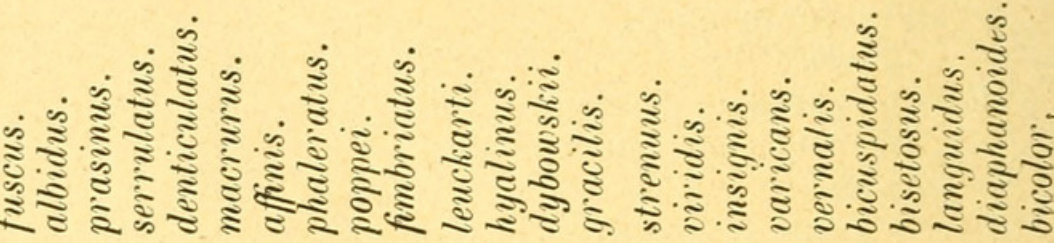

Eisenbahnbrücke bei Neuenburg.

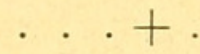

$++$

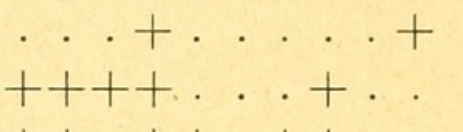

$++\cdot++.++$

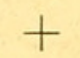

. + . . .

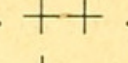

$+.+$

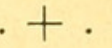

. . . + .

$+\cdot .+.+$
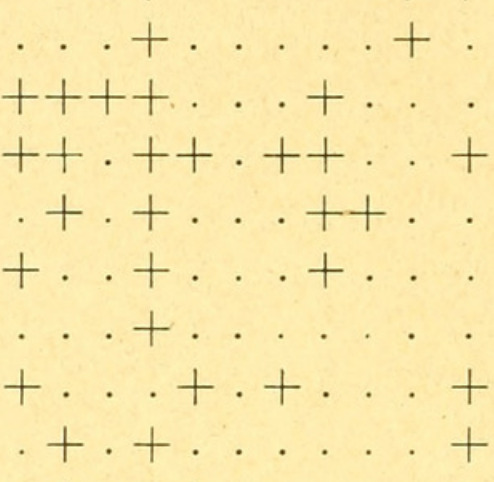

$+$

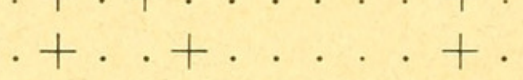

Neuenburg, oberhalb der Brücke.

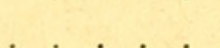

$+$

Neuenburg, unterhalb der Brücke.

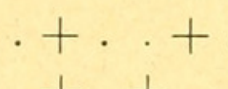

Eichwald (Schalampe).

Eisenbahnbrückè.

Klein Landau.

Kembser Bach.

Kembs am Damm oberh. d. Dorfes.

Unterhalb Rosenau (auf der Höhe des Löchle).

$+\cdot+$
$++\cdot+$
+

+++ .

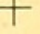

Unterhalb Rosenau (auf der Höho der Richardshäuser).
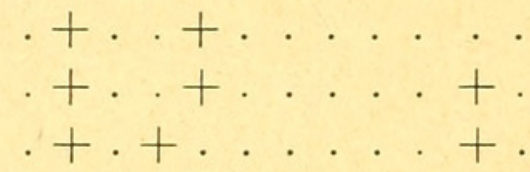

$$
+\cdot+\text {. }
$$

... . . . . +

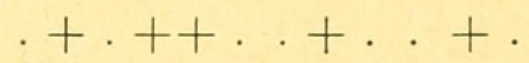

Unterhalb Rosenau ( $1 / 2 \mathrm{~km}$ v.Dorf $).+$. + .

Rosenau beim Altbürgermeister.

Rosenau am Dorf.

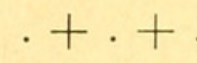

Rosenau beim Kirchenerkopf.

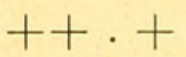

Rosenau bei der Schleuse Nr. 2.

Altwasser unterhalb Neudorf.

.++ .

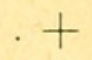

Grosser Neudorfer Weiher.

$++.+\ldots++$.

Kleiner Neudorfer Weiher.
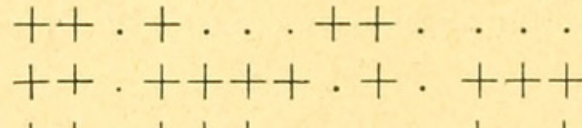

$+$

.++++ .

$+.++.+$ 
Centropagidæ. Harpacticidæ.

Heterocope. Diaptomus. Cinthocamptus.

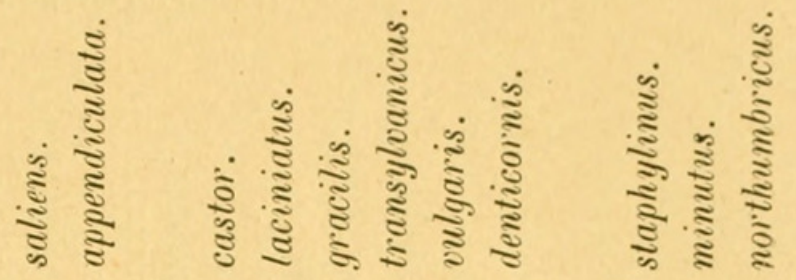

Rhein.

Kleinhüningen-Klibeck.

Kleiuhüningen-Holzschleife.

Kleinhüningen-0bere Schanze.

Kleinhüningen-Untere Schanze.

Märkt.

Istein.

Felsmühle.

Kleinkems (oberhalb des Dorfes).

Kleinkems (Dorfweiher).

Rhein weiIer.

Steinenstadt.

Bucht oberh. d. Eisenbahnbrücke.

Eisenbahnbrücke bei Neuenburg.

Neuenburg, oberhalb der Brücke.

Neuenburg, unterhalb der Brücke.

Eichwald (Schalampe).

Eisenbahnbrücke.

Klein-Landau .

Kembser Bach.

Kembs am Damm oberh. d. Dorfes.

Unterhalb Rosenau (auf der Höhe des Löchle).

Unterhalb Rosenau (auf der Höhe der Richardshäuser).

Unterh. Rosenau (1/2 Ku. v. Dorf).

Rosenau beim Altbürgermeister.

Rosenau am Dorf.

Rosenau beim Kirchenerkopf.

Rosenau bei der Schleuse Nr. 2.

Altwasser unterhalb Neudorf.

Grosser Neudorfer Weiher.

Kleiner Neudorfer Weiher. 
Cyclopidæ: Genus Cyclops.

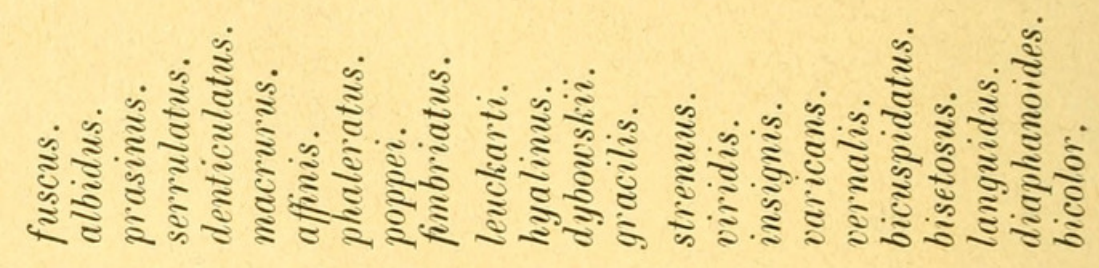

Schäferhof oberhalb Kembs.

Stutz, Eisweiher.

Fischzuchtanstalt, Spitzweiher.

$\cdot .+$
.+++

Fischzuchtanst., Turbinenweiher.

Fischzuchtanst., rechts vom Eing. + + + .

Fischzuchtanst., links vom Eing.

Fischzuchtanstalt, Schlittschuhweiher.

$++\cdot+$

Fischzuchtanstalt, Welsteich.

$++\cdot+$.

Fischzuchtanstalt, Quellwassergraben für Regenbogenforellen.

Fischzuchtanst., bei den Tannen.

Haberhäuser.

Zwischen Haberhäuser und dem Kanal.

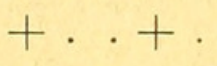

Schleuse Nr. 2, Graben mit Potamogeton.
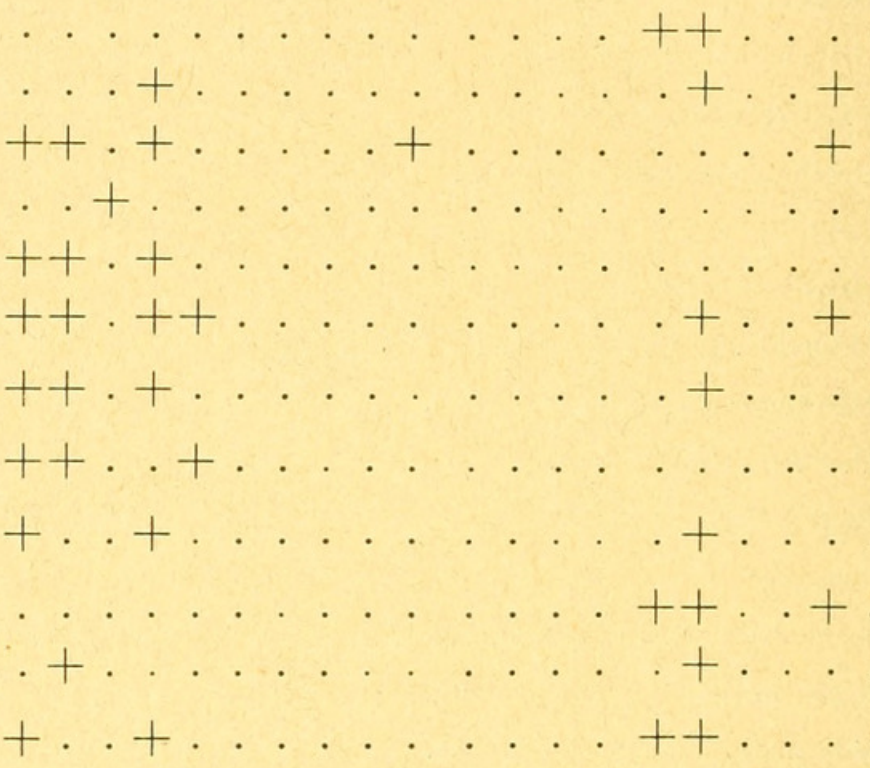

Schleuse Nr. 2, Graben mit Chara.

Oberhalb der Schleuse Nr. 2.

$Z$ wischen Langenhäuser u. Kanal

Langenhäuser.

Brücke von Neudorf.

Oberhalb der Brücke gegen Hüningen zu.

Fischteiche von Michelfelden.

Quellwassergraben.

Michelfelden, Nr. IV.

Michelfelden, Nr. III.

Michelfelden, Nr. II.

Michelfelden, Nr. I.

St. Ludwig.

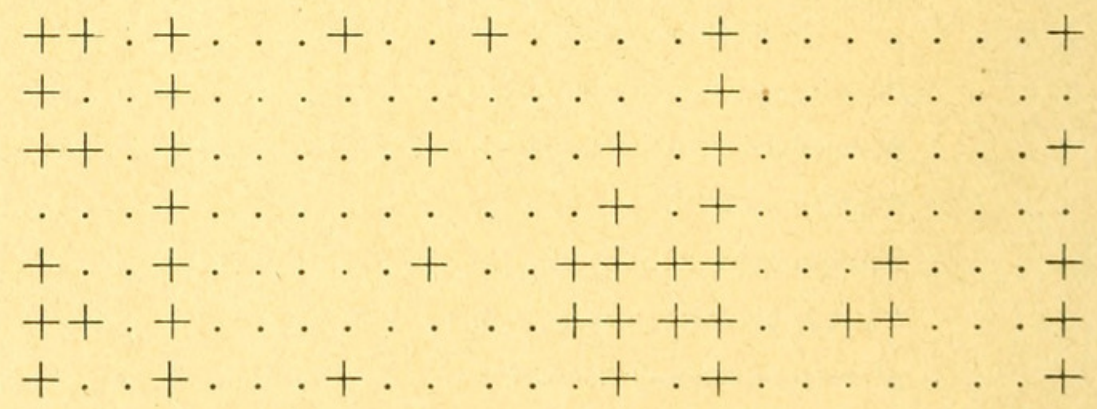




$$
\text { Centropagidæ. }
$$

Heterocope. Diaptomus.

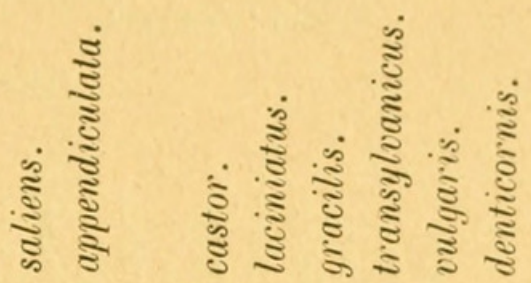

Schäferhof oberhalb Kembs.

Stutz, Eisweiher.

Fischzuchtanstalt, Spitzweiher.

Fischzuchtanst., Turbinenweiher.

Fischzuchtanstalt, rechts vom Eingang.

Fischzuchtanstalt, links vom Bingang.

Fischzuchtanstalt, Schlittschuhweiher.

Fischzuchtanstalt, Welsteich.

Fischzuchtanstalt, Quellwassergraben für Regenbogenforellen.

Fischzuchtanst., bei den Tannen.

Haberhäuser.

Zwischen Haberhäuser und dem Kanal.

Schleuse Nr. 2, Graben mit Potamogeton.

Schleuse Nr 2, Graben mit Chara.

Oberhalb der Schleuse Nr. 2.

Zwischen Langenhäuser u. Kanal.

Langenhäuser

Brücke von Neudorf.

Oberhalb der Brücke gegen Hüningen $\mathrm{zu}$.

Fischteiche von Michelfelden.

Quellwassergraben.

Michelfelden, Nr. IV.

Michelfelden, Nr. III.

Michelfelden, Nr. II.

Michelfelden, Nr. I.

St. Ludwig.
Harpacticid $x$.

Canthocamptus.
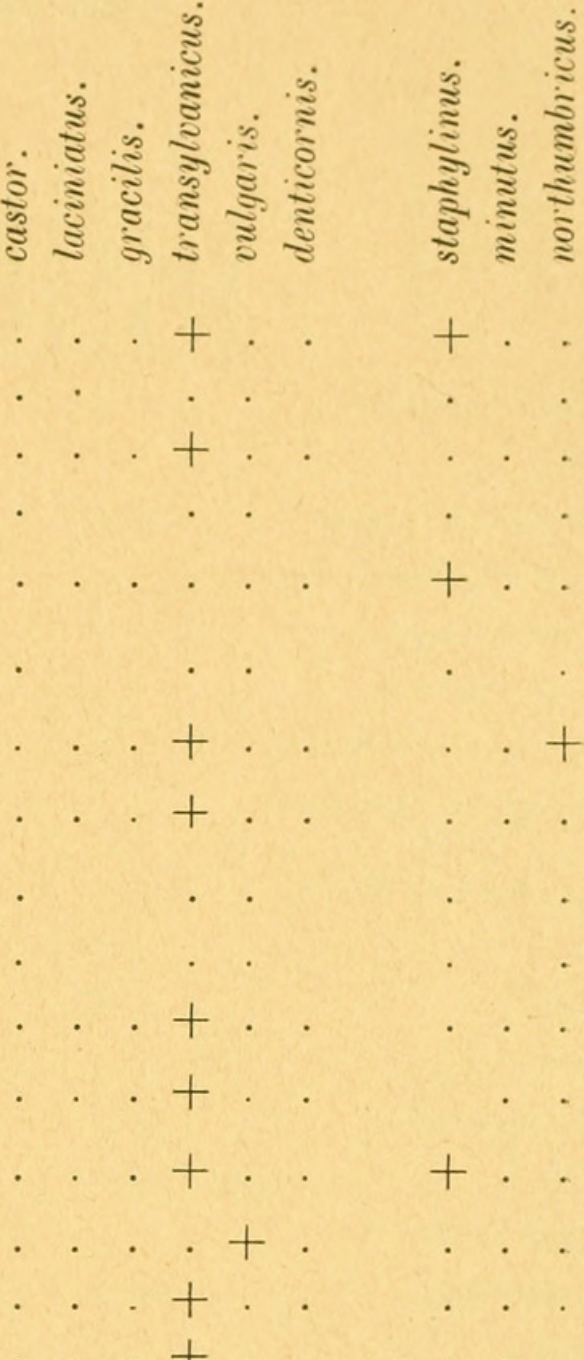

. . . +

. . +

. . . +

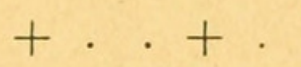

$+. .+$

. . . + .

$+\cdot .+$

$+$

+ .

++ .

+ . 
Cyclopidæ: Genus Cyclops.

\author{
Sectio : Trifida. Sectio: Bifida.
}

Chætophora. Acanthophora.

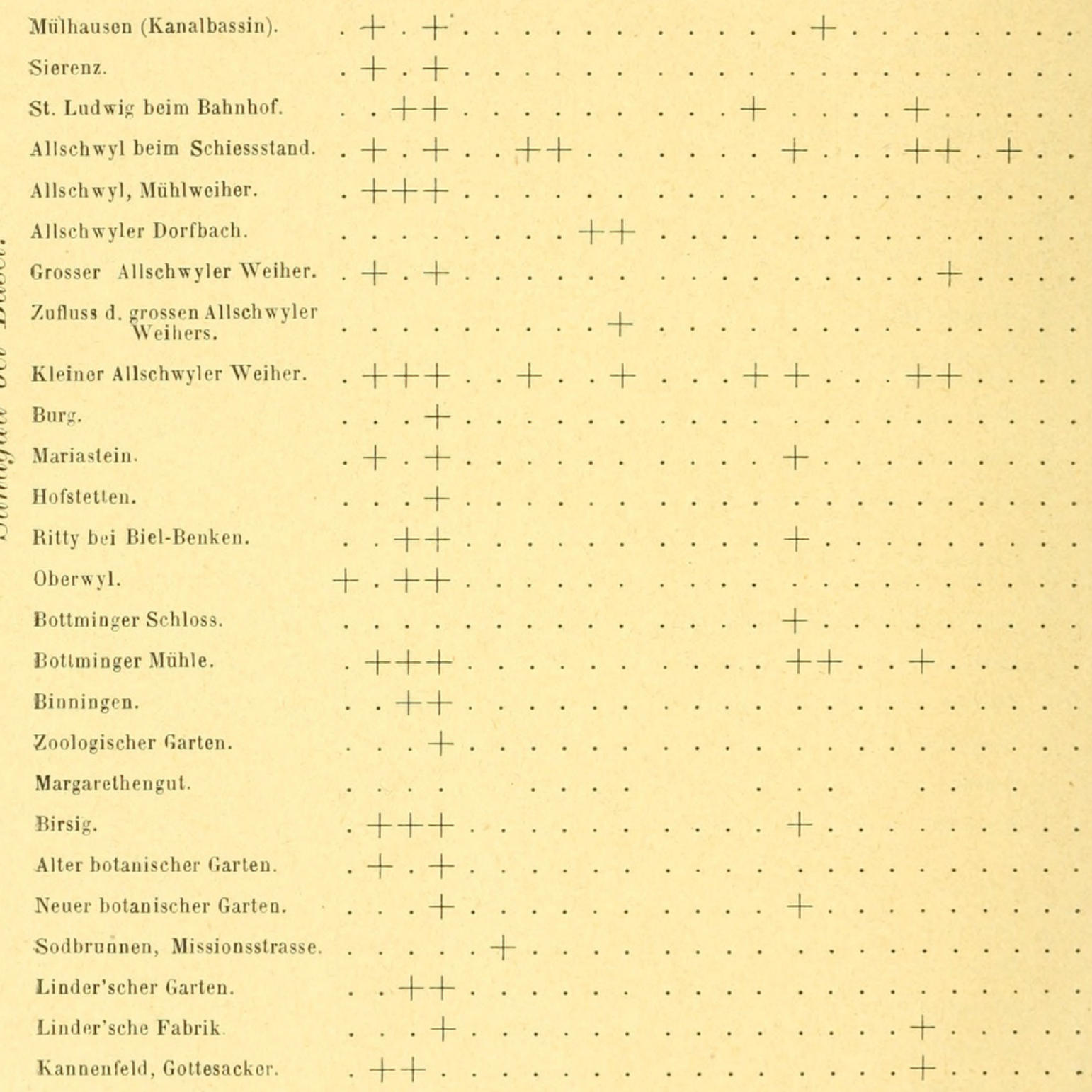




$$
\text { Centropagidæ. Harpacticidæ. }
$$
Heterocope.
Diaptomus.
Canthocamptus.

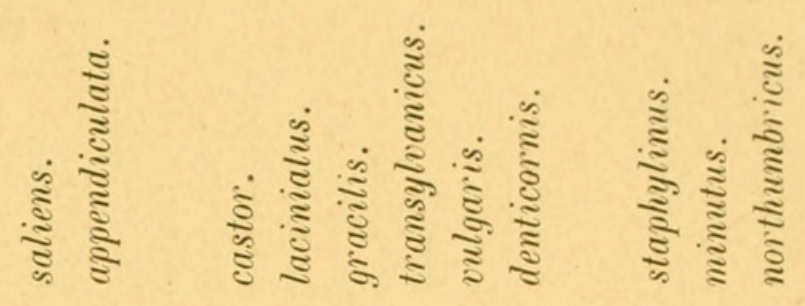

Mülhausen (Kanalbassin).

Sierenz.

St. Ludwig beim Bahnhof.

Allschwyl beim Schiessstand.

Allschwyl, Mühlweiher.

Allschwyler Dorfbach.

Grosser Allschwyler Weiher.

Zufluss d. grossen Allschwyler Weihers.

$\lesssim \quad$ Kleiner Allschwyler Weiher.

Burg.

Mariastein.

Hofstetten.

'Ritty bei Biel-Benken.

Oberwyl.

Bottminger Schloss.

Bottminger Mühle.

Binningen.

Zoologischer Garten.

Margarethengut.

Birsig.

Alter botanischer Garten.

Neuer botanischer Garten.

Sodbrunnen, Missionsstrasse.

Linder'scher Garten.

Linder'sche Fabrik.

Kannenfeld, Gottesacker. 
Cy clopidæ: Genus Cyclops.

Sectio : Trifida.

Sectio : BIFIDA.

Chætophora. Acanthophora.

Bellelay : Etang du Bas.

Bellelay: Tourbières.

Lucelle : Etang de Lucelle.

Lucelle : Eisendrahtwerk.

Montsevelier : Mühlweiher.

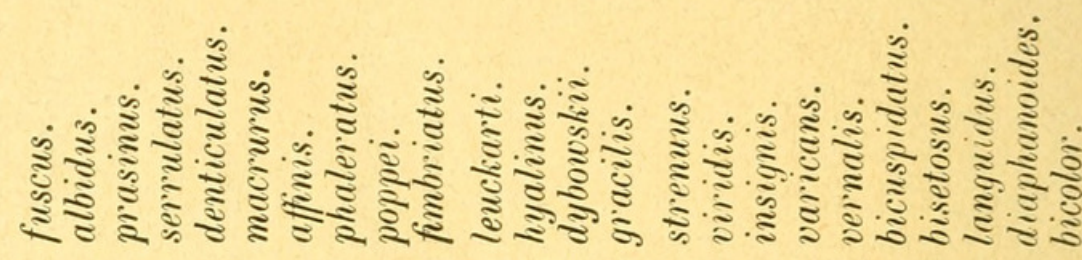

Montsevelier: Zufluss zum Mühl-

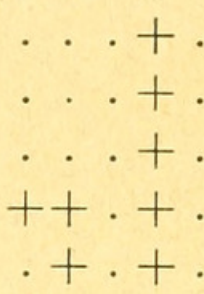

weiher.

Bogentalweiher beim Passwang.

Glashütte bei Neuhüsli.

Beinwyler Klosterweiher.

ح Bachmatt bei Laufen.

Gausshard bei Sewen.

Baslerweiher bei Sewen.

Hochwald, Feuerweiher.

Aesch oberh. Schloss Augenstein.

Aesch unterhalb Pfeffingen.

Arlısheim, die zwei oberen Weiher.

Arlesheim, der unterste Weiher.

Monchensteiner Au.

Gruth.

Mönchensteiner Feuer weiher.

Asp, Altwasser der Birs.

Muttenz.

Lachmatten.

Bruderholz.

Breite, Weiher.

Breite, Ausfluss des Weihers.

Birsfelden, Bett der Birs.

Neue Welt, Belt der Birs.
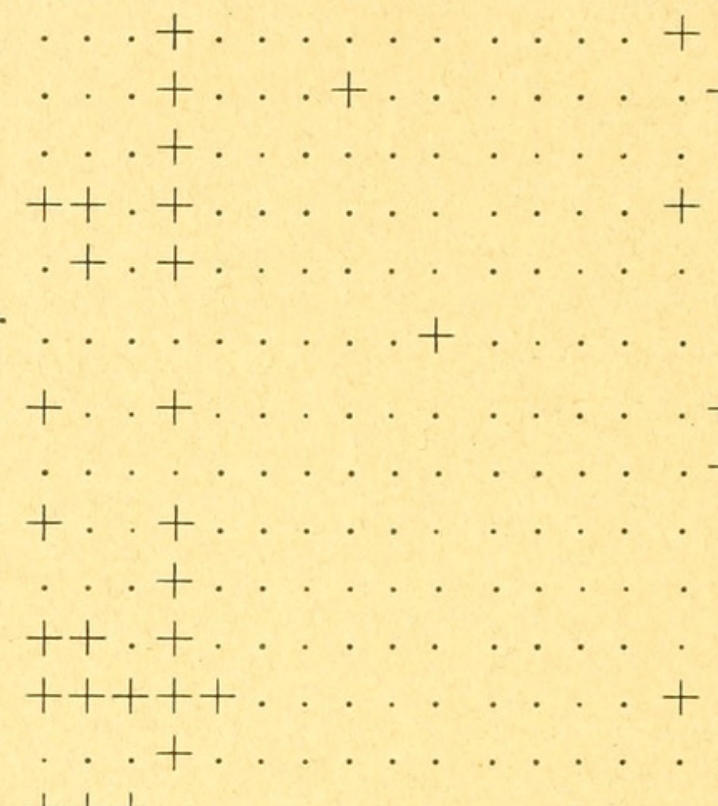
Centropagidæ. Harpacticidie.

Heterocope. Diptomus. Canthocamptus.

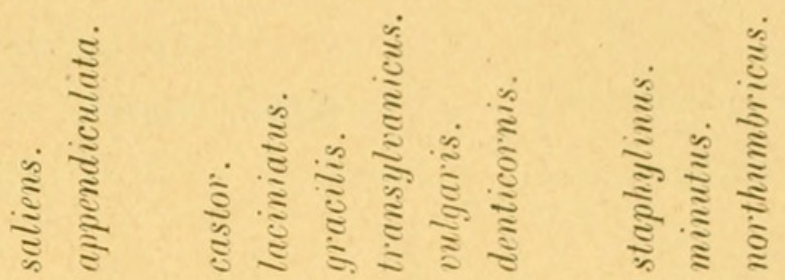

Bellelay : Etang du Bas.

Bellelay: Tourbières.

Lucelle: Etang de Lucelle.

Lucelle: Eisendrahtwerk.

Montsevelier : Mühlweiher.

Montsevelier: Zufluss zum Mühl-
weiher.

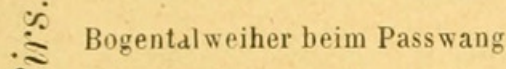

Glashütte bei Neuhüsli.

S Beinwyler Klosterweiher.

- Bachmatt bei Laufen.

Gausshard bei Sewen.

Baslerweiher bei Sewen.

Hochwald Feuerweiher.

$\underset{F}{*}$ Aesch oberh. Schloss Angenstein.

Aesch unterhalb Pfeflingen.

Arlesheim, d. $z$ wei oberen Weiher.

Arlesheim, der unterste Weiher.

Mönchensteiner Au.

Gruth.

Mönchensteiner Feuerweiher.

Asp, Altwasser der Birs.

Multenz.

Lachmatten,

Bruderholz.

Breite, Weiher.

Breite, Ausfluss des Weihers.

Birsfelden, Bett der Birs.

Neue Welt, Bett der Birs.

Rev. Suisse de Zool. T. 11. 1903. 
Cyclopidæ: Genus Cyclops. Sectio : Trifida. Sectio : BIFIDA. Chætophora. Acanthophora.

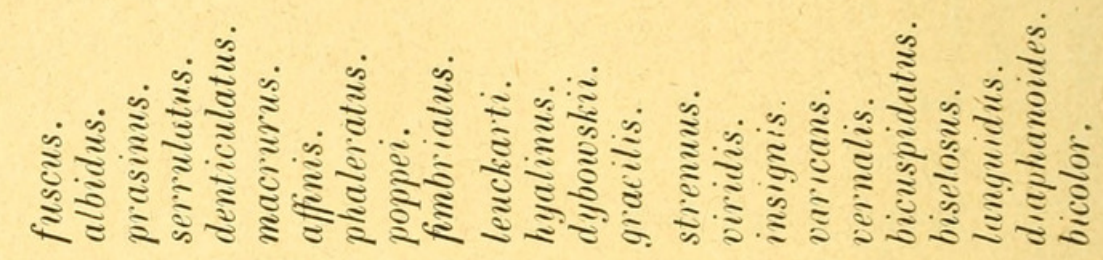

Glashülte bei Neuhüsli.

Bogental am Passwang.

22 Brunnen bei der Spitielmatt.

Langenbruck an der Landstrasse.

Kloster Schöntal.

Bach an der Bölchenfluh.

Brunnen bei Oberbölchen.

Schmutzberg: Oberer Brunnen.

Schmutzberg: Unterer Brunnen.

Mapprach : Parkweiher.

Rünenberg : Feuerweiher.

Sissach : Schloss Ebenrain, unteres Bassin.

Sissach: Schloss Ebenrain, oberes Bassin.

Lausen.

Büren: Mühlweiher.

Wildenstein, Weiher.

Wildenstein, Brunnen.

Oristal.

Rheinfeldon.

Igelsee.

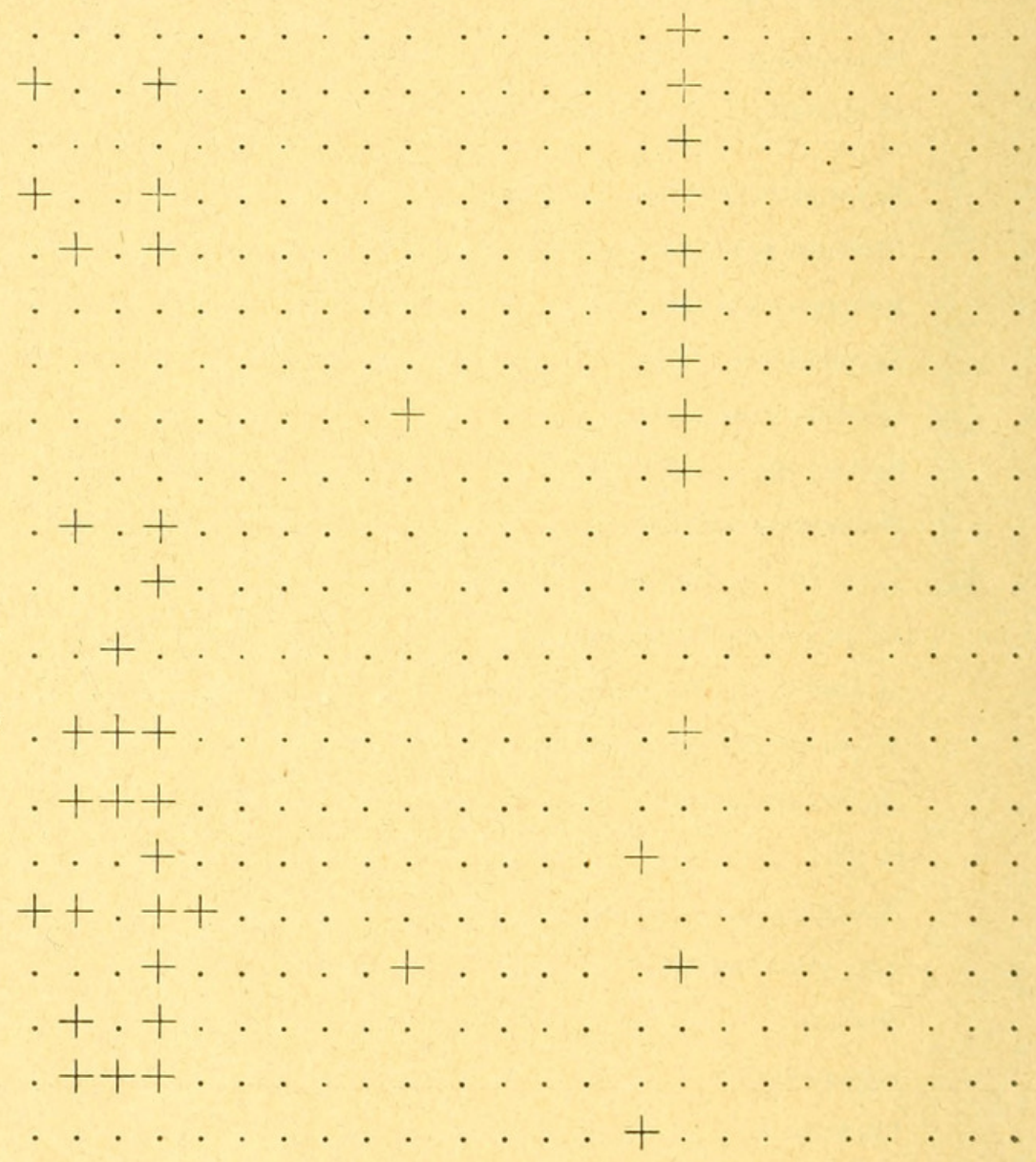




$$
\text { Centropagidæ. Harpacticidæ. }
$$

Heterocope. Diaptomus. Canthocamptus.

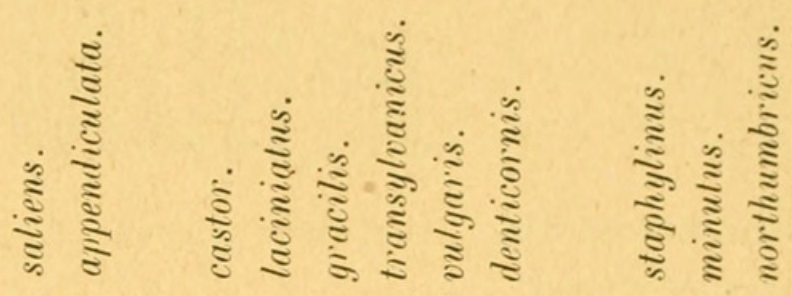

Glashütte bei Neushüsli.

Bogental am Passwang.

Brunnen bei der Spittelmatt.

Langenbruck an der Landstrasse.

Kloster Schöntal.

Bach an der Bölchenfluh.

Brunnen bei Oberbölchen.

Schmutzberg: Oberer Brunnen.

Schmutzberg : Unterer Brunnen.

Mapprach : Parkweiher.

Rünenberg : Feuerweiher.

Sissach: Schloss Ebenrain, unteres Bassin.

Sissach: Schloss Ebenrain, oberes Bassin.

Lausen.

Büren: Mühlweiher.

Wildenstein, Weiher.

Wildenstein, Brunnen.

Oristal.

Rheinfelden.

Igelsee. 
Cyclopidæ: Genus Cyclops.

Sectio: Trifida.

Sectio: BIFIDA.

Chætophora. Acanthophora.

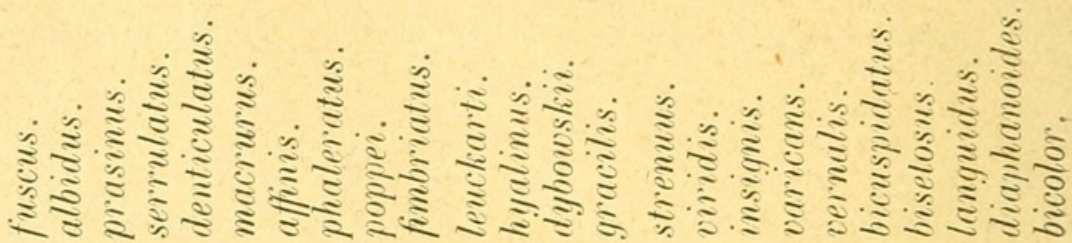

Inzlingen, Schlossweiher. $+1+t$

Crischona, Waldweiher.

Bettingen, Feuerweiher.

Grenzach, Feuerweiher.

Riehen, Eisweiher.

Friedlingen, Waldweiher

Fıiedlingen, Bach.

Lange Erlen, Parkweiher

Lange Erlen, Bach.

Schorenmatten

Wiese.

Säckinger See.

Lochmühle bei Harpolingen, Weiher.

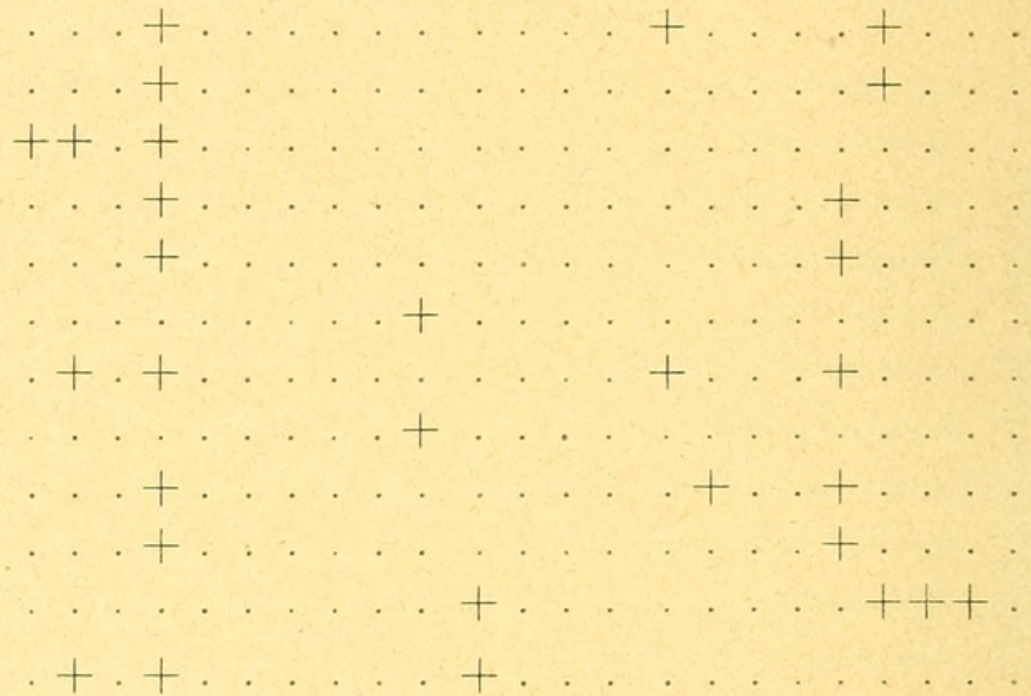

Lochmühle bei Harpolingen, Graben.

Willaringen.

Jungholz: Weiher am Weg nach Egg.

Jungholz: Torfstich

Jungholz: Fenerweiher.

Brenet: Feuerweiher

Mühlweiher von Präg.

Nonnenmattweiher.

Feldsee.

Titisee.

Schluchsee.
$+$

... +

$++$

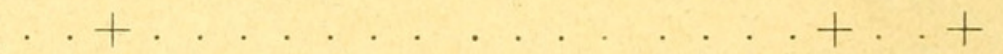

..++ .

.++ .

$\ldots+$.

$\ldots+++\ldots \ldots \ldots++\ldots \ldots+$

$++.+$

.+++ . $++\cdot+$. 
Centropagidæ.

Heterocope. Diaptomus.

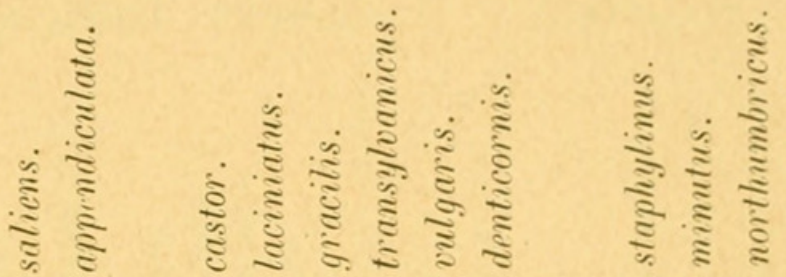

Inzlingen, Schlossweiher.

Crischona, Waldweiher.

Bettingen, Feuerweiher.

Grenzach, Fenerweiher.

Riehen, Eisweiher.

Friedlingen, Waldweiher.

Friedlingen, Bach.

Lange Erlen, Parkweiher.

Lange Erlen, Bach.

Schorenmatlen.

Wiese.

Säckinger See.

Lochmühle bei Harpolingen, Weiher.

Lochmühle bei Harpolingen, Graben.

Willaringen.

Jungholz: Weiher am Weg nach Egg.

Jungholz: Torfstich.

Jungholz : Feuerweiher

Brenet: Feuerweiher.

Mühlweiher von Präg.

Nonnenmattweiher.

Feldsee.

Titisee.

Schluchsee.

Harpacticidæ.

Cianthocamptus.

$$
\frac{d}{\stackrel{5}{a}}
$$

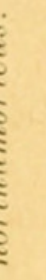




\section{Cyclopidæ: Genus Cyclops}

Sectio : Trifida. Sectio: Bifida.

Chætophora. Acanthophora.

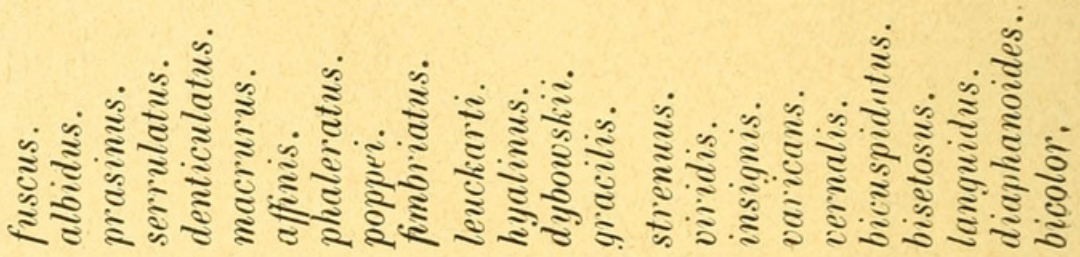

Sternsee am Ballon d'Alsace.

Neuweiher am Ballon d'Alsace. Ahlfeldsee am Ballon d'Alsace. Seewener See.

Etang de la Forge bei Belfort. Bas d'Evette bei Belfort.

Jonchery.

Faverois.

Fourcheau.

Le Puix, Dorfweiher.

Bambois.

Bonfol bei Pruntrut.

Vendlincourt bei Pruntrut.

Bieler See.

Neuenburger See.

Neuenburger See, Tiefenregion. Lohweiher.

Walensee.

Moosseedorfsee.

Katzensee.

Lac des Brenets.

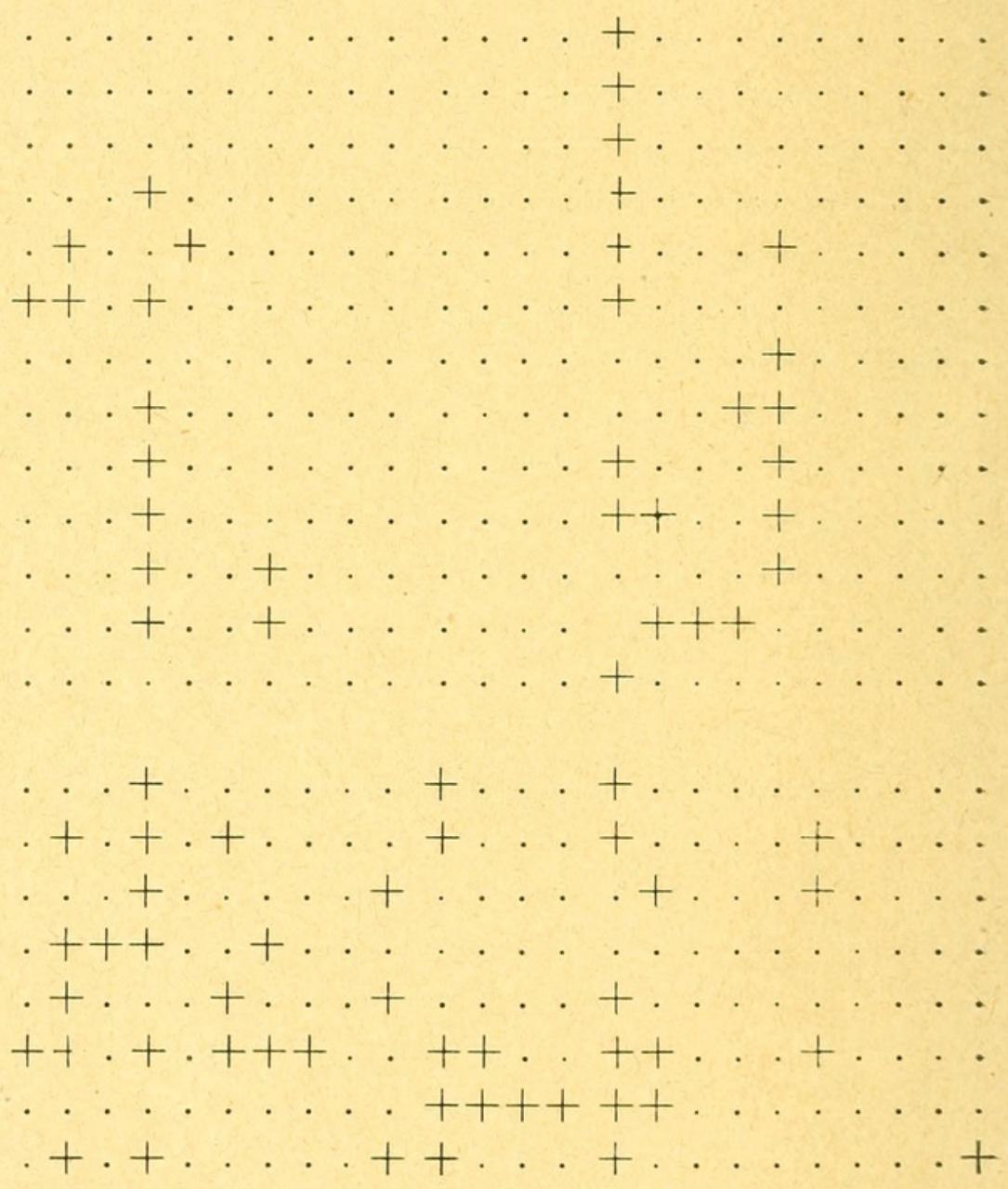


Centropagidæ.

Heterocope. Diaptomus.

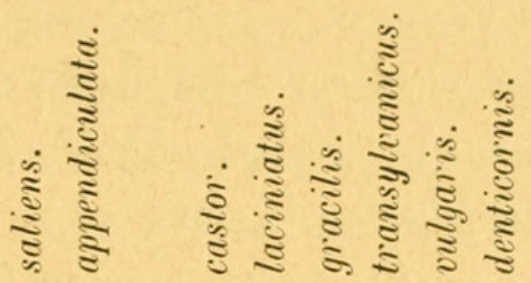

H arpacticidæ.

Canthocamptus.

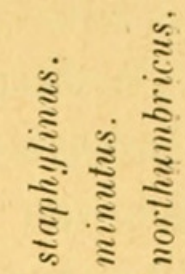

Sternsee am Ballon d'Alsace.

Neuweiher amBallon d'Alsace.

Ahlfeldsee amBallon d'Alsace.

Seewener See.

Etang de la Forge bei Belfort.

Bas d'Evette bei Belfort.

Jonchery.

Faverois.

Fourcheau.

Le Puix, Dorfweiher.

Bambois.

Bonfol bei Pruntrut.

Vendlincourt bei Pruntrut.

Bieler See.

Neuenburger See.

Neuenburger See, Tiefenregion.

Lohweiher.

Walensee.

Moosseedorfsee.

Katzensee.

Lac des Brenets. 


\section{Die Verteilung der Centropagiden.}

Hiezu Karte.

Vergl. auch Tabellen 1-7.

Während mit wenigen Ausnahmen die Vertreter des Genus Cyclops sich einer gleichmässigen Verbreitung erfreuen, scheiden sich die Centropagiden nach ihrem Vorkommen. Von den 25 sicheren Arten, die jenes Genus zählt, habe ich bei Basel 22 gefunden, von den 67 Diaptomusarten hingegen nur 6. Zusammen mit den beiden Arten des anderen Centropagidengenus Heterocope sind diese 6 Diaptomus so über das Gebiet verteilt, dass man in demselben nach ihrem Vorkommen scharf begrenzte Bezirke unterscheiden kann. Diaptomus denticornis, der sich wie die beiden Heterocopearten durch nordischen, glazialen, alpinen Charakter auszeichnet, findet sich in den beiden Seen des Schwarzwalds, die über 900 Meter hoch liegen. Die Arten Heterocope saliens und appendiculata, die für einander vikarieren, finden sich mit ihm zusammen. Ausserdem tritt noch Heterocope saliens in dem 848 Meter hochgelegenen Titisee auf in Gesellschaft von Diaptomus laciniatus. Der Schluchsee beherbergt merkwürdigerweise keinen Centropagiden.

Die Ebene unterhalb St. Ludwig, links vom Kanal, ist das Revier des seltenen Diaptomus transylvanicus. Er findet sich auch auf dem rechten Kanalufer bis nahe an den Rhein, aber nur in den schon seit Anfang des letzten Jahrhunderts bestehenden Altwassern. Er verschwindet beim Dorfe Rosenau mit dem Auftreten der Gewässer jüngeren Datums, die bei starkem Hochwasser noch von Rheinwasser durchströmt werden.

An 2 Stellen hat sich Diaptomus vulgaris von Süden und Westen her eingedrängt. Sein Gebiet berührt sehr nahe das des 
Diaptomus transylvanicus. Er findet sich beim Bahnhofe von St. Ludwig und zwischen diesem Dorfé und Grosshüningen. Er ist auch der Diaptomus unserer Stadt. Ich fand ihn in den grossen Bassins des botanischen Gartens und des Margarethenguts. Er kommt auf dem rechten Rheinufer in der Regel nicht vor, eine einzige Ausnahme bildet sein sporadisches Erscheinen im Dorfe Kleinhüningen. Die beiden Allschwiler Weiher und der des Bottminger Schlosses besitzen ihn auch, ebenso das Kloster Mariastein, und wo sich überhaupt im Basler Jura ein Diaptomus vorfand, so war es Diaptomus vulgaris. An dem Westabhang und in der Trouée de Belfort gesellt sich ihm Diaptomus castor zu, der so auch durch sein Auftreten bekundet, dass er in seinem Genus eine besondere Stelle einnimmt. Im scharfen Gegensatz zu den Cyclopsarten, schliessen nahverwandte Diaptomus einander aus. Wir sahen dies schon bei den Formen des Schwarzwalds und finden das Gleiche bei den Formen der Ebene. Wie Diaptomus denticornis und laciniatus sich nicht zusammen zeigten, so kann man auch bei Anwesenheit des Diaptomus vulgaris auf Abwesenheit des Diaptomus transylvanicus schliessen. Und wie Heterocope saliens, die nur der ihr nahe stehenden Heterocope appendiculata ausweicht, sich einmal mit Diaptomus laciniatus, das andere Mal aber mit denticornis vorfindet, so erblicken wir Diaptomus castor, der im französischen Westen mit vulgaris lebt, unterhalb Basel in Gesellschaft des Diaptomus transylvanicus. Es lässt sich dies auf der beigegebenen Karte leicht verfolgen. Jedesmal wo in ein und demselben Gewässer 2 Centropagiden zusammen gefischt wurden, verbindet ein Bogen $(\neg)$ die beiden den betreffenden Arten entsprechenden Zeichen.

In das Gebiet nun, das hier skizziert worden ist, schiebt sich wie ein Keil dem Rhein entlang auf beiden Ufern der Bezirk des Diaptomus gracilis ein. Wir finden ihn oberhalb und unterhalb Säckingen, dann bei Kleimhüningen und von da bis nach 
Neuenburg. Auf dem linken Ufer muss er dem über den Kanal kommenden Diaptomus transylvanicus in den älteren Gewässern weichen, tritt aber schon beim Dorf Rosenau wieder auf und von da nun auch auf dem linken Ufer bis nach Neuenburg.

Diaptomus gracilis ist ein Bewohner des schweizerischen Mittellandes. Da er zusammen mit anderen Formen des schweizerischen Mittellandes vorkommt, da ich ihn ferner bei Hochwasser im Rheine fischte und zwar in Gesellschaft einer dieser Formen, Cyclops leuckarti, stehe ich keinen Augenblick an, anzunehmen, dass die Hochfluten des Rheines das Gefährt waren, das den Diaptomus gracilis in die Basler Umgebung brachte. Demnach würde Diaptomus transylvanicus aus der Gegend von Michelfelden und Neudorf zur autochthonen Fauna gehören, ein Ueberbleibsel sein jenes reichen Sumpfgebietes, das die fortschreitende Urbarmachung der Gegend jedes Jahr sichtlich einschränkt. Der besonderen Fauna dieser Sümpfe entsprechen auch besondere Verhältnisse. Während die das Rheintal begrenzenden Gebirge starke Flüsse dem Rheine zusenden, bewegen sich vom sundgauischen Hügellande her und ohne ihn zu erreichen nur seichte Bäche dem Strome zu. Sie versickern in dem durch abgelagerten Schotter gebildeten Boden, um dann als Schichtenquelle am Fusse der alten Rheinufer-Terrasse, auf der St. Ludwig und die Dörfer des Neuwegs stehen, hervorzutreten. Hiemit sind die Bedingungen für ein Sumpfgebiet gegeben, zu dessen Bildung die Altwasser des Rheines nie genügt hätten. Wie reich und wie eigenartig die Tierwelt dieses Sumpfgebietes ist, ergiebt sich einmal aus dem Auftreten von Diaptomus transylvanicus, der bis jetzt erst in Siebenbürgen und bei Triest nachgewiesen worden ist, und wird sich auch in dem folgenden Kapitel zeigen, der das Vorkommen der Harpacticiden schildern soll. 


\section{Die Verbreitung der Harpacticiden.}

Hiezu Tabellen 1-7.

In meiner Mitteilung über die Harpacticiden des Val Piora habe ich auf die entgegengesetzte Entwicklung hingewiesen, die die Kenntniss der Genera Cyclops und Canthocamptus durchgemacht. Bei jenem eine hundert übersteigende Zahl von Arten, die auf zwanzig zusammenschmilzt, bei diesem zuerst zwei Arten, Canthocamptus staphylinus und minutus, dann in wenigen Jahren an Arten und verwandten Gattungen so zunehmend, dass für die Süsswasserfamilie der Harpacticiden, wie für die Cyclopiden, - auch die Artenzahl zwanzig erreicht worden ist. MrazeK schreibt den Umstand, dass die meisten Autoren in ihren Verzeichnissen nur die beiden altbekannten Arten von Canthocamptus anführen, der schablonenhaften Bestimmung zu. Ich teile diese Auffassung nicht. Meine Erfahrungen sprechen vielmehr für einen tiefgehenden Unterschied im Vorkommen der beiden Genera. Ich habe die Bemerkung des böhmischen Forschers beherzigt und trotzdem nur drei Canthocamptusarten in unserer Umgebung gefunden, zwei davon jeweilen nur ein einziges Mal, trotz wiederholtem Durchsuchen des Fundortes. Die dritte Art, der gemeine C. staphylinus trat trotz seiner weiten Verbreitung sehr unregelmässig auf, verschwand aus dem einen Weiher, um dafür in einem andern aufzutauchen. Dieses scheinbar unmotivierte, sporadische Auftreten dürfte der eine Grund sein für die allzukurzen faunistischen Verzeichnisse der Canthocamptusarten. Ein z weiter Grund ist zu suchen in der Angabe ZschokKEs, dass von den Canthocamptusarten des Hochgebirgs zwei sich durch ihr Vorkommen in Hochgebirgsseen als Kosmopoliten, und die andern durch das Vorkommen in Gebirgsbächen und kalten Quellen 
sich als nordische Formen, als nordisch-glaziale Relikte dokumentieren. Die beiden Kosmopoliten sind: Canthocamptus staphylinus und minutus, und dies sagt uns, warum die faunistischen Verzeichnisse, - was MrazeK vor allem rügt, - gerade immer diese beiden Namen enthalten. Es gibt Gegenden, in denen die Familie besonders günstige Verhältnisse vorfindet, und der Erforscher dieser Gegenden stellt dann durch aussergewöhnlich reiche Funde diejenigen der meisten andern in den Schatten. Zu diesen begünstigten Gegenden hat die Umgebung Basels während der Zeit meiner Untersuchungen nicht gehört. Im ganzen Gebiet mit Ausschluss des Jura hat sich, besonders im Winter, Canthocamptus staphylinus als gemein erwiesen. Die beiden andern Arten habe ich in dem in jeder Beziehung reichen Gebiet zwischen Kanal und Neuweg gefunden. Canthocamptus minutus bei Michelfelden, Canthocamptus northumbricus in einem der Karpfenteiche der Fischzuchtanstalt. Dieser Fundort ist deshalb von Interesse, weil der Teich die Winterzeit hindurch trocken liegt, und DouwE gerade für Canthocamptus northumbricus die Angabe macht, dass er die Fähigkeit besitzt, das Eintrocknen eines Sumpfes zu überstehen.

\section{Die Stellung der Süsswasser-Copepoden im System.}

Die geschichtliche Entwicklung der einzelnen Wissensgebiete hat es mit sich gebracht, dass wir in ihnen nur äusserst selten logisch abgegrenzte und in sich zusammenhängende systematische Einheiten vorfinden. So bilden auch die SüsswasserCopepoden ein aus Opportunitätsgründen festgehaltenes, durch und durch heterogenes Ganzes. Nur insofern es sich um Copepoden, um Vertreter einer einzigen Ordnung, handelt, dürfen wir in ihnen eine systematische Einheit sehen. Wie jeder biologische Faktor, so hat auch hier das Süsswasser nah Ver- 
wandtes getrennt und Auseinanderstehendes vereinigt. Auf diesem Riss im System beruht nun im Studium der Copepoden eine Arbeitsteilung, die die Trennung nahverwandter Formen nicht bloss in der Litteratur fortsetzt, sondern, was nicht vergessen werden darf, auch im Geist und in der Auffassung des Forschers. Ausgenommen einige Forscher älterer Observanz, und unter denen namentlich Carl Claus, wissen die Kenner der Süsswasser-Copepoden eher über entfernter stehende Crustaceen, über Cladoceren und Ostracoden Auskunft, als über die allernächsten Verwandten der von ihnen studierten Formen.

Die Copepoden des Süsswassers können sich, was Artenreichtum und Formenmannigfaltigkeit anbelangt, in keiner Weise mit den marinen messen, und so ist es gekommen, dass bei dieser Arbeitsteilung den Erforschern der Meeresfauna der Ausbau des Systems zugefallen ist, und denen des Süsswassers nur übrig bleibt, es jeweilen, zur Einreihung der ihnen zufallenden Arten, in der Form anzunehmen, in der sie es vorfinden. Die aus diesem Verhältniss entstehende Abhängigkeit und der Mangel an der nötigen Uebersicht machen die Aufstellung einer einwandfreien Systematik zu keiner geringen Aufgabe. Die Schwierigkeit erstreckt sich bis auf die Einreihung der Genera in die einzelnen Familien, da sich erst von der Stufe des Genus an einheitliche Gruppen von Süsswasserformen vorfinden. Solch ein Süsswassergenus mag nun noch so eingehend studiert, und seine systematische Abgrenzung und Gliederung noch so vollkommen sein, die endgiltige Einteilung kann erst dann erfolgen, wenn das System der marinen Formen eine endgiltige Gestaltung erfährt. Hievon sind wir aber noch weit entfernt, und für die so genau beschriebenen Arten des Süsswassers müssen wir uns noch mit einem Provisorium begnügen. So hatte Claus das Genus Diaptomus im Jahre 1863 in die grosse Familie der Calaniden gestellt.

Von den Calaniden spaltete SARs 1886 die Familie der Dia- 
ptomiden ab, die die Genera Centropages, Temora und Diaptomus umfasste. Die Einteilung dauerte bis zum Jahre 1892, wo Giesbrecht in der «Fauna und Flora des Golfes von Neapel » sein Werk über die marinen, pelagischen Copepoden veröffentlichte. Indem er darin neue, schon früher von ihm empfohlene Einteilungsprinzipien durchführte, trennte er die einzelnen Glieder der Calaniden und der Diaptomiden auseinander, und heute hat das Genus Diaptomus eine Unterkunft in der kleinen Familie der Centropagiden gefunden.

Ausser Diaptomus finden sich in der Umgebung Basels drei weitere Genera von Süsswasser-Copepoden vor: Heterocope, $\mathrm{Cy}$ clops und Canthocamptus. Von ihnen gehören, wenn wir uns an das Giesbrecht'sche System halten, Heterocope mit Diaptomus in die Familie der Centropagiden, Cyclops mit der wenigstens dem Namen nach gut bekannten marinen Form Oithona in die der Cyclopiden und Canthocamptus in die der Harpacticiden. Da für die letzte der aufgezählten Familien selbst GIEsBRECHT Wandlungen in Aussicht stellt und hier wie an andern Orten den provisorischen Charakter der neuen Einteilung betont, muss man sich hüten, aus dem System Schlüsse auf den genetischen Zusammenhang der Familien zu ziehen. Um über den wichtigsten Einteilungsgrund GiesBrechT's klar zu werden, müssen wir uns genau den Grenzbezirk zwischen dem Cephalothorax und dem für die Copepoden so charakteristischen fusslosen Abdomen vorstellen. Bei dem einen Teil der Ordnung der Copepoden nimmt das Abdomen das letzte Cephalothoraxsegment auf. Nach Stellung und Aussehen ist dieses Segment dem letzten Cephalothoraxsegment der übrigen Copepoden durchaus homolog, aber es genikuliert vereint mit dem Abdomen, unter auffallender Reduktion des von ihm getragenen fünften Fusspaares. Auf diesem Unterschiede fussend, fasst GiesbrechT unter dem Namen Gymnoplea diejenigen Familien zusammen, deren Cephalothorax 6 Segmente zählt und deren Abdomen sich 
nur aus den ursprünglich abdominalen, den fusslosen, ,„nackten“" Segmenten zusammensetzt. Den Gegensatz hiezu bilden die Familien der Podoplea, bei denen der Cephalothorax genau genommen nur noch 5 Segmente zählt, da das sechste vom Abdomen aufgenommen wurde. Das Abdomen ist auf diese Weise, - daher der Name „Podoplea", — in den Besitz eines wenn auch sehr reduzierten Fusspaares gekommen.

Von unsern Süsswasser-Copepoden gehören die Centropagiden : Diaptomus und Heterocope zu den Gymnoplea, die beiden übrigen Gattungen Cyclops und Canthocamptus zu den Podoplea.

Diese doppelte morphologische und physiologische Trennung des Copepodenkörpers ist beanstandet worden, vor allem, wie von Claus und SchmeIL, die Art und Weise der Bezeichnung, da GiesBRecht den lateinisch-griechischen Ausdrücken Cephalothorax und Abdomen einen ausschliesslich morphologischen und den entsprechenden deutschen einen ausschliesslich physiologischen, funktionellen Sinn beilegt.

Der Einteilung selbst liegt jedenfalls ein entscheidender Unterschied und ein greifbares Merkmal zu Grunde. Es ist nur zu befürchten und es spricht verschiedenes dafür, dass die Verkürzung des Cephalothorax bei den verschiedenen Podoplea nicht viel mehr als eine Konvergenzerscheinung bedeutet. GIESBRECHT wäre dann in den Fehler seiner allerersten Vorgänger verfallen, den definitiv zu beseitigen er sich zum Ziel gesetzt hatte. Wie Latreille und Milne Edwards durch Benutzung der Mundteile als grundlegendes Einteilungsprinzip die biologisch verschiedenen, aber systematisch verwandten Gruppen der freilebenden und der parasitären Copepoden weit von einander getrennt hatten, so scheint heute auch GIESBREchT, wenigstens nach aprioristischen Gründen zu urteilen, in seinen Gymnoplea und Podoplea nur biologische Gruppen geschaffen zu haben. Er sagt Seite 4 seines Werkes, in anderem Zusammenhang, die Podoplea enthielten neben den para- 
sitären Formen auch schwimmende (wie die Gymnoplea). Doch zwischen dem Schwimmen der einen Unterordnung und dem der anderen besteht ein tiefgehender Unterschied der nicht genug betont werden kann. Die Gymnoplea sind, wie Giesbrecht selbst hervorhebt (pag. 3), im Stande ihr Leben schwimmend zuzubringen, die schwimmenden Podoplea hingegen sind mehr oder weniger genötigt, sich zeitweise an einem Gegenstande festzuhalten oder aufzustützen. Die Gymnoplea sind pelagische, die schwimmenden Podoplea littorale Tiere. Wir haben es durchaus mit biologischen Gruppen zu tun, und dass diese mit der GIESBRECHT'schen Einteilung übereinstimmen, ist nicht Zufall; denn die anatomische Eigentümlichkeit, auf der die Einteilung aufgebaut ist, lässt sich nicht nur mit der entsprechenden Lebensweise in innigen Zusammenhang bringen, sondern kann sogar nur durch diese allein erklärt werden. Die Schwimmart der pelagischen Tiere, das freie Schweben, ist, wie ich später ausführen werde, nur möglich bei einem langen Cephalothorax und einem im Verhältnis bedeutend kürzeren Abdomen. Dieses spezifische Verhältnis verliert sich jeweilen mit der Anpassung an eine neue Lebensweise, deshalb die Verkürzung des Cephalothorax zu Gunsten des Abdomens bei den littoralen schwimmenden Formen, den kriechenden Grundformen und den parasitären, die alle miteinander die Unterordnung der Podoplea bilden.

Der Vorgang, der diese Verkürzung hervorruft, besteht in einer proximalen Wanderung des die beiden Körperteile trennenden Gelenkes eine interessante Verschiebung, die in der Entwicklungsgeschichte nicht vereinzelt dasteht.

In jeder der beiden Unterordnungen GIEsBREchts finden wir das entgegengesetzte Verhalten wenigstens angedeutet, bei den primären Gymnoplea ein sekundäres Stadium in der beginnenden Reduktion des fünften Fusspaares, bei den sekundären Podoplea eine besondere frühe Entwicklungsstufe durch die 
beim männlichen Geschlechte noch vorkommenden Spuren eines sechsten Fusspaares.

Die Umformungen, die die Antennen im männlichen Geschlecht als Kopulationsorgane erleiden, sind von GIEsBREcHT beim weiteren Ausbau seines Systems als Einteilungsgründe benützt worden und mit gutem Erfolge. Wie aus der von mir zusammengestellten Uebersicht ersichtlich ist, gibt es ein anschauliches Bild der freilebenden Copepoden. Die Familien, die Vertreter im Süsswasser haben, sind in dieser Uebersicht besonders hervorgehoben worden.

\section{Uebersicht Der Einteilung Giesbrechts DeR}

\section{Freilebenden Copepoden}

ORDO: COPEPODA.

Begattung vermittelst Spermatophoren.

Subordo I: Gymnoplea. Die Trennung des Rumpfes in Vorder- und Hinterleib fällt zwischen Thorax und Abdomen.

Tribus I : Amphascandria. Beide $\sigma^{\Upsilon}$ Antennen sind mit Spürschläuchen versehen.

Fam.: Calanidæ.

Tribus II: Heterarthrandria. Eine $\sigma^{\Upsilon}$ Antenne durch Verstärkung und Umformung der Muskulatur und Gelenkbildung zum Greifen eingerichtet.

Fam.: Centropagidæ.

Fam.: Candacidæ.

Fam.: Pontellidæ.

Subordo II: PoDopleA. Das letzte Thoracalsegment mit dem fünften Fusspaar gehört dem Hinterleib an. Rev. Suisse de Zool. T. 11. 1903. 
Tribus I : Ampharthrandria. Im $\sigma^{x}$ Geschlecht sind beide Antennen zum Greifen eingerichtet.

Fam.: Mormonillidæ.

Fam. : Cyclopidæ.

Fam.: Harpacticidæ.

Fam. : Monstrillidæ.

Tribus II : Isocerandria. Im $\sigma^{r}$ Geschlecht genikulieren die vorderen Antennen nicht.

Fam.: Oncacidæ.

Fam.: Corycacidæ.

Zur Systematik des Genus Cyclops.

Die Genera Heterocope, Diaptomus, Cyclops und Canthocamptus stammen wie alle wirbellosen Süsswassertiere mit Ausschluss der Tracheaten aus dem Meer. Wir ersehen aus dem System Giesbrechts, dass sie nicht einmal unter sich ein geschlossenes Ganzes bilden, sondern da und dort im System an marine Copepoden anzugliedern sind.

Es ist deshalb unmöglich, ohne Berücksichtigung der marinen Formen genetische Beziehungen zwischen den einzelnen Genera aufzufinden. Man kann aber sehr gut die Familien unter sich auf ihre Entwicklungsstufe hin vergleichen und dann sehen, welches die primären, welches die sekundären Formen sind und wie sich mit dem Grade der Entwicklung die Lebensweise verhält. Auch die Lösung dieser bescheidenen Aufgabe muss Auffassung und Verständnis für die in Frage kommenden Formen fördern.

Wir legen unserer Vergleichung die Urform der Crustaceen zu Grunde, wie sie von Arnold Lang im zweiten Bande seines Lehrbuches der vergleichenden Anatomie der Wirbellosen, Seite 
419 , vor über einem Dezennium beschrieben worden ist. Ohne weiteres wird dann klar, dass wir die Centropagiden als die ursprünglichen, die Cyclopiden und die Harpacticiden als sekundäre Formen aufzufassen haben.

So hat Diaptomus :

1. Noch ein Herz und ein Ostienpaar,

2. Kein Receptaculum,

3. Die grösste Gliederzahl der Antennen,

4. Beinahe homonome Segmentierung der Antennen,

5. Gespaltene zweite Antennen,

6. Deutlich gespaltene Mandibeln,

- 7. Ein gut entwickeltes, gespaltenes fünftes Fusspaar.

8. Das letzte Cephalothoraxsegment ist nicht vom Abdomen aufgenommen worden.

Vergleichen wir nun die einzelnen Arten des Genus Cyclops mit dem Bauplan der Diaptomusarten, so sehen wir (vergl. Cyclops fuscus), dass mehrere Arten jenes Genus der Form Diaptomus näher kommen als andere. Es sind die Arten, die im Stande sind, ein pelagisches Leben zu führen, oder wenigstens noch in geringerem Grade die Fähigkeit besitzen, zu flottieren. Pelagische Gewohnheiten und die Fähigkeit zu flottieren, zeichnen auch Diaptomus aus und können als die ursprüngliche Lebensweise der Cyclopsarten angesehen werden. Es finden sich unter ihnen aber schwimmende und kriechende Formen. Da im Meere das Genus keinen Vertreter hat, müssten sich diese Formen erst im Süsswasser gebildet haben und zwar aus den pelagischen, als eine Anpassung an die verschiedenen Existenzbedingungen des neuen Mediums.

Diaptomus scheint nur einer solchen angepasst zu sein. Es ist dies sehr wahrscheinlich die Ursache, warum von den vielen Arten des Genus in einer und derselben Gegend so wenige vorkommen. Die Arten verdrängen einander, und zwar nicht nur aus grösseren Bezirken, sondern auch aus einzelnen Gewässern, 
daher auch die Erscheinung des Vikarierens der Diaptomusarten, die wir in dem Abschnitt über die Verteilung derselben beschrieben haben. Bei Cyclops haben wir alle Uebergänge von der schwebenden Lebensweise mit pelagischem Charakter bis zur kriechenden. Nicht nur kann dadurch ein Süsswassersumpf in allen seinen verschiedenen Teilen von dem Genus als solchem in Besitz genommen werden, sondern dieses wird auch für die verschiedenartigsten Gewässer mit noch so einseitigen Bedingungen irgend einen Vertreter zur Verfügung haben. So erklärt es sich, dass wir im Gegensatz zum Genus Diaptomus erstens die kleine Phalanx von ungefähr 25 Cyclopsarten unter so verschiedenen Himmelsstrichen beisammen finden und zweitens so selten in diesem Genus vikarierenden Arten begegnen.

Die Eigenart der Cyclopsarten in der Lebensweise und der geographischen Verbreitung muss auch morphologisch zum Ausdruck kommen, und wir dürfen sie nicht aus den Augen verlieren, wollen wir den Bau des Cyclopskörpers verstehen. Hiezu brauchen wir bloss die Formen nach dem Grade ihrer Anpassung von der pelagischen an die schwimmende und von dieser an die kriechende Lebensweise zu ordnen. Was sich dann von einer Form zur andern mit der allmählichen Anpassung allmähliç ändert, was der allgemeinen Tendenz unterliegt, das ist auch das physiologisch wirksame, das heisst das Wesentliche in der Gestalt des Tieres, wemn wir sein Verhalten in dem ihm eigenen Medium begreifen wollen, zugleich aber auch das Unwesentliche, dem wir kritisch aus dem Wege gehen müssen, wenn es gilt, die genealogische Verwandtschaft zu eruieren. In beiden Fällen aber ist es eine conditio sine qua non, genau feststellen zu können, was in der Gestalt des Tieres durch Vererbung historisch geworden ist, und was die unmittelbare logische Folge der Anpassung an das bestimmte Medium ist. Bevor wir den eben beschriebenen Weg durch Aufstellung von Entwicklungsreihen einschlagen, wollen 
wir uns eines direkten Verfahrens bedienen. Wir vergleichen zwei extreme Fälle, einen schwebenden Diaptomus mit pelagischem Charakter und einen schwimmenden Cyclops. Wir fragen uns, was ist der Unterschied in ihrem Verhalten und wie lässt sich dieser mit der Form in Einklang bringen.

Der Diaptomus hält seine Antennen, deren Länge reichlich der des ganzen Körpers entspricht, links und rechts vom Kopfe gerade und horizontal ausgestreckt. Scheinbar hängt er unbeweglich in vertikaler Richtung an den horizontalen Antennen. Scheinbar, denn in Wirklichkeit sinkt er langsam. Dieses Sinken dauert eine kurze Weile; dann giebt er, bei kleinen Bewegungen mit der Furka, bei grösseren mit den fünf Paaren von Schwimmfüssen, einen Schlag ins Wasser und befindet sich an einer andern Stelle wieder auf der alten Höhe. Deutlich lässt sich beobachten, wie der Krebs bei dem „Durch das Wasserschiessen" und noch im Momente des Anhaltens eine horizontale Lage einnimmt und dann mit dem Körper als Radius um das Vorderende einen Bogen von $90^{\circ}$ beschreibt und so in die Ruhelage kommt. Ist diese erreicht, so beginnt das Spiel von neuem. Bei Cyclops finden wir von alledem nichts. Geschäftig schwimmt er umher, bald den Kopf nach unten und bald nach oben gerichtet, und wir fragen uns: ,Woher mag dieser Unterschied im Verhalten der beiden Tierarten kommen?" Folgende Betrachtung soll diese Frage beantworten:

Auf den im Wasser befindlichen Körper wirken drei Kräfte :

1. Die Schwerkraft, — sie greift im Schwerpunkte des Körpers an.

2. Der Auftrieb, - er greift an im Schwerpunkt des verdrängten Wassers.

3. Die Reibung, - sie ist gleich Null, wenn der Körper in Ruhe ist, wächst aber sehr rasch bei der geringsten Bewegung mit der ersten Potenz der Geschwindigkeit des bewegten 
Körpers, je nach Beschaffenheit der Körperoberfläche sogar mit der zweiten Potenz.

Ist der Körper homogen, so fallen sein Schwerpunkt und der des verdrängten Wassers zusammen. Es ist nicht anzunehmen, dass dem genau so sei; doch der mit Wasser durchtränkte Körper ist leicht und es sind nur die geringsten Differenzen möglich. Deshaib und nach dem Grundsatz: Principia non sunt multiplicanda præter necessitatem, nehmen wir an, der Körper sei homogen und der Angriffspunkt der Schwerkraft falle zusammen mit dem des Auftriebs. Da jene grösser ist als dieser, so fängt der Crustaceenkörper, der nach einer ruckweisen Bewegung eben zur Ruhe gekommen ist, langsam an zu sinken, In diesem Moment, d. h. gleichzeitig mit dem Sinken beginnt die dritte Kraft, die Reibung, zu wirken. Bei Diaptomus gehen vom Kopfe aus ungefähr im rechten Winkel die beiden langen, gestreckten Antennen. An ihrem Ende sind diese noch mit drei nach abwärts gerichteten, stark gefiederten Borsten versehen. Wenn nun bei beginnendem Sinken die Reibung ihre Kraft, die im Moment der Ruhe gleich Null war, entfaltet, so wird die Reibung am vorderen Körperende in Folge der Antennen und ihrer Hemmungsvorrichtungen stärker wirken als am hintern und dieses darum schneller sinken als jenes. Wir haben dann ein Kräftepaar, dessen eine, die aufwärts gerichtete Komponente, die Resultierende der Reibung ist, dessen andere, die abwärts gerichtete, in der Differenz aus Schwerkraft und Auftrieb besteht. Das Drehmoment wirkt, bis der sich um den vorderen bewegende, hintere Körperteil in einer Vertikalen mit dem vorderen befindet. Der Hebelarm ist dann verschwunden, und das Drehungsmoment, das Produkt aus Kraft und Hebelarm ist gleich Null; - der Diaptomuskörper verharrt wieder in seiner scheinbaren Ruhe.

Da bei Cyclops die Antennen kurz sind, so kann die Reibung am Kopfende nicht so gross sein wie bei Diaptomus. Zu den 
kürzeren Antennen, in Korrelation damit, kommt am hinteren Körperende eine lange starre Furka hinzu mit langausgezogenen Apikalborsten, und zu der schwächeren Reibung am vorderen dadurch eine starke am hinteren Körperende. Der oben geschilderte Vorgang kann sich nun nicht mehr abspielen; denn das Entstehen eines Drehungsmomentes ist unmöglich gemacht worden.

Was also Diaptomus auszeichnet, ist eine kurze, bewegliche Furka mit kurzer Bewehrung und lange Antennen.

Im Gegensatz dazu besitzt Cyclops eine starre, ausgezogene Furka und kurze Antennen.

Jenes Verhältnis entspricht der pelagischen, schwebenden, dieses der littoralen, schwimmenden Lebensweise.

$\mathrm{Zu}$ demselben Resultat kommen wir, wenn wir im Genus Cyclops Entwicklungsreihen aufstellen, in denen wir die Formen mit den ursprünglichen Merkmalen (im Sinne der Urform LANGS) zu Ausgangspunkten nehmen. Diese Formen zeichnen sich aus durch die längsten Antennen und das kürzeste Abdomen; die Bewehrung der Furka erinnert nicht nur durch die Kürze und das gleichmässige Aussehen der Borsten an Diaptomus, sondern auch durch die Befiederung der Innenseiten der Furkaläste. Die jüngeren Formen, die sich durch kurze Antennen auszeichnen, verlängern Abdomen, Furka und Furkalborsten. Von den vier Apikalborsten eines Astes werden die beiden äussern reduziert, die beiden inneren ausgezogen. Die Befiederung zieht sich von der Furka zurück, ebenso vom proximalen Teil der Borsten, um sich auf deren distalen Teil zu beschränken. Die Befiederung verliert ihren früheren Charakter; sie wird weniger dicht, die einzelnen Fiedern werden kürzer, sie werden allmählich aus Haaren zu Dornen, und in einer Gruppe differenzieren sie sich, indem die proximalen zu kurzen Dornen werden, die weit abstehen, und die distalen zu längeren, die auch kürzere Abstände aufweisen. 
Die vergleichende Methode ist erschöpfender als die direkte Beobachtung. Sie zeigt uns, dass die Umwandlung von einer pelagischen $\mathrm{zu}$ einer littoralen Form noch von einer Reihe weiterer Veränderungen begleitet ist. Die Antenne, die an Länge verliert, gewinnt an sensorischer Bedeutung dadurch, dass ein Sinneskolben entsteht und dieser an Grösse zunimmt. Die Schwimmfüsse werden kürzer, entweder durch Reduktion der Grösse der einzelnen Segmente oder durch Reduktion der Zahl der Segmente. Ebenso wird auch das rudimentäre Füsschen eingliederig. Die Verbindungslamellen der Basalteile der Schwimmfüsse verlieren ihre Haar- und Dornensäume, überall finden wir, wenn wir die Hinterleibsregion ausnehmen, Reduktion.

Besondere Bedeutung gewinnen diese scheinbar geringfügigen Erscheinungen bei der Aufstellung des Systems. Hier kommt es, wie es die Geschichte der Pflanzen- und Tiersystematik auch im Allgemeinen zeigt, darauf an, die konvergierenden Reihen als solche zu erkennen und auseinander zu halten. Dieses kann nur dadurch geschehen, dass man die Verhältnisse, die eine Entwicklungsstufe bezeichnen, bei der Aufstellung der Untergruppen nicht als Merkmale benützt. Auch nachdem erkannt worden ist, dass physiologische und systematische Bedeutung eines Merkmales nicht zusammenfallen, pflegt man immer noch zwischen wichtigen und unwichtigen Merkmalen zu unterscheiden, und doch ist der Begriff wichtig relativ wie wenig andere. Wir müssen deshalb die Zwecke, denen ein systematisches Merkmal dienen soll, auseinander halten. Es sind deren zwei : Erstens zu vereinigen; die Formen mit gemeinsamen Merkmalen werden zusammengestellt. Zweitens zu trennen; die Formen und Gruppen von Formen mit unterscheidenden Merkmalen werden auseinandergehalten. Für den zweiten Zweck sind alle Merkmale gleich wichtig, die Formen und die Gruppen von Formen, die unterscheidende Merkmale aufweisen, müssen immer unterschieden 
werden. Nicht so ist es mit den Merkmalen, die dem ersten Zweck dienen, die Gleichartiges zusammenstellen. Handelt es sich um genealogische Gleichartigkeit, so sind alle Merkmale, die bloss auf biologische Gleichartigkeit hinweisen, zu vermeiden. Sie sind dann nicht etwa nur unwichtig, sondern irreführend und besitzen demnach auf ihre Weise eine Art von Wichtigkeit, die unbedingt berücksichtigt werden muss. Sie stellen die Klippen dar, an denen der Versuch ein System aufzustellen, scheitern kann.

Wir dürfen als Merkmale bloss Verhältnisse gebrauchen, die von der Entwicklungstendenz verschont bleiben, Verhältnisse, die sich durch alle biologischen Anpassungen hindurch erhalten haben. Das einfachste Mittel, diese Verhältnisse zu finden, besteht in der Aufstellung von Entwicklungsreihen, und im Eliminieren aller Merkmale, die zu dieser Aufstellung gedient haben. Was an gemeinsamen Merkmalen übrig bleibt, kann allein zum Zusammenstellen von Gruppen gebraucht werden.

Im Genus Cyclops werden die genealogischen Merkmale vor allem von dem rudimentären Füsschen geliefert. Das Füsschen als solches unterliegt zwar auch der Entwicklungstendenz; aus einem zweigliedrigen wird es zu einem eingliedrigen. Doch bleiben von der Tendenz verschont: Die Zahl der Endborsten (zwei oder drei), die Gestalt dieser Endanhänge (Borste oder Dorn) und der Ort der Insertion des einen Anhangs (ob lateral oder apical). Diesen Merkmalen entsprechen andere, so zum Beispiel am Receptaculum seminis, an der Verbindungsplatte des vierten Schwimmfusspaares, an den letzten Segmenten der weiblichen Antenne, und den seitlichen Ecken des fünften Cephalothoraxsegments. Durch Benützung dieser Verhältnisse kommen wir zu natürlichen, scharf umgrenzten Gruppen.

Auf den beiliegenden Stammbäumen kommen die eben besprochenen genealogischen Merkmale ausser denen des rudimentären Füsschens, die der Einteilung zu Grunde liegen, nicht 
zur Geltung. Die Stammbäume sollen bloss zeigen, was sich im Genus verliert und was neu auftritt, das heisst die biologischen Verhältnisse, den Uebergang von der pelagischen zur littoralen Form.

Die Schemata des Stammbaums zeigen Querlinien. Es geben diese die Grenze zwischen den einzelnen Entwicklungsstufen. Sie sagen, ob die Antenne 17 - oder 16 gliedrig ist, ob das rudimentäre Füsschen ein oder zwei Segmente zählt u. s. w. Die vertikalen Linien trennen die Gruppen, die die konvergente Entwicklung durchmachen. Innerhalb der vertikalen Linien wird zusammengefasst, was genealogisch zusammengehört, innerhalb der transversalen, was denselben Grad der Entwicklung zeigt.

In dem Stammbaume liegt die Geschichte der Systematik unseres Genus offen da. Es ist die Geschichte jeder natürlichen Systematik. Zuerst wurde in Gruppen zusammengestellt, was in die Querreihen gehörte, und mühsam von Jahrzehnt zu Jahrzehnt wurden die vertikalen Rubriken ausgefüllt. Die Systeme von Fischer, Richard, Vosseler, Schneil, Clads und MrazeK sind alle in dem Schema wieder zu erkennen. Zu bemerken ist noch, dass die Querreihen die Entwicklungsstufen nicht ganz genau wiedergeben, weil auf dem Stammbaum die Reduktion nur teilweise zur Geltung kommt.

Die Reduktion kann zwei Wege einschlagen. Die Antenne z. B. kann erstens durch den Verlust von Segmenten kürzer werden, oder aber ohne ein einziges Segment zu verlieren, dadurch, dass jedes Segment kürzer wird. Die reduzierte Antenne entspricht in diesem Falle ganz der längeren, wie eine Kopie oder eine kleinere Nummer. So kommt es, dass es sehr lange und sehr kurze siebzehngliedrige Antennen giebt und dass zwölfgliedrige länger sein können als siebzehngliedrige. Das erste Reduktionsprinzip habe ich das der Zahlabnahme, das zweite das der Grössenabnahme genannt. Das Schema 
des Stammbaums, - es ist eben ein Schema, - giebt nur die Zahlabnahme und nicht die Grössenabnahme.

Zuletzt wirken beide Prinzipien zusammen, um den endlichen Grad der Spezialisation herbeizuführen. Eines bereitet das andere vor.

Die Probe auf die Richtigkeit des Stammbaumes ist die: Diejenigen Eigentümlichkeiten, die sich nicht durch die Tendenz der Entwicklung, durch Umwandlung in Folge von Anpassung erklären lassen, höchstens als Folge früherer Anpassung an verlassene Bedingungen, d. h. bloss genealogisch, müssen in kontinuierlichen Zusammenhang gebracht werden können. Sie müssen an der Wurzel des Stammbaumes die divergierenden Aeste vereinigen. Dass dies hier geschehen, wird aus den verschiedenen Stammbäumen ersichtlich. Hier seien noch kurz solche primären, die ursprünglichen Formen vereinigenden Merkmale übersichtlich zusammengestellt:

1. Die hyaline Rudermembran, die den Ersatz für die drei grossen abwärts gehenden Borsten der Diaptomusantenne darstellt.

2. Die Dörnchenreihen, die die proximale Fortsetzung der Membran bilden.

3. Die Näpfchen, von unbekannter physiologischer Bedeutung, die in der Cuticula auftreten.

4. Die innere Behaarung der Furka, die wenn auch nicht sicher als ein der Befiederung der Furkalglieder bei Diaptomus homologes, so doch analoges Gebilde anzusehen ist.

5 . Die bunte Färbung, die im Genus der typischen Braunfärbung weichen muss.

Ich habe den Stammbaum einer Einteilung des Genus zu Grunde gelegt, die ich folgen lasse: Das Einteilungsprinzip bilden Zahl, Natur und Insertionsstelle der Anhänge des rudimentären Fusses. 


\section{Subordo II. PODOPLEA}

Tribus : AmpHaRTHRANDRIA

Fam. : Cyclopidæ.

Subfam.: Cyclopinæ.

Genus Cyclops O. F. Müller.

I. Sectio: Trifida

Cyclops fuscus, albidus

» prasinus, serrulatus, macrurus

》 affinis

" phaleratus

* poppei, fimbriatus.

\section{Sectio: Bifida}

a. Chætophora. (Der mediale Anhang ist eine Borste.)

ж. Die Borste ist lateral inseriert.

Cyclops leuckarti

$\beta$. Die Borste ist apikal inseriert.

Cyclops oithonoides, dybowskii

$\gg$ gracilis.

b. Acanthophora (Der mediale Anhang ist ein Dorn.)

๙. Der Dorn ist lateral inseriert.

Cyclops strenus, viridis

$\gg$ insignis

$\rightarrow$ varicans.

$\beta$. Der Dorn ist apikal inseriert.

Cyclops vernalis, bicuspidatus, bisetosus, languidus

- diaphanus, bicolor. 
I. Gruppe (Sectio) Trifida.

Die neun Formen der Trifida bilden ein von den übrigen Formen wohl unterschiedenes Ganzes. Am letzten Gliede des rudimentären Füsschens haben sie durch alle Umwandlungen 3 Anhänge, Borsten oder Dornen beibehalten. Zusammen mit diesem Merkmal, doch kaum in Korrelation damit, treten noch zwei durchgreifende Eigentümlichkeiten auf, die eine im männlichen, die andere im weiblichen Geschlecht. Die Greifantennen der Männchen tragen nie Sinneskolben, sondern immer nur Sinnescylinder. Das fünfte Cephalothoraxsegment der Weibchen ist zu beiden Seiten mit je einem Borstenbesatz oder Borstenbüschel versehen. Die Gruppe wird noch durch einige andere Merkmale ausgezeichnet, die, wenn auch nicht ausschliesslicher oder durchgreifender Natur, doch dazu geeignet sind, ihr ein besonderes Gepräge zu verleihen. Die Aeste der Schwimmfüsse zählen immer drei Glieder. Dieser Umstand ist um so auffallender, als an andern Organen die Reduktion bei den Trifida weitergeht als es bei irgend einer andern Gruppe des Genus $C y$ * clops der Fall ist. Während die Gliederzahl der weiblichen Antennen sonst nicht unter elf sinkt, haben wir hier eine Form mit zehngliederigen, und zwei mit achtgliederigen Antennen. Doch auch diese haben wie alle übrigen Trifida nur Schwimmfussäste mit drei wohlerhaltenen Gliedern. Die Mehrzahl der Arten der zu charakterisierenden Gruppe zeichnet sich durch auffallende Dornensäume an der Furka aus, oder wenigstens durch Ansätze zu solchen. Die eine Art, Cyclops serrulatus, verdankt ihren Namen einem solchen Saum von sägeartigem Aussehen. Bei Cyclops serrulatus findet er sich lateral und verläuft von der Seitenborste nach oben. Bei den verwandten Formen 
macrurus und prasinus ist der Saum nur angedeutet. Bei den Formen affinis und fimbriatus verläuft er quer und bei poppei schräg über den Rücken des Furkalgliedes. Bei phaleratus findet sich ähnlich dem bei serrulatus ein kurzer lateraler, während sich vom Rücken gegen die Innenseite noch 4 bis 5 Säume in gleicher Richtung hinziehen. Ebenso bezeichnend für die Trifida ist die Art der Färbung. Die typische Braunfärbung tritt bloss bei drei Arten auf, bei Cyclops serrulatus, macrurus und affinis, sonst aber herrschen die mannigfaltigsten Unterschiede. Schon bei Cyclops macrurus finden wir nicht das typische Braun, sondern ein eigentümliches Strohgelb. Das Männchen von Cyclops serrulatus zeigt bei intensiver Färbung sein Braun mit grellem Ultramarin kombiniert. Durch eine ähnliche, aber noch buntere Mischung zeichnen sich beide Geschlechter bei Cyclops phaleratus aus. Cyclops fimbriatus und in geringerem Grade auch Cyclops poppei können intensiv rosa gefärbt sein, eine Eigenschaft, die sie mit zwei nicht zu dieser Gruppe gehörigen Cyclops, oithonoides und bisetosus, teilen. Einzig stehen aber die beiden Formen fuscus und prasinus mit ihrem Farbenkleid da. Es ist ein leuchtendes und so dunkles Grün, dass die betreffenden Tiere dem blossen Auge schwarz erscheinen. Bei Cyclops fuscus sind dem Grün dunkelblaue Partien untermischt, die im Verein mit der sienaroten Samentasche die Art zur buntesten und grellsten ihres Genus machen. Cyclops albidus hingegen ist trübe und missfarben, bekundet aber seine Zusammengehörigkeit mit den übrigen Trifida dadurch, dass die charakteristische Braunfärbung bei ihm niemals auftritt. Einzelne Teile seines Körpers zeigen mehr oder weniger dunkle, graue Flecken, die bald ins Grünliche, bald ins Bläuliche hinüberspielen. In negativer Weise zeichnen sich die Trifida aus durch das Fehlen von Formen, deren hyaline Membran statt an den drei letzten Gliedern der Antenne, nur an den letzten und vorletzten auftritt, sowie durch das Fehlen von Formen, die im Stande 
sind, auch ein rein pelagisches Leben zu führen. Der Umstand, dass bei Cyclops fuscus und albidus die Antennen das Ende des Cephalothorax erreichen, überhaupt die längsten sind, die im Genus vorkommen, könnte denjenigen, der mit der Lebensweise der beiden Arten nicht näher bekannt ist, dazu verleiten, sie für pelagische zu halten ${ }^{1}$. Sehr wahrscheinlich steht der plumpe Cephalothorax einer solchen Lebensweise hindernd im Weg. Bei allen auch im Plankton vorkommenden Cyclopsarten beträgt das Verhältnis der Länge des Vorderleibes zur Breite im geringsten Falle $2: 1$. Unsere beiden Arten weisen nur das Verhältnis 1,75: 1 und 1,7:1 auf. So geschlossen diese Gruppe erscheint, so umfasst sie doch die weitesten Extreme. Neben diesen beiden Arten mit den längsten Antennen des Genus finden sich auch solche mit den kürzesten und den an Gliederzahl ärmsten. Auf den Umstand ist schon aufmerksam gemacht worden. Er drückt sich aus in dem Verhalten der Tiere in ihrem Medium, dem Wasser. Zwei Formen, die sich noch durch stark genäherte Eierballen auszeichnen, Cyclops fuscus und prasinus, erinnern in Ruhelage und Bewegungsweise stark an das Genus Diaptomus, deren Vertreter mit vertikaler Körperlage frei im Wasser schweben und mit Vorliebe mit dem Rücken nach unten gerichtet schwimmen. Das andere Extrem bilden die Formen, die sich auch kriechend fortbewegen kömnen. Diese Art der Bewegung ist für die Vertreter unserer Gruppe äusserst charakteristisch; ausserhalb ihr sind bloss zwei Fälle bekannt, in denen sie deutlich, wenn auch nur in etwas bescheidenerem Masse auftritt (Cyclops languidus und bisetosus.) Angedeutet finden wir sie bei Cyclops serrulatus, der gerne an Pflanzenteilen haften und am Grunde liegen bleibt. In Glasgefässen- sieht man ihn oft der Glaswand entlang emporsteigen. Weit energischer gestaltet

1 Vergl. Gottlieb Burckhardt, Zooplankton. Revue Suisse de Zool., T. 7, 1899, Seite 638 und 639. 
sich das Kriechen auf fester Unterlage bei den übrigen Formen der Gruppe, die in der Anpassung an das littorale Leben weiter vorgeschritten sind. Es erlaubt ihnen diese Bewegungsart, die kohäsive Kraft eines auf Glas befindlichen Wassertropfens zu überwinden und diesen zu verlassen, eingehüllt in eine dünne Schicht von haften gebliebenem Wasser. Es sind dies die Arten Cyclops affinis, phaleratus, poppei und ganz besonders fimbriatus. Der letztere hält sich deshalb mit Vorliebe in allerdings nur schwach fliessendem Wasser auf, oder am Ufer grösserer Gewässer, wo die Brandung dem Wasser stärkere Bewegung verleiht. Es ist die einzige mir bekannte fluviatile Cyclopsart. Von selteneren Formen gehört nur eine zu den Trifida, Cyclops affinis. Zwei der Formen sind geradezu gemein zu nennen, Cyclops albidus und serrulatus. Es ist schwierig, ein Gewässer zu finden, in dem Cyclops serrulatus nicht vorkäme. Alle neun Arten der Gruppe habeich in der Rheinebene nördlich von Basel gefunden, auf einer Gesammtoberfläche von nicht einmal $1 \mathrm{~km}^{2}$, - ein schönes Beispiel für den Kosmopolitismus von Süsswasserorganismen.

II. Gruppe (Sectio) Bifida.

Die zweite Gruppe des Genus Cyclops, die in ihrer Entwicklung der ersten konvergent ist, unterscheidet sich von ihr dadurch, dass das letzte Glied des rudimentären Füsschens statt drei grösseren Anhängen deren nur zwei zählt. Ich habe deshalb für die zweite Gruppe den Namem Bifida, im Gegensatz. zum Namen der ersten Gruppe, der Trifica, gewählt.

In beiden Gruppen bleibt die Zahl der Anhänge unverändert, auch nachdem durch regressive Entwicklung das rudimentäre 
Füsschen sein Basalglied eingebüsst hat. Wir müssen deshalb in der Zahl der Anhänge ein wichtiges genealogisches Merkmal sehen.

Zur Beurteilung der Natur eines genealogischen Merkmales und überhaupt des Verhältnisses der genealogischen zu den „epharmonischen" ist das Studium des die beiden Cyclopsgruppen trennenden Merkmales sehr geeignet. Besonders gilt dies von seinem Verhalten in der Gruppe der Bifida. Die Reduktion geht hier soweit, dass bei einer Form, bei Cyclops varicans, das letzte Glied oft nur noch einen einzigen Anhang trägt und deshalb noch bei SchyeIL mit nur einer Borste abgebildet ist. MrazeK hat die zweite, die laterale Borste bei Jugendformen an der Stelle, die sie bei Cyclops stremus einnimmt, entdeckt, ich selbst habe sie auch bei erwachsenen Exemplaren, wenigstens angedeutet gesehen. Bei ursprünglichen Formen der Bifida finden wir nach der anderen Richtung hin ebenso lehrreiche Verhältnisse. Cyclops strenuus und Cyclops bicuspidatus lassen bei stärkerer Vergrösserung $(\times 700)$ aussen am kürzeren, medianen Anhang einen dritten erkennen, der als dem dritten der Trifida homolog gedeutet werden muss, und der den Schluss erlaubt, dass beide Gruppen, sowohl Bifida als Trifida, von Formen abstammen, deren rudimentäres Füsschen drei oder mehr Anhänge zählt. In diesem Falle wenigstens existiert also zwischen genealogischen und ,epharmonischen "Merkmalen kein durchgreifender Unterschied. Die genealogischen leisten der Reduktion Widerstand, doch auch für sie kommt der Zeitpunkt, in dem sie das Schicksal der „epharmonischen" Merkmale teilen.

Die Gruppe der Bifida ist nicht so scharf charakterisiert wie die erste. Ausser dem soeben besprochenen wird sie bloss durch Merkmale negativer Natur zusammengehalten. Und das nicht etwa, weil die Gruppe nicht natürlich wäre, sondern weil sie selbst wieder in zwei scharf umgrenzte Gruppen zerfällt, deren 
jede für sich, der ersten, der der Trifida, vielleicht gleichgestellt werden könnte.

Von den Bifida in ihrer Gesamtheit lässt sich sagen, dass sie unter sich keine Formen zählen, deren fünftes oder gar viertes Cephalothoraxsegment seitlich mit Borsten oder Dornensäumen versehen wäre. Eine Ausnahme machen eine von mir in Egypten gefundene Varietät des Cyclops leuckarti und eine in die gleiche Unterabteilung gehörige neue Art, so dass eine natürliche Brücke von den Bifida zu der Schwestergruppe hinüberführt. Ebenso fehlt den Bifida jede Spur von heteronomer Befiederung der Apicalborsten der Furka. Dafür zeigen unter ihnen die Formen, die Claus irrigerweise zu einem Gerus Micrecyclops zusammengestellt hatte, Schwimmfussäste mit nur zwei Gliedern, im Gegensatz zu den Trifida, bei denen die Reduktion der Schwimmfüsse nur durch Grössenabnahme erfolgt. Es ist dies der einzige Fall, wo die Entwicklung bei unserer Gruppe weiter geht als bei den Trifida; er bedeutet aber bezeichnender Weise keine Neubildung, sondern eine Verkümmerung.

Ein weiteres Charakteristikum der Gruppe ist, dass ihr sämtliche pelagische Cyclopsarten ausschliesslich angehören. A priori würde man dies nicht ohne weiteres erwarten, da sich die langen Antennen, ein wichtiges Merkmal der pelagischen Form, bei den Trifida, so bei Cyclops fuscus, albidus und prasinus, viel besser erhalten haben.

Beide Gruppen zeigen konvergente Entwicklung. Sie beginnen mit Formen, deren Antennen siebzehngliedrig und deren rudimentäre Füsschen zweigliedrig sind.

Die Entwicklung, die stark den Charakter der Reduktion trägt, geht jedoch in den beiden Gruppen verschieden weit. Zu den Trifida gehören Cyclops phaleratus mit zehngliederigen Antennen, poppei und fimbriatus mit sogar bloss achtgliederigen. Bei den Bifida geht die Reduktion nur bis auf elf. Ebenso verschwindet das Basalsegment des rudimentären Füsschens, — da 
wo dieses eingliederig wird, — nicht so vollständig wie bei den Trifida. Die Borste des vom Cephalothorax aufgesogenen Fusssegmentes bleibt als Cephalothoraxborste bestehen. Allerdings werden bei den schwächlichen Endgliedern der Entwicklungsreihen unserer hier zu charakterisierenden Gruppe nur zweiSegmente an den kümmerlichen Schwimmfüssen ausgebildet, und die Entwicklung geht bei den Trifida hier in dem Punkte nicht so weit. Dafür setzt sie bei dieser Parallelgruppe anderweitig in einer Weise ein, die uns diese als eine aufblühende, entwicklungsfähige erscheinen lassen.

Wir können zusammenfassend sagen, dass die Entwicklung auch da, wo sie in blosser Reduktion besteht, bei den Trifida früher ansetzt und weiter geht als bei den Bifida. Deshalb und weil die gemeinschaftliche Urform der beiden Gruppen den Trifida ähnlich sehen musste, können wir die Bifida als einen Seitenast des Genus bezeichnen. Da die Trifida keine pelagischen Arten in sich begreifen, obschon Cyclops fuscus und albidus, d. h. die Arten des Genus, die an ursprünglichen Merkmalen am reichsten sind, zu ihnen gehören, so müssen wir annehmen, dass bei ihnen die Anpassung an das littorale Leben früher erfolgt ist, als bei den Bifida. Diese Annahme würde auch erklären, warum bei den Trifida sich bis zu den spezialisiertesten Formen ursprüngliche Charaktere erhalten haben. Die Trifida scheinen sich nicht nur früher als ihre noch stark pelagisch gebliebene Parallelgruppe, sondern auch gründlicher an das littorale Leben angepasst zu haben. Hiefür spricht einmal ihre grössere Häufigkeit. Der von ihnen sich abzweigende Ast hat es neben seinen pelagisch gebliebenen Arten nur zu einer wirklich häufigen Art gebracht, und diese, Cyclops viridis, steht in dieser Eigenschaft immer noch weit hinter Cyclops serrulatus und albidus zurück. Cyclops viridis, wenn auch nicht mehr pelagisch, dokumentiert sich durch seine siebzehngliederigen Antennen als eine ältere Form. Die jüngeren Formen der Bifida sind alle 
selten, ihre Verbreitung ist weder extensiv noch intensiv. Soweit man im Genus Cyclops überhaupt von seltenen Arten reden kann, so gehören diese den Bifida und keine den Trifida an. Für die gründlichere Anpassung an die nicht pelagischen Existenzbedingungen des Süsswassers bei den Trifida spricht neben ihrer Häufigkeit und weiten Verbreitung ihr Charakter als aufblühender Zweig des Genus; d. h. ihre Vitalität drückt sich nicht nur aus in ihrem Vorkom men, sondern ganz besonders auch in ihrer Gestalt. Abgesehen davon, dass die geschilderte Verlängerung des Abdomens, der Furka und ihrer Borsten, die wir als Korrelation zur Verkürzung der Antennen kennen lernten, bei den Trifida viel ausgeprägter ist als bei den Bifida, können wir nur bei jenen von eigentlichen Neubildungen reden; bei diesen haben wir als alleinige Anpassung - Reduktion. Es fehlen ihnen alle die Verhältnisse, die wir als von der Abteilung der Trifida neuerworben zusammenstellen können, so die heteronome Befiederung der Furkalborsten, die starke Bewehrung der Furkaläste und bei den kriechenden Formen auch der Schwimmfüsse, sowie bei denselben Formen die neuen Greif- und Sinnesorgane der männlichen Antenne; das Hineinwachsen der Ovarien in das Abdomen bei Cyclops phaleratus, diebesondere Ausbildung der Kittdrüsen bei affinis und die eigenartige Gestalt des Receptaculums bei prasinus. Für die kriechenden Formen der Trifida machen ReHBeng und FrIC auch eine abweichende ontogenetische Entwicklung geltend und stellen sie deshalb in Gegensatz zum ganzen übrigen Genus. Nichts charakterisiert die Bifida so gut, als diese Aufzählung der in der Schwestergruppe neu auftretenden Verhältnisse; denn nicht nur fehlen diese vollkommen, sondern es fehlen auch entsprechende, die an ihre Stelle treten könnten. Der einzige Punkt, in dem bei den Bifida die Spezialisation weitergeht, die Reduktion der Schwimmfussäste auf zwei Glieder, kann nur den Eindruck bestärken, dass wir es in den vorgeschrittenen Formen der 
Bifida mit einseitig spezialisierten Kümmerformen zu tun haben.

Wir haben in den Bifida einen in seinen Anfängen pelagisch gebliebenen Seitenast der Trifida kennen gelernt, dessen Weiterentwicklung durch immer tiefergehende Reduktion in der Bildung seltener Kümmerformen bestand. Es bleibt uns noch übrig, einer letzten Eigenschaft zu gedenken. Die Gruppe zählt zu ihren Arten alle diejenigen, die als ausgesprochene Kaltwassertiere figurieren und von ZschokkE als Relikte der Glazialzeit beansprucht werden. Zu der parallelen Gruppe der Trifida gehören nur eurytherme Kosmopoliten und Warmwasserformen. Ob sich diese Tatsache später noch zur Erklärung des verschiedenen Verhaltens der beiden Gruppen des Genus Cyclops wird verwerten lassen, lässt sich zur Stunde nicht sagen. Sicher ist vorläufig nur, dass die pelagischen Formen und die Kaltwasserformen durch ihr alleiniges Auftreten innerhalb der Bifida diese zu ihrer Schwestergruppe in einen scharfen Gegensatz stellen.

\section{a. CHжторHORA.}

Die Bifida zerfallen in zwei wohlunterschiedene Untergruppen, eine Trennung die auch im Bau des rudimentären Füsschens ihren Ausdruck gefunden hat. Während in der einen Untergruppe sich die beiden Anhänge des Endgliedes differenziert haben, zu einem kurzen Hacken und einer längeren Borste, ist bei der andern Untergruppe die Differenzierung kaum durch verschiedene Befiederung angedeutet. Dort, wo sich in jener Untergruppe ein starker Dorn erhebt, finden wir in dieser eine dünne Borste. Wir haben sie deshalb die Untergruppe der Chatophora genannt. Das Receptaculum ist von charakteristischer Gestalt. Der untere Teil ist verlängert, der obere seitlich ausgezogen, so dass das ganze Organ einem Hammer nicht unähnlich sieht. Der obere Rand des oberen Teiles ist in der Mitte 
ausgeschweift und das Organ kann deshalb, wo die Einbuchtung stärker ist, herzförmig genannt werden. Da wo die durchsichtige Rudermembran nicht verschwunden ist (Cyclops hyalinus, gracilis), tritt sie nur an den beiden letzten Segmenten auf. Während in den übrigen Abteilungen des Genus Cyclops die Reduktion der Ruderlamelle nur durch Grössenabnahme erfolgt, kommt in der Abteilung der Chatophora zur Grössenzuerst noch die Zahlabnahme.

Die mediane Zwischenplatte der Basalglieder der Ruderfusspaare zeichnet sich an den Seiten ihres oberen Randes durch je eine charakteristische Erhebung aus, die durch einen Dornensaum eine Art von Zinnenkranz erhält. Bei Cyclops leuckarti verschmelzen Dornen und Erhebung zu einem starken Hacken und bei Cyclops gracilis findet sich auch von diesem nichts mehr.

Alle Arten, mit Ausnahme von Cyclops gracilis, kommen auch pelagisch vor. Der häufigste ist Cyclops leuckarti. In der Umgegend von Basel ist Cyclops dybowskii während der Zeit meiner Untersuchungen erst im Jahre 1900 aufgetreten und hat merkwürdigerweise überall den Cyclops gracilis verdrängt, der sich in diesem Jahre nur beim Dorfe St. Ludwig, bis wohin Cyclops dybowskii nicht vorgedrungen war, vorfand.

\section{b. ACANTHOpHORA}

Die Acanthophora sind nicht so gut zu charakterisieren wie die Chetophora; nicht dass die Gruppe eine künstliche wäre, sondern sie zerfällt selbst wieder in zwei Abteilungen, die ihrerseits sich sehr scharf von einander und zusammen von den übrigen Arten des Genus abgrenzen. In der einen Abteilung ist der Dorn überall kurz und seitlich inseriert, auf halber Höhe des Endgliedes. In der andern ist der Dorn in der Regel lang und immer apikal inseriert. Die erste Abteilung zeichnet sich noch dadurch aus, dass bei drei von ihren vier Arten sich die Befiederung der inneren Seite der Furkaläste erhalten hat, wie bei 
Cyclops fuscus. Daneben zeigen auch die Receptacula der einzelnen Arten eine unverkennbare Aehnlichkeit. In der zweiten Abteilung finden wir als sekundäre Charaktere ein sehr langes Endglied des rudimentären Füsschens. Wenn dieses Glied das Resultat der Verschmelzung zweier Segmente ist, so hat in dieser Abteilung die Reduktion bloss durch Zahlabnahme und nicht auch durch Grössenabnahme stattgehabt. Bei den älteren Formen haben wir eine grosse Aehnlichkeit der Furka, die sich besonders durch eine Einkerbung am distalen Ende des oberen Drittels ausdrückt. Bei den jüngeren Formen tritt besonders die in der ganzen Abteilung vorhandene Aehnlichkeit des Receptaculums hervor. Es zeigt sich diese durch eine ventrale Austreibung, die besonders in der Seitenlage deutlich sichtbar ist.

Cyclops strenus und Cyclops viridis sind häufig zu nennen, obschon Cyclops stremuus eine nördliche Form ist. Cyclops insignis, varicans und diaphanus zeigen zwar wie alle Cyclops ausgedehnte Verbreitung, sind aber zu den seltenen Formen des Genus zu rechnen. Bis auf einen einzigen Weiher, den Weiher des Bottminger Schlosses, ist in der Umgebung Basels Cyclops strenus nur im Winter aufgetreten. Er ist der einzige pelagische Vertreter seiner Gruppe, die Arten viridis, bicuspidatus, vernalis, bisetosus, kommen trotz ihrer siebzehngliedrigen Antennen nur am Grunde der Gewässer vor. Ein einzigartes Revier besitzt Cyclops viridis auf den Jurahöhen; es sind dies die Brunnentröge der Bergweiden.

Beschreibung Der Arten.

Cyclops fuscus Jurine.

Monoculus quadricornis fuscus Jurine (1820).

Cyclops fuscus Sostarié (1888) ; Schmeil, Richard, Steck, Scourfield.

Cyclops signatus Koch (1838); Sars, Brady, Daday, Vosseler, Thallwitz, Lande, Cragin. 
Ciyclops quadricornis var c. Baird (180̈0).

Cyclops coronatus Claus (1857); LubBock, Fric, Ноеск, Matile.

Cyclops fuscus var. fascicornis Cragin (1883).

Ciyclops tenuicornis var. a. signalus Herrick (1884).

Juv. Cyclops palustris Sowinsky (1888).

Cyclops signatus var. coronatus Brewer (1898).

Cyclops fuscus zeigt von allen Cyclopsarten am meisten ursprüngliche Merkmale. Durch einen Teil dieser Merkmale erinnert diese Art stark an Diaptomus. Ohne auf ein Verwandtschaftsverhältnis zwischen den beiden Formen schliessen zu lassen, stellen sie den Cyclops auf eine Entwicklungsstufe, die sich der eines Diaptomus in höherem Grade nähert als die irgend einer anderen Cyclopsart.

1. Die Furka ist kurz und breit.

2. Die Furkaläste tragen an der Innenseite einen starken Haarsaum.

3. Die Längenunterschiede der Apikalborsten der Furka sind die geringsten im Genus.

4. Die Eiballen liegen nicht nur dem Abdomen enge an, sondern erinnern auch in ihrer Gestalt an die Eiballen eines Diaptomus. Sie sind bohnenförmig und kehren die konkave Seite einander zu. Denken wir uns die beiden Oeffnungen der Ovarien bis zum Punkt genähert, wo die ausfliessenden Eier der beiden Oeffnungen sich berühren müssen, so haben wir ganz den Eiballen eines littoral lebenden, fruchtbaren Diaptomus.

5. Die Antennen sind die längsten des Genus. Zurückgeschlagen reichen sie bis zum fünften Cephalothoraxsegment und manchmal darüber hinaus.

6. Die Antennen entbehren noch eines Sinneskolbens. An dessen Stelle sitzt auf dem zwölften Segment ein kurzer, dünner, borstenartiger Sinnescylinder.

7. Die zweiten Antennen sind länger als bei irgend einer anderen Cyclopsart; sehr deutlich wird der Längenunterschied 
durch Vergleichung des dritten Gliedes mit dem dritten Gliede dieses Organs bei Cyclops albidus.

8. In der Ruhestellung nimmt Cyclops fuscus jene vertikale Lage ein, die für das ganze Genus Diaptomus so charakteristisch ist.

Die angeführten Merkmale nähern nicht nur Cyclops fuscus in seiner Entwicklungsstufe dem Genus Diaptomus, sie weisen ihm auch im Stammbaum des eigenen Genus eine unterste Stelle an. Ganz dasselbe ist der Fall bei einer Reihe weiterer Merkmale, die einzeln auch bei andern Arten des Genus Cyclops auftreten, in ihrer Gesamtheit aber Cyclops fuscus den Charakter der ursprünglichsten Cyclopsform verleihen.

1. Die Antennen sind siebzehngliedrig.

2. Die drei letzten Glieder der ersten weiblichen Antennen sind mit einer Rudermembran versehen. Diese Rudermembran, die bei kürzer werdender Antenne und bei grösser werdendem Sinneskolben im Genus Cyclops rasch zerfällt (bei den Trifida und Acanthophora durch Grössenabnalıme, bei den Chatophora durch Grössen- und durch Zahlabnahme) zeigt sich bei Cyclops fuscus in stattlicher Breite mit komplizierter Struktur.

3. Die Haar- und Dornensäume, die an den proximalen Gliedern der Antenne, die Fortsetzung der Rudermembran bilden und deshalb sehr wahrscheinlich mit ihr homodynam sind. (Bei Cyclops serrulatus var. denticulatus tritt an Stelle der Membran ein Dornensaum.)

4. Die Haarreihen der Lamellen, die die Basalglieder je des dritten und vierten Schwimmfusspaares verbinden. Die Lamelle des dritten Fusspaares zählt eine Reihe, die des vierten deren zw ei, zu denen als Randsaum noch eine dritte kommt. Ein Vergleich der Verbindungslamellen oder Platten der verschiedenen Cyclopsformen zeigt, dass die Haarreihen rasch zerfallen. Zuerst verschwindet die Reihe des dritten Fusspaares. Der in so frappanter Weise gleichgefärbte Cyclops prasimus ist ausser fuscus 
die einzige Art, die diese Reihe besitzt. Verfolgen wir die Entwicklung, die die Reihen der Lamelle des vierten Fusspaares durchmachen, so müssen wir mit der Reduktion der Reihen auch die beiden verschiedenen Wege konstatieren, die diese Reduktion einschlägt. Durch Grössenabnahme der einzelnen Elemente der Reihen werden diese unscheinbarer und sind schwieriger nachzuweisen, so bei Cyclops stremus. Zur Grössenabnahme tritt die Zahlabnahme hinzu und die eine der Reihen verschwindet gänzlich, so bei Cyclops viridis und bicuspidatus. Allein wirksam ist die Zahlabnahme bei Cyclops albidus, wo wir nur eine, aber dafür sehr gut entwickelte Haarreihe vorfinden. Das Endresultat des Prozesses ist die vollständige Abwesenheit auch der geringsten Spuren dieser Haarbekleidungen bei Cyclops serrulatus, bisetosus und den andern noch weiter entwickelten Formen.

5. Das rudimentäre Füsschen, das zweigliederig ist, am zweiten Gliede drei Borsten trägt und durch seine Grösse, seine starken Borsten und gut entwickelten Haarornamente dokumentiert, dass es von den rudimentären Füsschen des ganzen Genus die Bezeichnung rudimentär am wenigsten verdient.

6. Die Einsenkungen der Cuticula, die besonders am ersten Abdominalsegment, am Kopfe und am Basalglied der vorderen Antennen auftreten. SchmeIL und Claus haben sie mit Näpfchen verglichen, sie geben den Körperteilen, aus denen sie auftreten ein pockennarbiges Aussehen und sind bloss an solchen Formen nachzuweisen, die anderer Gründe wegen als die ursprünglichsten anzusprechen sind, wie Cyclops strenuus, bicuspidatus, bisetosus und leuckarti, doch unregelmässig und nicht an jedem Exemplar.

7. Die Färbung. Sie besteht aus einem intensiven Blaugrün, das ins Tiefblaue (Indigo) spielen oder durch Grüngelb hindurch ins Braune führen kann. Das bunte Aussehen wird noch erhöht durch die ungleichmässige Stärke der Färbung. Das erste 
Cephalothoraxsegment, die Ventralseite des Genitalsegments, das letzte Abdominalsegment mit der Furka sind am stärksten gefärbt. Schon weniger stark sind es jeweilen die hinteren Randpartieen der thoracalen Segmente und die Extremitäten, während die dazwischen liegenden Teile fast farblos erscheinen.

In dieser bunten Färbung kommt die Zusammengehörigkeit von Cyclops fuscus mit den Trifida sehr deutlich zur Geltung, wir haben in ihr aber auch ein primäres Merkmal zu sehen, im Gegensatz zu der für die Cyclopsarten sonst so bezeichnenden monotonen Braunfärbung. Ist doch schon, ganz allgemein gesprochen, überall wo wir Entwicklung haben, das Mannigfaltige zugleich auch das Primäre, aus dem das Besondere sich herausspezialisiert. Die Braunfärbung tritt so ziemlich an denselben Körperteilen auf, bei den verschiedensten Formen in derselben Weise. Das Kleid der anders gefärbten Tiere wechselt von einer Art zur andern so stark, dass keine darin mit der andern übereinstimmt, weder im Farbenton noch in der Zeichnung. Wir können noch aus einem anderen Grunde auf die Ursprünglichkeit der bunten Färbung schliessen. Hiezu müssen wir von einer von WALLAcE zuerst ausgesprochenen Annahme ausgehen, die sich in der Tiergeographie heute eines unbedingten Konsensus erfreut. Es ist dies die Annahme, nach der alle Formen des Süsswassers, die sich nicht direkt von Landtieren ableiten lassen, dem Meere entstammen. Die Vorfahren der SüsswasserCopepoden wären demnach Meertiere gewesen, mit den Eigenschaften und Eigentümlichkeiten, die wir heute an den MeeresCopepoden vorfinden. Ein Blick auf die Tafeln der GiesBrecht'schen Monographie genügt, uns zu überzeugen, dass auch bei den Copepoden das Meer neben der Heimat des Stammes auch die Heimat der schönen Farben ist, und dass die einförmige braune Zeichnung eine Besonderheit des Süsswassers sein muss. Gehen wir von den Copepoden zu andern Tiergruppen über, so finden wir übergenug Analogien für die Annahme, dass die 
braune Farbe die Farbe des Süsswassers und ganz besonders des mit Pflanzen bestandenen Süsswassers ist, eines Milieus, in dem sich die grellroten Kugeln der Wasserspinnen Eylais, Hydrachna und Limnochares fremdartig genug ausnehmen. In Uebereinstimmung mit diesen Schlüssen sehen wir die bunte Färbung hauptsächlich bei Formen auftreten, die wir anderer Gründe wegen gezwungen sind als ursprüngliche anzusehen, wie Cyclops fuscus, albidus, oithonoides, oder bei solchen, die mit ursprünglichen in genetischen Zusammenhang gebracht werden müssen, wie Cyclops prasinus, phaleratus, fimbriatus und poppei.

Eine Ausnahme macht Cyclops bisetosus. Dieser Cyclops ist eine kriechende Form, und es ist deshalb wohl möglich, dass mit der kriechenden Lebensweise eine Wiederaufnahme der ursprünglichen Färbung verbunden ist. Ihre Intensität bei Cyclops phaleratus dürfte dann auch mit derselben Ursache in Verbindung zu bringen sein. Ebenso muss auch die bei Cyclops fuscus so auffallende Dunkelheit der Färbung, der das Tier auch seinen Namen verdankt, nur als ein ihm eigentümlicher Artcharakter ausgelegt werden, als eine spezielle Anpassung an dunkle Gewässer. Sie lässt sich mit derjenigen Lebensweise, die wir als die urspüngliche anzusehen gezwungen sind, der pelagischen, nicht vereinbaren. Darum kann nicht die Färbung als solche, in der Art, wie sie auftritt, so dunkel und schwärzlich, als primär bezeichnet werden, sondern bloss das, was so dunkel wird, die Farbenanlage und die Zeichnung. Cyclops fuscus erinnert durch sein Verhalten an die ebenfalls dunkel gefärbten Diaptomusarten, wie zum Beispiel Diaptomus castor, die auch nicht im Plankton zu finden sind.

Zur vollständigen Diagnose bleibt uns noch Folgendes zu bemerken :

Der Cephalothorax ist breiter als bei den pelagischen Formen. Seine Länge verhält sich zur Breite, wie 1,75:1. Das 
fünfte Segment trägt seitlich und symmetrisch je einen Borstenund einen Dornenbesatz. Regelmässig tritt der eine oder andere von beiden bei den Trifida auf.

Die Rudermembran ist in der proximalen Hälfte des siebzehnten Gliedes am Rande schräg buchtig gezähnt, resp. gesägt. Die Zähne der Säge sind nach der Basis der Antenne, also nach rückwärts gerichtet. Der Teil der Membran mit dem gesägten Rand ist stark chitinös und verdient eher den Namen einer hornigen Platte, als eines durchsichtigen Häutchens. Die Auffassung, die in der "hyalinen Membran » ein sensibles Organ sieht, ist von Claus und RichaRd mit Erfolg bekämpft worden. Doch wird es nicht überflüssig sein, auf diese stärker gebaute Partie der Membran aufmerksam zu machen, da die Anhänger jener Hypothese besonders die zarte Beschaffenheit des Organs und die Aehnlichkeit mit den innervirten Borsten und Kolben betonen.

Das Receptaculum seminis ist grell, braunrot gefärbt und wird dadurch zu einem untrüglichen Artmerkmal. (Vergl. Jurine, Taf. 3, Fig. II.)

Die Grösse, der von mir gemessenen Exemplare schwankte zwischen $3,3-4,2^{\mathrm{mm}}$.

Ueber das Vorkommen schreibt SchmeIL: «Das Thier ist wie aus den Angaben von Koch, Claus, Rehberg, Vosseler, Poppe, Zacharias und Thallwitz hervorgeht, über ganz Deutschland verbreitet. Es scheint kleinere, aber klare Gewässer den grossen Seen vorzuziehen. Niemals trifft man es in solchen Mengen, wie zum Beispiel den Cyclops stremus Fischer, u. a., sondern stets vereinzelt. " RICHARD sagt: "Cette forme est très répandue partout, et il est pour cela inutile d'énumérer les nombreux points de la France où elle a été recueillie. » Von England hören wir dasselbe: "This is one of the most widely distributed and commonest of the genus. » (BRADY.) Italien, sowie die iberische und die Balkanhalbinsel sind die einzigen Teile Europas, für die unser Cyclops nicht nachgewiesen worden ist. 
ZschоккE sagt von ihm: "Durch häufiges Auftreten in Mitteleuropa zeichnet sich C. fuscus aus. Nach Süden scheint er seltener zu werden, nach Norden häufiger. Von nordischen Stationen des Tiers nenne ich nach verschiedenen Autoren Janaland, Sibirien, die Shetlandsinseln, Schottland, die Provinz Nordland im nördlichsten Norwegen, Island und Grönland. In den Alpen konnte $C$. fuscus an zwei weit auseinander liegenden Lokalitäten bis zu 1800 Meter verfolgt werden. » In der Schweiz fanden ihn Jurine um Genf, Vernet im Rhôneund Rheintal, STEck im Moosseedorfsee. Die Art seines Auftretens in Basels Umgebung spricht erstens für seine Häufigkeit: C. fuscus fand sich in allen von mir untersuchten Gebieten. So kam er im Rheintal in 12 von 31 untersuchten Weihern vor, zwischen Kanal und Neuweg sogar in 16 von 24. Zweitens konnte ich auch seine Vorliebe für kaltes Wasser konstatieren. $\mathrm{Er}$ fand sich in den höchsten der von mir untersuchten Juragewässer, bei Langenbruck und im Bogental, ebenso im Feldsee in einer Höhe von 1113 Meter. Zweimal, so bei den Fischteichen von Michelfelden (Tabelle 2), und bei Harpolingen (Tabelle 6) fand ich ihn in 1-2 Meter tiefen durch Quellwasser gespiesenen Graben, während er im nebenstehenden Weiher fehlte. Er kommt den ganzen Winter ununterbrochen vor; doch findet er sich auch den Sommer über. Stenotherm ist er nicht, sein nordischer Charakter geht nicht so weit. Es ist kein Monat, in dem ich ihn nicht regelmässig gefischt hätte. C. fuscus ist eine der ausgesprochensten eurythermen Formen. Merkwürdig ist noch, dass er aus dem grossen Weiher von Neudorf, in dem er in den Jahren 1895 und 1896 nicht selten war, verschwunden und bis auf heute nicht wieder aufgetreten ist. C. fuscus scheint überhaupt, - es ergiebt sich das auch aus den Erfahrungen beim Transport, - ein sehr empfindliches Tier zu sein. Seiner nahen Verwandtschaft mit pelagisch lebenden Formen und seines Habitus wegen ist noch sein spärliches Auftreten zu betonen 
und die Tatsache, dass er sich nie im Plankton vorfindet. Zum pelagischen Leben gehen ihm zwei Eigenschaften ab: Die Schlankheit und die Durchsichtigkeit. Er liebt schattige, kühle Gewässer; in den mit dichten Lemnateppichen hermetisch bedeckten Feuerweihern ist er ein häufiger Gast.

\section{Cyclops albidus Jurine.}

Monoculus quadricornis albidus Jurine (1820).

Cyclops albidus Sostarié (1888); Schmeil; Richard.

Cyclops annulicornis Koch (1838).

Cyclops quadricornis var $b$. Baird (1850).

Cyclops tenuicornis Claus (18ä7), Lubbock, Fric, Hoeck, Brady, Thallwitz, Lande, Matile.

Cyclopis pennatus Claus (1857).

Cyclops tenuicornis u. anmulicornis Sars (1863); Richard.

C.yclops Clausii Poggenpol (1874).

Cyclops latissimus Poggenpol (1874) (?).

Cyclops signatus Uljanin (187̋̈).

Cyclops tenuicornis var. b. Herrick (1884). juv. Cyclops korostyschewi Sowinsky (1888).

Cyclops signatus var. tenuicornis Brewer (1898).

Cyclops albidus und Cyclops fuscus sind zwei sehr nah verwandte Arten. Nach Vosseler soll Cyclops albidus nur eine Varietät von Cyclops fuscus sein, und nach dem Amerikaner HERRICK sogar nur eine Eier tragende Jugendform. Der Russe Ulianin hat die beiden Arten miteinander verwechselt. Auch sind Formen gefunden worden (Richard, SchMeIL), die sich nicht gut anders denn als Bastarde der beiden Formen deuten lassen. Trotz dieser nahen Verwandtschaft haben wir es mit zwei gänzlich verschiedenen Arten zu tun, die sich durch zahlreiche Merkmale sehr leicht und schon mit blossem Auge unterscheiden lassen. Auch das Verhältnis, in dem sie zu ein- 
ander stehen, lässt sich feststellen. Eine Reihe von Merkmalen unserer Art zwingen zu dem Schluss, dass sie, die HeRrick als ein primäres Jugendstadium des verwandten Cyclops fuscus ansah, im Gegenteile eine sekundäre Form ist, die sich von einer dem Cyclops fuscus ähnlichen ableitet:

1. Der Cephalothorax ist plumper als bei Cyclops fuscus. Das Verhältnis seiner Länge zu seiner Breite beträgt 1,74: 1, während es bei Cyclops fuscus 1,8:1 ist.

2. Das Abdomen ist länger als bei Cyclops fuscus. Bei diesem verhält sich die Länge des Cephalothorax zum Abdomen wie $1: 0,52$, bei Cyclops albidus hingegen, wie $1: 0,53$.

3. Die mittleren Furkalborsten sind länger als die der verwandten Form. Zählt man ihre Länge zu der des Abdomens, so erhält man für den ganzen Schwanzteil bei Cyclops fuscus, wenn man die Länge des Cephalothorax gleich 1 setzt, die Zahl $1-1,2$, bei Cyclops albidus 1,45 .

4. Auch dass Verhältnis der apikalen Furkalborsten unter sich ist ein anderes als bei Cyclops fuscus und zwar ein sekundäres. Vor allen andern hat sich die äusserste der Furkalborsten verkürzt.

5. Ist bei Cyclops albidus die Behaarung der Innenseite der Furkaläste verloren gegangen.

6. Die Rudermembran an den Antennen ist einfacher geworden. Die Chitinzacken finden sich nicht mehr vor.

7. Die Dornensäume, die die Fortsetzung der hyalinen Membran in proximaler Richtung darstellen, sind bei Cyclops albidus schwächer ausgebildet als bei der Stammform.

8. Cyclops albidus hat einen wohlentwickelten Sinneskolben, wo Cyclops fuscus kaum einen schwachen Ansatz dazu in Form eines kurzen Cylinders hat.

9. An der Zwischenplatte des vierten Ruderfusspaares ist einer der Dornensäume verschwunden, so dass, den Randsaum einge- 
rechnet, sich deren noch zwei vorfinden, statt drei wie bei Cyclops fuscus.

10. Die zweite Antenne zeigt sich gegenüber der der Stammform erheblich verkürzt. Das dritte Segment zeigt die Verkürzung am meisten. Seine Gestalt ist glockenförmig, seine Länge beträgt zwei und ein halbmal die Breite; bei Cyclops fuscus hingegen ist das Segment fünfmal so lang als breit.

11. Die Eiersäckchen, die bei Cyclops fuscus so stark an Diaptomus erinnern, stehen bei Cyclops albidus weit ab (etwa $\left.70^{\circ}\right)$.

Besondere Merkmale, an denen Cyclops albidus, ausser den schon angeführten, noch zu erkennen ist, sind der Bau des Receptaculum seminis, und der Dorsalplatte. Die Umrisse dieser Organe sind aus den Figuren ersichtlich.

Bekannt ist der grosse Unterschied der Samenelemente der beiden Arten albidus und fuscus. Bei dieser liegen die kleinen spindelförmigen Körper central in der Spermatophore und werden vom peripherisch gelegenen Austreibekörper verdeckt. Bei Cyclops albidus haben die Samen fadenförmige Gestalt, sind leicht gekrümmt und sind in der Spermatophore in zwei sichtbaren Bündeln angeordnet. Aehnliche Unterschiede sind durch GRoBBen bei Decapoden und durch WEISMANN und GRUBER bei den beiden Arten Moina paradoxa und rectirostris bekannt geworden. Sehr wahrscheinlich klingt die Annahme GrobBens, dass wir es hier mit Verhinderung der Kreuzung nahverwandter Arten im Sinne der physiologischen Selektionstheorie von Romanes zu tun haben. Allerdings steht dieser Annahme in unserem Falle zur Stunde noch die Tatsache entgegen, dass von SCHMEIL und RICHARD Zwischenformen gefunden worden sind, die sich nicht gut anders denn als Bastarde der beiden Arten deuten lassen.

Zum Erkennen des Cyclops albidus mit blossem Auge ist auch dessen Färbung sehr wichtig. Diese ist weisslichgrau in

Rev. Suisse de Zool. T. 11. 1903. 
der Anlage, die Hinterränder der Segmente sind stärker gefärbt, und so erhält das Tier ein geripptes, sehr charakteristisches Aussehen.

Was die Grösse anbelangt, so waren die Exemplare aus der Umgebung Basels durchschnittlich kleiner als die von Cyclops fuscus. Während hier die Grösse nie unter $3,2 \mathrm{~mm}$. sank, schwankte sie dort um $2,5 \mathrm{~mm}$.

Alle Autoren, die über das Vorkommen von Cyclops albidus berichten, betonen dessen Häufigkeit, und so intensiv sein Vorkommen, so weit ist auch seine Verbreitung. Ausser den untersuchten europæischen Ländern ist er auch in Asien und den beiden amerikanischen Kontinenten gefunden worden. Bei Basel steht er in der Häufigkeit des Vorkommens nur dem Cyclops serrulatus nach. Sehr häufig beherbergen ihn die Seen, er kommt dort in der Uferregion vor, in der Region der Seerosen und Potamogetonarten.

Interessant ist auch, dass wir ihn so häufig mit seinen nächsten Verwandten vergesellschaftet finden, so mit Cyclops serrulatus, oft auch mit fuscus und prasinus. Die Weiher sind nicht selten, die alle vier Arten zu gleicher Zeit beherbergen. (Vergleiche Tabelle 1, 2, 4, 6). Es ist kein Monat, in dem ich Cyclops albidus nicht gefunden hätte, doch schien er mir immerhin einige Neigung zur Stenothermie zu haben, indem er in seltenen Fällen, aber dann mit grosser Regelmässigkeit in den Wintermonaten wegblieb. So in dem von mir monatlich untersuchten kleinen Allschwyler Weiher. Nach Zschokke hat Heuscher Cyclops albidus im Gebiet der grauen Hörner in einer Höhe von 1902-2381 m. gefunden. Die Kälte kann also nicht die direkte Ursache jener Neigung zur «Stenothermie » sein. Gegen die Annahme sprechen auch folgende Tatsachen: Im Monat März, in dem Cyclops stremus im Allschwyler Weiher zu verschwinden begann und Cyclops albidus wieder auftrat, fand sich der erstere in den wärmeren Teilen des Weihers $\left(12^{\circ}\right)$, dieser 
aber in den kältesten, wo die Temperatur, durch den Zufluss eines kaum über handbreiten Bächleins nur $6^{\circ}$ betrug. So fand ich auch in dem Feuerweiher des Klosters Mariastein den Cyclops hauptsächlich in dem mit Nasturtium bewachsenen Teil, der den Ausfluss eines nebenstehenden Brunnens aufnimmt. Im Weiher, - die Messungen wurden am 22. März vorgenommen, - betrug die Temperatur an der Oberfläche 12,4 , am Boden $10,3^{\circ}$, im Umkreise der Brunnenkresse hingegen $7,2^{\circ}-7,6^{\circ}$. Die Kälte wird es also nicht sein, die Cyclops albidus vertreibt, und wir müssen uns nach einer andern Ursache umsehen. Ich glaube diese in dem Auftreten des Cyclops strenus gefunden zu haben. Es spricht für diese Annahme das Zusammenfallen der beiden Erscheinungen und die Verteilung der beiden Arten im Hochgebirge. In der Ebene verschwindet Cyclops strenuus im Sommer regelmässig, da findet unsere Form, - wie einige Fälle beweisen, - immer wieder Gelegenheit, sich einzunisten und zu persistieren. Wenn diese Fälle auch nicht so häufig sind, wie die, in denen die eine Form die andere das ganze Jahr hindurch ausschliesst, und wenn dann auch gewöhnlich, besonders in grösseren Gewässern nachgewiesen werden kann, dass die Bezirke der beiden Arten scharf getrennt sind, so könnten sie doch genügen, einen sichern Schluss unmöglich zu machen. Ich habe deshalb die Arbeiten von ZschokKE und Funrmans über die alpine Tierwelt daraufhin verglichen und meine Vermutung bestätigt gefunden. In den Alpen, wo Cyclops stremuus das ganze Jahr über vorkommt und in viel grösseren Mengen als in der Ebene, fehlt Cyclops albidus vollkommen, so in den Seen des Gotthardmassifs und des St. Bernhard, trotzdem er sonst - bei Abwesenheit von strenuus - für eine Höhe von 2381 Metern nachgewiesen worden ist.

Einerseits zeigen die Tabellen in auffallender Weise, dass Cyclops albidus am häufigsten mit nahrerwandten Formen auftritt und andererseits sind wir gezwungen anzunehmen, dass die entferntere Form Cyclops strenuus das Vermögen hat, ihn 
zu verdrängen. Es ist dieses Verhalten das gerade Gegenteil von dem, was wir bei den Centropagiden beobachten können. Hier verdrängen sich die nahverwandten Formen und bestehen nebeneinander die entfernteren. Dass Cyclops albidus in seinem Genus 'mit seinem Verhalten nicht vereinzelt dasteht, beweist das vereinte Auftreten von Cyclops strenus und viridis im Nonnenmattweiher und Schluchsee, in 6 Weihern der Tabelle 2, in den Eisweihern von Bottmingen, in 2 Weihern der Tabelle 4, sowie im Dorfweiher von Le Puix. Eine weitere Illustration zum gemeinsamen Vorkommen eng verwandter Arten des Genus Cyclops bildet die Liste des Säckingersees mit bicuspidatus, bisetosus und languidus und die von Jungholz mit languidus und diaphanoides.

\section{Cyclops prasinus Fischer.}

Monoculus quadricornis prasinus Jurine (1820); SchmeIL, Claus, MraZEK, STEUER.

C'yclops prasinus Fischer (1860); Schmeil, Claus, Mrazek, Steuer.

Cyclops longicornis Vernet (1871).

Cyclops magnoctavus Cragin (1883).

Cyclops fluviatilis Herrick (1884); BREWER.

Cyclops horvathi Daday (1883).

Cyclops pentagonus Vosseler (1886); SchмeIL.

Cyclops pentagonus var. Vichyensis Richard (1887).

Cyclops prasinus bildet die Mittelform, die die Gruppe mit zwölfgliedrigen Antennen an die Gruppe mit siebzehngliedrigen anschliesst. Seine Antennen zählen zwölf Glieder, sein rudimentäres Füsschen ein einziges; trotzdem ist seine Verwandschaft mit Cyclops fuscus so deutlich ausgeprägt, dass er ihm ähnlicher sieht als der vorhin beschriebene Cyclops albidus. Bei diesem könnte man von einer morphologischen, bei Cyclops prasinus hingegen von einer physiologischen Verwandtschaft zu Cyclops fus- 
cus reden: Bei ihm hat die Reduction an den Antennen bloss nach dem Prinzip der Zahlabnahme stattgefunden. Die Länge der Antennen beträgt wie bei den pelagischen Arten, trotz der geringen Zahl von zwölf Gliedern, doch die Länge der drei oder gar der vier ersten Cephalothoraxsegmente. Zu den langen Antennen, die unserer Art im Jahre 1871 den Namen Cyclops longicornis eingetragen haben, kommen noch hinzu ein kurzes Abdomen mit einer sehr kurzen Bewehrung, sowie enganliegende Eiersäckchen. Allerdings, in den Verhältnissen der Furkalborsten unter sich kommt die beginnende Reduktion deutlich zum Vorschein. Die äusserste und die innerste der vier Borsten sind bedeutend verkürzt, so dass die mittleren dafür um so länger erscheinen. Deshalb ist es gut, diese mit dem ganzen Körper zu vergleichen. Nimmt man an, die Länge des Cephalothorax sei 1, so erhalten wir für das Abdomen die Zahl 0,55-0,57, während wir bei fuscus und albidus bloss 0,52 und 0,53 erhalten. Nun sind die Furkalborsten so kurz, dass die grössere Länge des Abdomens wieder ausgeglichen wird. Die Länge des Cephalothorax sei wieder 1, so ist die Länge des Abdomens und der Furkalborsten zusammen gleich 1,1. Für fuscus lautet die Zahl 1-1,2, für albidus 1,45. Diese Zahlen erklären das Verhalten unserer Art, das dem des Cyclops fuscus so ähnlich ist, dass, wäre nicht ihre ausserordentliche Kleinheit, man sie mit dieser verwechseln müsste. Zu dem kommt noch die auffallende Färbung unserer Art, ein lauchartiges Grün, das ihr simultan von zwei Autoren den Namen prasinus eingetragen hat, und das sie einzig mit Cyclops fuscus gemein hat. Die vertikale Ruhelage, die ihr die langen Antennen und das kurze Abdomen ermöglichen, die anliegenden Eiballen, die grüne Färbung, sind nicht die einzigen Punkte, die unsere Art mit Cyclops fuscus verbinden; es kommt als vierter noch die Zwischenplatte des vierten Paares hinzu, die wie bei der Stammform drei Dornensäume trägt. Der Sinneskolben der Antenne nimmt eine Mittel- 
stellung ein. Die Verdickung des Kolbens ist nicht sehr deutlich ausgeprägt.

Die Grösse schwankte zwischen 0,8 und $0,9 \mathrm{~mm}$.

Cyclops prasinus scheint eine mehr südliche Form zu sein und nach Norden hin seltener zu werden. In Frankreich geht sie bis nach Rouen und soll nach Richard bei Belle-Isle (Bretagne) und bei Vichy (Auvergne) gemein sein. Claus hat den Cyclops bei Wien gefunden und Steuer bei Triest. MrazeK nennt ihn den gèmeinsten Cyclops Afrikas. Die Schweiz scheint sich wie Mittelfrankreich zu verhalten. Sehr wahrscheinlich ist er schon von JURINE gefunden worden. VERNET nennt ihn sehr häufig, und ich selbst habe ihn südlich vom Jura im Lohweiher bei Zofingen gefunden. In die Alpen hinauf geht er nicht. Von Interesse ist nun sein Vorkommen um Basel. In der Stadt selbst und auf derselben Breite ist er noch häufig, nördlich davon wird er selten. Der nördlichste Punkt seines Vorkommens ist der Nonnenmattweiher (Höhe über Meer 925 M.)

Der Umstand, dass der Nonnenmattweiher ein Torfmoos ist und Cyclops prasinus auch in den Torfstichen von Jungholz - und zwar das ganze Jahr hindurch - zu Hause ist, lässt auf besondere Vorliebe für moorige Gewässer schliessen. In der Rheinebene war der nördlichste Punkt seines Vorkommens die Fischzuchtanstalt, wo er in einem tiefen, pflanzen- und tierarmen, an modernden Blättern reichen Weiher als einziger Copepode vorkam. Ein Blick auf die Tabellen 3, 4, 5 und 6 zeigt, welchen Grad von Häufigkeit er südlich von Basel erreicht. Er bewohnt die verschiedenartigsten Teiche; Gartenbassins, mit Lemna bedeckte Dorfweiher und mit Schilf bewachsene Teiche. Auffallend ist sein alleiniges Vorkommen in 3-4 m. tiefem, warmem Wasser, wo er allerdings im Kleinen und nie in Scharen auftretend, die Rolle des pelagischen Tieres spielt. 


\section{Cyclops serrulatus Fischer.}

Cyclops semulatus Fischer (1851), Lilljeborg, Claus, Sars, Lubbock, Heller, Fric, Ulianin, Hoeck, Schmeil, Richard, Mrazek, Matile, Brewer.

C'yclops agilis Daday (1883̈), Vosseler, Sostarie, Thallwitz, Lande.

Cyclops alajensis Ulianin (1874).

Cyclops serrulalus var. montanus Brady (1878).

Cyclops nover-zealandice G. M. Thomson (1878).

Cyclops anophthalmus Joseph (1882).

Cyclops serrulatus var. elegans Herrick (188').

Cyclops serrulatus var. brevicaudata Sowinski (1888).

Cyclops serrulatus wird von allen Autoren übereinstimmend die gemeinste Form genannt. Die Art zeichnet sich aus durch wunderbare Anpassungsfähigkeit; kein anderer Cyclops vermag so wie dieser unter den denkbar verschiedensten Bedingungen zu gedeihen. Morphologisch kommt dieser Umstand in den generellen Körperformen des Tieres, die unter den übrigen Arten des Genus die Mitte halten, sehr deutlich zur Geltung. Das Verhältnis zwischen Thoraxlänge und Abdomenlänge ist $1: 0,73-0,75$; zählt man zum Abdomen noch die Furkalborsten, so ist das Verhältnis $1: 1,45-1,5$. Zum ersten Mal zeigt sich hier bei den beiden mittleren Furkalborsten heteronome Befiederung. Bei den drei beschriebenen Formen fuscus, albidus und prasinus hatten wir annähernd gleich geformte Fiedern in annähernd gleichen Abständen. Etwaige leichte Unterschiede kamen nur in unmerklichen Uebergängen zur Geltung. Mit dem Längerwerden der Borsten wird die proximale Befiederung lichter oder geht ganz verloren. Es ist, wie wenn die Borsten einen Stiel erhalten hätten. Innerhalb der distalen Befiederung, auf dem proximalen Teil der Borste, tritt eine neue Bewaffnung in Form von kurzen, weiter auseinanderstehenden Dornen auf. Bei Cyclops serrulatus ist, von der Basis an gerechnet, das erste Viertel der Borste nackt, das zweite mit den Dornen bewehrt, die distale 
Hälfte befiedert. Bei Cylcops affinis tritt die Befiederung noch weiter zurück und bei Cyclops phaleratus kommt noch eine dritte Art der Bewehrung zur Geltung. Die "Säge» der Furka, die sich bei den Männchen nie vorfindet und die ScHMEIL in wenigen Fällen auch am Weibchen vermisste, hat in den Hunderten von Exemplaren, die ich gesehen, auch nicht ein einziges Mal gefehlt. Die Antennen sind kürzer als bei Cyclops prasinus und länger als bei macrurus. Das vierte Cephalothoraxsegment wird nur in den seltensten Fällen erreicht, gewöhnlich nur der Hinterrand des dritten. Doch unterliegt die relative Antennenlänge grossen Schwankungen, so finden wir Formen, deren Antennen das erste Cephalothoraxsegment nur um weniges überragen. Auffallend ist, wie stark sich die letzten Segmente der Antenne verjüngen. In Korrelation hiezu steht die gut ansgebildete Rudermembran, die den schmalen Gliedern die nötige Breite verleiht. Sie ist bedeutend breiter und besser zu erblicken als bei Cyclops prasinus. Rückständige Entwicklung zeigt nur der kurze unscheinbare Sinnescylinder.

Wenn die Antenne mit der breiten Membran und dem unscheinbaren Sinnescylinder einen ursprünglicheren Habitus gewährt als bei Cyclops prasinus, so bekundet sich Cyclops serrulatus als fortgeschrittenere Form wieder in der Zwischenplatte des vierten Paares. Von den drei Dornsäumen, von denen bei Cyclops prasinus keiner und bei albidus einer fehlt, ist bloss noch der mittlere erhalten geblieben und zwar so schwach, dass auch dieser eine nicht immer nachzuweisen ist. Bei männlichen Exemplaren fehlte er nie, und schien mir auch stärker ausgebildet zu sein. Das rudimentäre Füsschen zeichnet sich aus durch seine Borste an der Innenecke; diese Borste ist wohl drei- bis viermal so dick als die beiden andern. Die Eiballen zeigen regelmässig eine stark lichtbrechende stumpfe Spitze aus der Kittsubstanz in welcher die Eier gebettet sind. Zum ersten Mal tritt bei den Trifida die Braunfärbung 
auf, die für das Genus Cyclops so bezeichnend ist. Das Genitalsegment ist jeweilen, gerade bei Cyclops serrulatus besonders stark gefärbt. Nie fand ich Weibchen von $2 \mathrm{~mm}$. Länge, die längsten zählten 1,85 mm., die kürzesten $1 \mathrm{~mm}$.

Cyclops serrulatus ist Kosmopolit. Australien ist der einzige Weltteil, in dem er nicht nachgewiesen worden ist. Es beherbergen ihn auch alle, bis dahin untersuchten Gebirge. FuHRMans hat ihn bei der Punta nera in einer Höhe von $2456 \mathrm{~m}$. gefunden. Seine Verbreitung ist aber nicht allein eine ausgedehnte, sie ist auch äusserst intensiv. Alle Autoren stimmen darin überein: Cyclops serrulatus ist die gemeinste Art des Genus, der gemeinste Süsswasser-Copepode überhaupt. Nur in bestimmten Bezirken, unter besonderen Bedingungen, an die andere Arten besonders angepasst sind, wird seine Häufigkeit erreicht oder gar übertroffen, so in gewissen Alpengegenden von Cyclops strenuus, in den Brunnentrögen der Jurabergweiden, von Cyclops viridis, in fliessendem Wasser und unterirdischen Gewässern von Cyclops fimbriatus. Aber überall behauptet er sich und macht den spezialisirten Formen in ihrem ureigensten Milieu oft erfolgreiche Konkurrenz. Er findet sich unter den,für Copepoden ungünstigsten Verhältnissen. Bekannt ist, dass Richard ihn in den Schwefelquellen von Enghien gefischt hat. So habe ich ihn mehrere Male in Gesellschaft des sauerstoffreiches Wasser aufsuchenden Gammarus gefunden, während, wie sich mir gezeigt hat, man aus der Anwesenheit der Gammariden in nichtfliessendem Wasser mit absoluter Sicherheit auf Abwesenheit von Copepoden schliessen könnte, wenn nicht eben Cyclops serrulatus in einigen Fällen diese Regel zu Nichte machte.

Cyclops serrulatus Fischer var. nov. denticulata.

Cyclops serrulatus Richard (1891).

In seiner "Revision des Copépodes libres d'eau douce qui vivent en France » gibt Richard auf Tafel VI in der Figur 19 
eine Zeichnung des rudimentären Füsschens von Cyclops serrulatus, auf der die innere Borste sich von den andern beiden in der Dicke nicht unterscheidet. Gestützt auf umfangreiche Beobachtungen, kann ich sagen, dass die abweichende Form des rudimentären Füsschens mit einer andern Variation zusammen auftritt und dass man von der einen auf die andere schliessen kann. An die Stelle der Rudermembran tritt ein äusserst feiner Dörnchensaum, der bloss in der proximalen Hälfte den Charakter einer nach rückwärts gerichteten Zähnelung annimmt. Die Zähne, zehn bis elf an der Zahl, stehen in deutlichen Abständen und sind hyalin wie die Rudermembran. SchveIL hat diese Variation der Antenne beobachtet und beschrieben. Interessant ist nun, dass mit der Antenne und dem rudimentären Füsschen auch die Furkalbewehrung von ihrem gewöhnlichen Verhalten abweicht. Bei unserer Varietät, - ich habe sie in Anbetracht ihrer gezähnelten Antenne denticulata genannt, ist die innere Furkalborste länger als bei der forma typica. In der Regel fällt der Unterschied ohne weiteres auf. Doch fand ich bei dem typischen Cyclops serrulatus weite Schwankungen, so dass ich mich gezwungen sah, Messungen auszuführen. In solchen Fällen kann nur die statistische Methode entscheiden. Da gerade Cyclops serrulatus sich durch bedeutende Grössenschwankungen auszeichnet, gebe ich keine absoluten Zahlen. Ich habe die Länge der in Frage kommenden Borste mit der der äussersten verglichen. Sie ist stark, von dornartigem und constantem Aussehen und leicht zu messen. In den nun hier folgenden Zahlenreihen habe ich ihre Länge immer gleich 1 gesetzt.

Cyclops serrulatus forma typica.

Länge der innersten

Länge der äussersten Borste. Borste.

Eisenwerk bei Lützel

$\begin{array}{ll}1,3 \text { (12 Exemplare) } & 1 \\ 1,43 & 1\end{array}$


Eisenwerk bei Lützel

$\begin{array}{lll}1,47 & & 1 \\ 1,48 & (4 \text { Exemplare }) & 1 \\ 1,5 & (2 \text { Exemplare }) & 1 \\ 1,51 & & 1 \\ 1,54 & (2 \text { Exemplare }) & 1 \\ 1,4 & (15 \text { Exemplare }) & 1 \\ 1,43 & (9 \text { Exemplare }) & 1 \\ 1,48 & & 1 \\ 1,49 & (4 \text { Exemplare }) & 1 \\ 1,53 & (4 \text { Exemplare }) & 1 \\ 1 & (6 \text { Exemplare }) & 1 \\ 0,94 & & 1 \\ 0,92 & (3 \text { Exemplare }) & 1 \\ 0,91 & \text { (5 Exemplare }) & 1\end{array}$

Neudorf

Rosenau, b.Kirchener Kopf

$\begin{array}{llll}» & 0,94 & & 1 \\ 》 & 0,92 & (3 \text { Exemplare }) & 1 \\ 》 & 0,91 & (5 \text { Exemplare }) & 1\end{array}$

Cyclops serrulatus nov. var. denticulata.

Länge der innersten Länge der äussersten

Neudorf Borste. Borste.

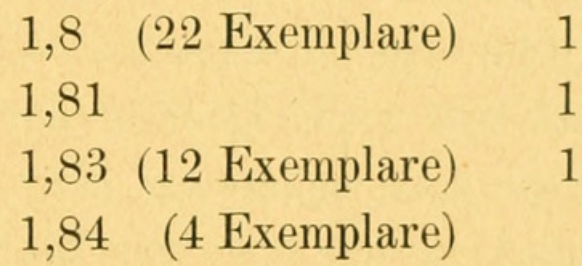

Schloss Wildenstein

$1,72 \quad 1$

1,74 (5 Exemplare) 1

1,78

1,79 (2 Exemplare)

1,81 (7 Exemplare)

1,82 (4 Exemplare) 1

$1,83 \quad 1$

Felsmühle bei Istein

1,8

1

Rheinaltwasser b. Steinenstadt 1,79

1,8 (2 Exemplare) 1 
Fischzuchtanstalt

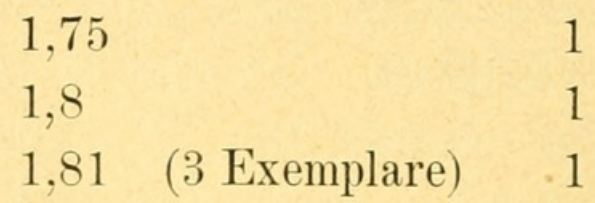

Cyclops macrurus Sars.

Länge der innersten Länge der äussersten Borste. Borste.

Neudorf

$\begin{array}{lll}1,84 & \text { (5 Exemplare) } & 1 \\ 1,85 & & 1 \\ 1,86 & \text { (2 Exemplare) } & 1 \\ 1,87 & & 1\end{array}$

Die angeführten Zahlen berechtigen nicht nur, zwischen den beiden Formen Längenunterschiede anzumehmen, sie zeigen auch, dass die var. denticulata einen Uebergang zu Cyclops macrurus bildet, einen Uebergang, der auch in der Gestalt des rudimentären Füsschens seinen Ausdruck findet. Ausser diesen beiden Formen von serrulatus habe ich noch eine dritte gefunden, die vom Typus nicht so sehr abweicht. Die innerste Borste zeigt die Längendifferenz nicht. Der Dorn des rudimentären Füsschens ist nur etwa zwei Mal so dick als die beiden Borsten des Füsschens und die Rudermembran ist stärker ausgebildet als bei denticulata. Statt des Dörnchensaums haben wir eine feingerippte Lamelle und statt der 10-11 Zähne etwa die doppelte Zahl derselben. Auffallend war an dieser Zwischenform die Kürze der Antennen, die kaum das erste Cephalothoraxsegment überragten, und die starke, lange Furka. Ich habe diese Form ein einziges Mal gefunden, in dem Quellwasserteich der Fischzuchtanstalt, der die Regenbogenforellen beherbergt. Eine vierte Form von Cyclops serrulatus zeichnete sich nur aus durch kurze, bis zur Hälfte des zweiten Cephalothoraxsegments reichende 
Antennen und einen abweichend, das heisst etwas breiter gestalteten Afterdeckel (Telson). Es liegt auf der Hand, dass diese Varietäten mit den von BRADY und HERRICK aufgestellten nichts zu tun haben. Von der Varietät denticulata ist noch nachzuholen, dass gewöhnlich die Färbung bei ihr nur angedeutet ist. und dunkle oder gar grelle Pigmentierung nicht vorkommt. Da RICHARD seine Zeichnung nach französichen Exemplaren gemacht haben wird, muss die neue Varietät auch in Frankreich heimisch sein. Meine Fundorte beziehen sich auf Deutschland und die Schweiz. Recht häufig ist sie auf beiden Rheinufern unterhalb Basel. Das Vorkommen der Varietät kennzeichnet besonders den Neudorfer Weiher, in dem ich sie 6 Jahre hindurch zu jeder Zeit gefunden habe. Von da folgt sie dem Rhein bis nach Neuenburg, gewöhnlich in Gesellschaft von Cyclops leuckarti und albidus. Sie dürfte deshalb im schweizerischen Mittelland heimisch sein, wie Diaptomus gracilis und Cyclops leuckarti, die in gleicher Weise die Rheinufer bevölkern. Gefunden habe ich die denticulata noch: im Nonnenmattweiher, bei Belfort, im Baslerweiher bei Seewen, bei Arlesheim und im Weiher bei Schloss Wildenstein, dort beherbergte der nebenstehende Brunnen die typisch und stark gefärbte forma typica.

\section{Cyclops macrurus Sars.}

Cyclops macrurus Sars (1863); Brady; Rehberg; Sostarié; Lande; Schmeil ; Richard ; Matile.

Cyclops maarensis Vosseler (1889).

Cyclops macrurus ist eine stark spezialisierte Form von $C y$ clops serrulatus. Die Antennen erreichen nur noch die Länge des ersten Cephalothoraxsegments. Dafür streckt sich das Abdomen ganz bedeutend und wird zum längsten im ganzen Genus. Seine Länge verhält sich zu der des Thorax, wie $0,78: 1$. Nimmt man die Länge der Borsten hinzu, die bei affinis bedeutender ist, so erhalten wir die Zahlen: 1,69: 1. Die ganze Länge des Abdo- 
mens hat ihre Ursache in der Länge der Furka; sie erreicht die der drei letzten Abdominalsegmente. Die Furkalglieder berühren sich an ihrer Basis nicht, im Gegensatz zu Cyclops serrulatus. Dieser Unterschied findet sich noch bei anderen nahverwandten Formen, wie z. B. zwischen Cyclops poppei und fimbriatus. Die nahe Verwandtschaft bekundet sich wieder an dem mittleren Seitenrand der Furkalæste, wo eine Reihe von sechs Dornen an die Serra des Cyclops serrulatus erinnert. An denselben Cyclops erinnert auch das Receptaculum seminis, nur dass der obere Teil mehr ausgeschweift ist und seine Enden spitz auslaufen. Fast identisch bei den beiden Formen ist die Bewehrung der Ecken des vierten und fünften Segmentes, die besonders in der Seitenlage des Tieres sich gut beobachten lässt. Der Sinnescylinder erweist sich bei näherer Betrachtung als kleiner Kolben. Von einer « hyalinen Membran » redet unter allen Autoren bloss SchyeIL. Ich selbst habe an meinen Exemplaren keine entdecken können. Das rudimentäre Füsschen gleicht dem der Varietät denticulata. Sehr charakteristisch für das Tier ist seine strohgelbe Farbe. In der Gefangenschaft ging diese bis auf das Genitalsegment und die Partien um den Mund verloren. Die Grösse ist dieselbe wie bei Cyclops serrulatus und deshalb sind die Männchen der beiden Arten, denen alle die charakteristischen Merkmale abgehen, nicht so leicht zu unterscheiden. Es bewährt sich hier das Verhältnis zwichen Cephalothorax und Abdomen auch für das männliche Geschlecht als ein zuverlässiges Merkmal.

Das Tier ist ohne sehr häufig zu sein, über ganz Europa verbreitet und geht über Russland hinaus nach Asien; er ist demnach, wie besonders die Fundorte in Südamerika beweisen, trotz seines Charakters als Warmwasserform, ein ausgeprägter Kosmopolit. In der Schweiz wurde es bis heute erst im Moosseedorfsee von STECK und von mir im Walensee und Neuenburgersee gefunden. Bei Basel ist mir nur ein einziger Fundort bekannt 
geworden: der mit dem Mooseedorfsee sich durch auffallende Analogien auszeichnende Neudorfer Weiher. Nach den Angaben von STECK und von HARTwig, sowie nach meinen Erfahrungen im Neudorfer Weiher und Neuenburgersee, scheint Cyclops macrurus sich mit Vorliebe in mit Schilf bewachsenem Wasser sich aufzuhalten.

\section{Cyclops affinis Sars.}

Cyclops affinis Sars (1863); Ulianin; Brady; Daday; Vosseler; Lande; Schneil ; Richard ; Matile ; Greter.

Cyclops pygmaeus Rehberg (1880); DADAY.

In der Entwicklung der Reihe der Trifida bedeutet die Form Cyclops affinis einen Wendepunkt. Die Anpassung an die schwimmende, littorale Lebensweise hat ihren Höhepunkt erreicht, der nicht mehr überschritten wird. Höchstens dass die Antennen nach dem Prinzip der Zahlabnahme um ein weniges weiter reduziert werden. Das Abdomen und die Furkalborsten nehmen von nun an an Länge etwas ab, allein die heteronome Befiederung der Furkalborsten bleibt bestehen, wird im Gegenteil noch schärfer ausgeprägt. Auch die Schwimmfüsse werden kürzer. Das ist alles. Es macht sich aber ein neuer Prozess geltend, der hier bei Cyclops affinis seinen Anfang nimmt und sich bei den noch übrigen Formen der Trifida, Cyclops phaleratus, poppei und fimbriatus weiter fortsetzt. Es ist dies die Anpassung an die kriechende, an festen Körpern haftende Lebensweise. Ihren besondern Ausdruck findet sie in dem Flacherwerden des Körpers - er wird dorsoventral zusammengedrückt und in dem unmerklichen Uebergang des Cephalothorax in das Abdomen. Der ganze Körper erhält dadurch ein walzenförmiges Aussehen, das an Canthocamptus erinnert.

Das Verhältnis der Länge des Cephalothorax zu dem des Abdomens ist $1: 0,68$ ohne die Furkalborsten und mit denselben 1: 1,5-1,7. Das Receptaculum errinnert an das von Cyclops serrulatus. Ich habe links und rechts von ihm an den Mün- 
dungen seiner Ausführgänge je zwei schöne birnförmige Kittdrüsen konstatieren können. Die «Säge », die sich bei Cyclops serrulatus und macrurus den Seiten der Furka entlang zieht, erstreckt sich bei Cyclops affinis von der Aussenborste an schräg. nach vorne über den Rücken der Furkalglieder. Die Aussenborste ist wie bei Cyclops serrulatus stark und an der Basis von Dornen umgeben. Die Innenborste erreicht nicht mehr die Länge der äussersten. Die mittleren sind nur noch in der distalen Hälfte befiedert, im zweiten Viertel bedornt, im ersten nackt. Die Antennen sind wie die von Cyclops gracilis, bicolor und diaphanus elfgliedrig. Der Sinneskolben ist nicht entwickelt. Die Länge der Antennen beträgt nur noch ein Drittel des Cephalothorax. Das rudimentäre Füsschen ist - eine Folge der Abplattung des Körpers — stark seitlich verlagert. Die drei Anhänge sind im Gegensatz zu Cyclops phaleratus, poppeiund fimbriatus alle gleich stark. Die Grösse der von mir gefundenen Weibchen betrug 0,8-1 $\mathrm{mm}$. Cyclops affinis ist einer der wenigen Trifida, denen die typische Braunfärbung des Genus eigentümlich ist.

Cyclops affinis geniesst eine weite Verbreitung, über ganz Europa und von Russland nach Asien. Doch gehen alle Autoren darin einig, dass sein Vorkommen spärlich ist. Es sind dies die Erfahrungen, die auch ich um Basel gemacht habe. Ich fand ihn südlich von Belfort, dann im Bernerjura, im Weiher bei Zofingen, wie ihn auch STECK im Moosseedorfsee nachgewiesen hat. Er scheint dem Schwarzwald zu fehlen, ebenso dem Jura und nur in der Ebene vorzukommen. So fand ich ihn bei Aesch, an zwei Stellen bei Allschwyl und auf dem rechten Rheinufer in Altwassern, was mit seinem Auftreten im schweizerischen Mittelland im Einklang steht. Die Monate, in denen ich das nur sporadisch auftretende Tier gefunden habe, sind: Februar, April, Mai, August, September, Oktober. Es scheint mithin eurytherm zu sein. Auf Zschokkes Liste der alpinen Copepoden figuriert Cyclops affinis nur als unsichere Art. 


\section{Cyclops phaleratus Koch.}

Cyclops phaleratus Koch (1838). Sars (1863), Ulianin, Brady, Herrick, Daday, Sostarié, Lande, Schmeil, Richard.

Cyclops canthocarpoides Fischer (1851). Lilljeborg, Claus, LubBock, Fric, Camera, Matile.

Cyclops setiger Frey (1869)?

Cyclops Fischeri Poggenpol (1874). Daday.

Cyclops lascivus Poggenpol (1874)?

Ciyclops perarmatus Cragin (1883).

Cyclops adolescens Herrick (188').

Cyclops transilvanicus Daday (1885)?

Die Anpassung an die kriechende Lebensweise, die bei Cyclops affinis begonnen, nimmt hier ihren Fortgang. Der Körper erscheint noch flacher und das Abdomen noch breiter als bei dem soeben genannten Cyclops. Der Uebergang des Thorax in das Abdomen wird ganz besonders unmerklich dadurch, dass das letzte Thoraxsegment seine Differenzierung in Rücken und Bauchplatte verliert und gleich einem Abdominalsegment nur noch von einem Chitinreifen umfasst wird. Die Einbeziehung dieses Segments in das Abdomen, die bei den übrigen Cyclopsarten wie bei allen Podoplea durch Verlagerung der gelenkigen Verbindung von Thorax und Abdomen materiell schon vollendet war, ist es nun bei Cyclops phaleratus auch formell geworden, da das Segment von seinem thoracalen Habitus nur noch das Borstenbüschchen der Trifida mit in das Abdomen hinübergerettet hat. Interessant ist, dass die Dornensäume nicht ab- sondern zunehmen. Die kriechende Lebensweise scheint ein reiches Dornenkleid hervorzurufen, vielleicht zum Schutz gegen die Raumparasiten. Die Dörnchensäume zwar an den Zwischenplatten sind definitiv verschwunden. Es hängt dies zusammen mit dem Kleinerwerden der Schwimmfüsse. Die lateralen Dornen- und Borstenansammlungen am Thorax bleiben bestehen, vom fünften und vierten Segment sind sie auch auf das dritte übergegangen. Die

Rev. Suisse de Zool. T. 11. 1903. 
Furkalglieder erhalten ein igelartiges Aussehen. Drei bis vier Reihen von Dornen verlaufen schräg über den Rücken der Furkalglieder, die noch reichlich mit zerstreuten Dörnchen bewehrt sind. Die äusserste $\Lambda$ picalborste hat die von Cyclops serrulatus an für die Trifida charakteristische Gestalt. Die innere von den beiden mittleren Borsten ist drei mal so lang als die äussere, bei Cyclops affinis beträgt das Verhältnis nur das doppelte. Die mittlere Borste zeigt nicht nur die grösste Länge im Genus, sie erreicht auch die grösste Differenzierung; zu den Fiederhaaren und Fiederborsten tritt noch eine dorsale Reihe von Schuppen oder schuppenartigen Dörnchen hinzu. SchyeIL sagt, dass von den meisten Autoren die Angaben über die Befiederungsverhältnisse der Apikalborsten nicht vollkommen genau seien. Da er von den Schuppen kein Wort sagt, so muss seine Kritik auch auf seine eigene Beschreibung bezogen werden, und wird wohl noch auf manchen späteren Autoren Bezug haben. Wie wenig einfach übrigens diese Verhältnisse sind, zeigt, dass die kürzere der mittleren Borsten nur innen mit Haaren befiedert ist, während die Aussenseite Dornen trägt. Die längere der beiden Borsten ist wie die kürzere im proximalen Drittel nackt, im mittleren mit Dornen und im distalen mit feinen Haaren versehen. Die Länge des Thorax verhält sich zu der des Abdomens wie 1: 0,59; zählt man die langen Borsten zum Abdomen, so verändert sich das Verhältnis zu $1: 1,53-1,58$.

Cyclops phaleratus ist der einzige seines Genus dessen Antennen nur zehn Glieder haben. Bei Cyclops poppei und fimbriatus sinkt diese Zahl allerdings noch bis auf acht. Bei allen entspricht dieses Abnehmen der Segmentzahl keinem Kürzerwerden der Antennen, diese sind eher etwas länger als die elfgliederigen des Cyclops affinis. Merkwürdiger Weise ist der Sinnescylinder der Antenne wie bei Cyclops affinis nur sehr schwach ausgebildet. Die zweiten Antennen wie die Schwimmfüsse zeichnen sich durch reiche Bewehrung mit Dornen- und Haarreihen aus. 
Die rudimentären Fusschen sind fast seitlich eingelenkt, wie bei allen Formen mit kriechender Lebensweise, und ganz nach dem Typus von Cyclops poppei, fimbriatus und serrulatus gebaut, nur dass eine der beiden Borsten unbefiedert ist, und die Verbindung mit dem Körper nicht in einem Gelenk besteht, da das ganze Füsschen seiner Breite nach festgewachsen ist. Auch das Receptaculum trägt die bezeichnenden Umrisse der Gruppe. Die Ovidukte ragen wie in der Gattung Canthocamptus weit in das breite Abdomen hinein. Wie Cyclops affinis und serrulatus, so trägt Cyclops phaleratus den braunen Cyclopsmantel ; die freigebliebenen Stellen sind, wie es oft der Fall ist, blau gefärbt. Hier, bei Cyclops phaleratus, — und das ist das Besondere, das ihn auszeichnet, - handelt es sich nicht um einen zarten Anflug, sondern um ein intensives, grelles Ultramarin. Die betreffenden Stellen sind : das zweite Cephalothoraxsegment, die Furka, die Mediane der Bauchseite und die Antennenspitzen. Das ganze Tier sieht auffallend dunkel aus.

Die Grösse der von mir gemessenen Exemplare betrug nie $2 \mathrm{~mm}$., sondern ähnlich wie die von SchmeIL und RichaRD $1-1,2 \mathrm{~mm}$.

Auch Cyclops phaleratus ist Kosmopolit. Ueber ganz Europa von Italien nach Norwegen ist er verbreitet und ist auch in. den Vereinigten Staaten, in Turkestan, in Aegypten und auf Ceylon nachgewiesen worden. Sein Vorkommen ist ein spärliches, wenn auch nicht in dem Masse wie das von Cyclops affinis. Bei Basel fehlt er vollständig dem Schwarzwald, ebenso dem Flussgebiete der Ergolz. Ganz zu Hause ist er indessen in den Altwassern des rechten Rheinufers. Er dürfte deshalb nach Analogie von Diaptomus gracilis, Cyclops leuckarti und affinis im schweizerischen Mittelland verbreitet sein. Bis heute ist er von STECK im Moosseedorfsee gefischt worden. Ausser den aufgeführten Fundorten nenne ich noch Michelfelden, Allschwyl, Arlesheim und das Torfmoos Bellelay im Bernerjura. 


\section{Cyclops poppei Rehberg.}

Cyclops poppei Rehberg (1880).

Cyclops fimbriatus Herrick (1884).

Cyclops fimbriatus var. poppei Schmeil (1892).

Mit den beiden Arten Cyclops poppei und fimbriatus wird wenigstens in der Antenne das Ultimum der Reduktion erreicht. Die Antenne ist achtgliederig. Im Gegensatz zu phaleratus und affinis haben wir einen sehr gut entwickelten, die Länge von über zwei Segmenten betragenden Sinneskolben. Das rudimentäre Füsschen und das grosse Receptaculum seminis sind nach dem Grundplan der betreffenden Organe bei den Arten serrulatus und phaleratus gebaut. Was von der Körpergestalt der Formen mit kriechender Lebensweise bei affinis und phaleratus gesagt wurde, trifft zum grossen Teil auch hier zu. Nur dass der Cephalothorax hier nicht so breit ist wie bei Cyclops phaleratus und das fünfte Cephalothoraxsegment aus Bauchund Rückenplatte besteht. Die Oviducte reichen nur bis in das erste Segment des Abdomens. Dieses verhält sich, was seine Länge anbelangt, zum Cephalothorax wie 0,69: 1 und, wenn man die Furkalborsten zum Abdomen hinzunimmt, wie 1,57 : 1. Die starke Bedornung an den Schwimmfüssen ist hier so auffallend als bei Cyclops phaleratus. An den Furkalgliedern zeigt sie sich anders, als wir es dort gesehen haben. Die Borste, die gewöhnlich am Aussenrande inseriert ist, findet sich hier zu Beginn des letzten Drittels auf dem Rücken. Quer über den Rücken zieht sich vom Rande her ein Dornensaum bis zu ihr, um dann an ihr vorbei in der Längsrichtung bis zum letzten Abdominalsegment zu gehen. ScHvEIL zeichnet ein Männchen, dem der longitudinale Teil des Dornensaums fehlt. Ebenso fehlt beim Männchen von Cyclops serrulatus die Säge. Es können noch zerstreute Dornen auftreten. Der Dornenbesatz des letzten Abdominalsegments geht der Afterplatte (Telson) entlang weiter 
bis zu deren oberem Rand. Zwischen ihrem Seitenrande und dem ihn begleitenden Dornensaum verläuft noch eine Reihe « knopfartiger » Erhöhungen. Die Exemplare ReHBERGs trugen wie bei Cyclops fimbriatus am Oberrande des « Analausschnittes » oder Telsons einen Dornenbesatz, der meinen und SchmerLs Exemplaren abging. Meine Exemplare massen 0,81-0,85 mm., diejenigen SCHMEILS 0,86.

Cyclops poppei, allem Anschein nach die Stammform von Cyclops fimbriatus, ist wohl oft mit ihr verwechselt worden. SchNeIL konnte diese Verwechslung bei HerRick konstatieren. Cyclops poppei ist demnach, da er in den Verein. Staaten vorkommt, in hohem Masse Kosmopolit. In der Umgebung Basels fand ich ihn auf elsässischem und badischem Boden, auf der Ebene bei Michelfelden; dann bei Neudorf, im grossen Weiher und weiter unterhalb in einem Altwasser, desgleichen in einem Altwasser unterhalb Kleinhüningen und in einem solchen bei Märkt. Aus diesem Vorkommen ist wie bei andern schon angeführten Arten auf ein Vorkommen im schweizerischen Mittelland zu schliessen.

\section{Cyclops fimbriatus Fischer.}

Cyclops fimbriatus Fischer(1853). Rehberg (1880), Vejdowsky, Daday, Vosseler, Lande, Schmeil, Richard, Zschokke.

Cyclops crassicornis Sars (1863). Ulianin, Brady, Sostarié.

Cyclops gredleri Heller (1870).

Cyclops pauper Fric (1872).

Cyclops chiltoni G. M. Thomson (1878).

Cyclops margoi Daday (1883).

Cyclops buthybius Daday (1896)?

Die Regel ist, dass die beiden Furkalglieder der Cyclopiden sich an ihrer Basis berühren und dann verschieden stark divergieren. Cyclops strenuus, Cyclops serrulatus und Cyclops poppei haben jeder von ihnen eine besonders nahestehende Form, bei 
der sich die Glieder anders verhalten : Sie berühren einander an der Basis nicht, zwischen beiden Aesten liegt ein deutlicher Zwischenraum, und die Aeste divergieren nicht mehr, sondern sind gleichgerichtet. Die drei Parallelformen heissen Cyclops insignis, Cyclops macrurus, Cyclops fimbriatus. Die Furka zeichnet sich bei ihnen ausserdem durch eine aussergewöhnliche Länge aus : Die Furka von Cyclops strenuus beträgt gewöhnlich die Länge der zwei, sehr selten der drei vorhergehenden Abdominalsegmente; bei Cyclops insignis ist die Furka regelmässig länger als die drei letzten Abdominalsegmente. Cyclops serrulatus und macrurus zeigen genau das gleiche Verhältnis, und bei Cyclops poppei und fimbriatus ist die Furkallänge bei dem ersten beinahe gleich der Länge der zwei, und beim zweiten gleich der Länge der drei letzten Abdominalsegmente. Cyclops macrurus und serrulatus haben ungefähr die gleiche Grösse, Cyclops insignis und fimbriatus sind erheblich grösser als ihre Parallelformen. Bei allen dreien ist das Verhältnis von Abdomen zu Cephalothorax ein anderes als bei ihren Verwandten.

Cephaloth. Abdom. Abdom. u. Furkalb.

$\begin{array}{ccclcc}\text { Cyclops strenuus } & 1 & : & 0,59-0,62 & : & 1-1,07 \\ \text { " insignis } & 1 & : & 0,65 & : & 1,3 \\ \text { " serrulatus } & 1 & : & 0,73-0,75 & : & 1,45-1,5 \\ \text { " macrurus } & 1 & : & 0,78 & : & 1,69 \\ \text { " poppei } & 1 & : & 0,69 & : & 1,57 \\ \text { " fimbriatus } & 1: & 0,71 & : & 1,6\end{array}$

Cyclops insignis und strenuus tragen beide auf dem Rücken ihrer Furkalglieder eine charakteristische Chitinleiste. Cyclops macrurus aber hat den grössten Teil der Furkalverzierung seiner Parallelform eingebüsst, und ebenso ist es Cyclops fimbriatus ergangen. Die Längsreihe von Dornen, die Cyclops poppei auszeichnet, ist bei Cyclops fimbriatus zu einer kurzen Querreihe geworden. Cyclops insignis unterscheidet sich von Cyclops stre- 
nuus durch kürzere Antennen, verschiedenes Receptaculum, ebenso Cyclops macrurus von Cyclops serrulatus. Cyclops fimbriatus ist von seinem Verwandten nicht so scharf unterschieden, und dieser wird deshalb von ScHMEIL, vielleicht mit Recht, als eine Varietät desselben angesehen. Immerhin sind noch andere Unterschiede da. So fehlen dem Cyclops fimbriatus die bei poppei beschriebenen, den Rand des Telson seitlich begrenzenden Dornenreihen. Ebenso fehlt die dazwischen liegende Reihe knopfartiger Erhebungen. Die Grösse betrug an meinen Exemplaren 0,89-1 mm.

Cyclops phaleratus und fimbriatus sind die beiden Arten der Gattung, die die Fähigkeit auf fester Unterlage zu kriechen im höchsten Grade besitzen. Bei Cyclops phaleratus sieht man dies an seinem Verhalten in der Gefangenschaft. Nicht nur dass er das Wasser im Teller verlässt, und dann die eingetrockneten Leichname unter besonders ungünstigen Verhältnissen einen Saum bilden um den Wasserspiegel, er ist auch im Stande, aus einem Glasgefäss mit senkrechter Wandung an dieser empor über den Wasserspiegel hinaus zu steigen. Gewöhnlich kehrt er, wie ich ihn oft beobachtet, sofort zurück, manchmal ist es aber sein Tod, und der Körper trocknet am Glase ein. Bei Cyclops fimbriatus kommt die neue Art der Lokomotion in anderer Weise zum Ausdruck. Er ist weniger lebhaft und vielleicht auch zarter gebaut als Cyclops phaleratus, wird aber in höherem Masse als dieser die Fähigkeit besitzen, sich festzuhalten. Ich schliesse das aus seinem Vorkommen in fliessendem Wasser. Seine Lebensweise würde ihn zu dem Namen fluviatilis berechtigen, und dies vor allen andern Cyclopiden, ja Copepoden. Bei Hochwasser kann ein Strom Copepoden mit sich führen, in stillen Buchten oder bei geringer Stromgeschwindigkeit ein Potamoplankton existieren, ebenso wird man etwa einmal in einem Bach den Cyclops serrulatus, der ja liberall vorkommt, fischen können; aber der einzige mir bekannte Copepode, der sich in mit 
Pflanzen bewachsenem, bewegtem Wasser als in seinem eigenen Element heimisch fühlt, ist eben nur Cyclops fimbriatus. Er unterscheidet sich dadurch besonders von den naheverwandten Cyclops phaleratus und poppei. Sehr überzeugend ergab sich dies aus einer Reihe von Fundorten, bei denen ich ceteris paribus vergleichen konnte. Es giebt viele Weiher, die entweder einen Zufluss oder einen Abfluss oder beides zugleich besitzen. Wo nun die Bedingungen günstig schienen, habe ich das stehende mit dem fliessenden Wasser genau verglichen.

Der grosse Allschwyler Weiher ${ }^{1}$ enthielt: Diaptomus vulgaris, Cyclops albidus, serrulatus, bicuspidatus.

Der Zufluss des grossen Allschwyler Weihers: Cyclops fimbriatus.

In Montsevelier ${ }^{2}$ enthielt der Mühlweiher: Cyclops albidus und serrulatus.

Der Zufluss des Mühlweihers: Cyclops fimbriatus.

Im Teich in der Breite ${ }^{2}$ (Basel) lebte: Cyclops serrulatus.

Im Ausfluss dieses Teiches: Cyclops fimbriatus.

Im Friedlinger Waldweiher ${ }^{3}$ bei Leopoldshöhe : Cyclops serrulatus, Cyclops vernalis.

Oben und unten an ihm, im Bach, der ihn durchfliesst: Cyclops fimbriatus.

Im Parkweiher in den Langen Erlen ${ }^{3}$ waren: Cyclops albidus, serrulatus, stremuus, vernalis, Canth. staph.

Im Bach, 2-3 Minuten unterhalb: Cyclops fimbriatus.

Weiter fand ich letztere Art im Allschwyler Dorfbach und mit Cyclops serrulatus zusammen in dem grossen Bach, der sich bei Kembs in den Rhein ergiesst. Auch aus der Litteratur lassen sich zwei Fälle anführen, die dasselbe wie meine persönlichen Erfahrungen beweisen. Vosseler fand Cyclops fimbriatus, wie

1 Tabelle 3.

2 Tabelle 4.

3 Tabelle 6 . 
er ausdrücklich hervorhebt, im langsam fliessenden Wasser bei Gschwend, und ZschокKE in dem sich durch ausgeprägten Flusscharakter auszeichnenden Lac des Brenets, - ein Beweis mehr für die Richtigkeit der von ZschokkE aufgestellten Theorie des Fluss-Seecharakters des von ihm untersuchten Sees.

Cyclops fimbriatus kommt auch in stehendem Wasser vor; er hält sich dort am Grunde oder in dichter Vegetation auf. Er ist überhaupt sehr anpassungs- und widerstandsfähig. Bekannt ist, dass ihn Richard auf dem Puy de Dôme in konzentriertem Mineralwasser gefunden hat. Er ist auch eine ausgesprochen eurytherme Form.

Er findet sich mit Cyclops strenuus im unteren See von Orny (ZschoкKE), in einer Höhe von 2686 m., die grösste Höhe, für die ein Cyclops nachgewiesen wurde. Die horizontale Verbreitung entspricht der vertikalen durchaus. Cyclops fimbriatus ist Kosmopolit; nur in Australien ist er noch nicht nachgewiesen worden. Er findet sich in den Tropen (Ceylon, Ostafrika, Südamerika) und in den höchsten Breiten von Grönland und Island bis nach Sibirien. Es ist interessant, dass ausgesprochen eurytherme Tiere sowohl Kosmopoliten sind, als auch hoch in die Alpen hinaufgehen, während die Kaltwasserformen im Hochgebirge heimisch sind, nach Süden aber seltener werden, und Warmwasserformen nicht in die Höhe steigen und nach Norden zu an Verbreitung abnehmen. Im Einklang mit dem ausgeführten steht das Vorkommen von Cyclops fimbriatus in den Brunnentrögen der Bergweiden (vergl. Tabelle 5), ebenso sein Vorkommen in Sodbrunnen (Tabelle 3). Das letztere ist eine bekannte Erscheinung, wie auch, dass unsere Art der häufigste Gast der unterirdischen Gewässer ist. Besonders lehrreich sind die Angaben ScHNEIDERS (zitiert bei SchmeIL, pag. 168), der die Gruben der sächsischen Kohlenreviere untersucht hat.

Zum Schlusse wollen wir noch einer Angabe SCHNEIDERs gedenken, derzufolge Cyclops fimbriatus durch seine Organisation 
befähigt wäre, ein vollkommen amphibisches Leben zu führen Diese Angabe ist von SchMeIL und STEuER und ganz besonders in die verschiedenen Arbeiten ZschokKEs aufgenommen worden. Es kommt nun alles darauf an, wie der Ausdruck amphibisch zu verstehen ist. ScHNEIDER sagt von Cyclops fimbriatus, dass die Organisation desselben ihm gestatte, sich in geringen Wassermengen und selbst auf trockener Unterlage weiterzubewegen. Das Wort amphibisch schliesst aber in sich den Begriff des Lebens und nicht nur den der Bewegung. Tatsächlich lebt nun Cyclops fimbriatus (wie alle seine kriechenden Verwandten) ceteris paribus in einem gleich grossen oder im selben Wassertropfen weniger lang als die nicht kriechenden Arten, weil er den Wassertropfen verlässt und, sobald die an ihm haftende dünne Wasserhülle verdunstet ist, eintrocknet. Zuerst trocknet das Wasser an den Furkalborsten ein, wodurch diese auf die Unterlage aufgekittet werden und das Tier festhalten, bis der Tod eingetreten ist. Die Fähigkeit, sich auf trockener Unterlage fortzubewegen, hängt nicht mit einer besonderen Neigung oder Vorliebe des Tieres zusammen, sic ist die zufällige, rein mechanische Folge der Bewegungsweise des Tieres, ein Nachteil derselben, - biologisch gesprochen; sie erlaubt ihm, die kohäsive Kraft im Wassertropfen durch Adhäsion auf der Unterlage zu überwinden. Schüttet man Bärlapp auf das Glas, so dass die Kohäsion zunimmt, so bleibt der Cyclops im Wassertropfen und prallt vergebens an dessen Wandung an. Der Ausdruck « amphibisch » lässt sich zur Not verteidigen, ist aber irreführend und deshalb zu verwerfen. Nit demselben Recht könnte man einen sich aus dem Wasser schnellenden Fisch, oder noch besser einen Taucher in seiner Glocke ein amphibisches. Geschöpf nennen.

Zschokke führt Cyclops fimbriatus unter den Tieren an, die "amphibische Gewohnheiten» haben, die «wenigstens eine Zeit lang ohne Schaden» der Luft ausgesetzt werden können. 
Er erklärt damit das Vorkommen der Art am steilen Ufer des Lac des Brenets. Da es sich bei Cyclops fimbriatus auch bei feuchter Luft nur um wenige Sekunden handelt, muss nach einer andern Erklärung gesucht werden. Der Flusscharakter des Sees und die Fähigkeit des Tieres der brandenden Kraft des Ufers zu widerstehen, dürften hiezu genügen. So habe ich im Hafen von Wallenstadt in $4-5 \mathrm{~m}$. vom Ufer entferntem Potamogeton pectinatus Cyclops fimbriatus gefunden. Da die Pflanze mit de $\mathrm{m}$ Wasserspiegel steigt und fällt, so giebt es hier für das Vorkommen von Cyclops fimbriatus in der Nähe des Ufers keine andere Erklärung als den fluviatilen Charakter des Tieres.

\section{b. BIFIDA. \\ Cyclops leuckarti Claus.}

Cyclops leuckarti Claus (183̈7). Sars, Herrick, Daday, Schmeil, Richard, Steck, Zschokke, Scourfield, Matile, Brewer, Burckhardt, Stingelin.

Ciyclops simplex Poggenpol (1874). Herrick, Daday, Vosseler, Thallwitz, LANDE.

Cyclops tenuicornis Ulianin (1875).

Cyclops Levenhoekii Hoeck (1878).

Cyclops pectinatus Daday (1885)?

Cyclops lucidus Russki (1889).

Cyclops leuckarti var. setosa Wierzeski 1892). Richard.

Wie Cyclops fuscus und stremus, so ist auch Cyclops leuckarti eine Anzestralform. Er ist ein ausgesprochener Kosmopolit, der dem höchsten Norden fehlt, aber sonst in allen 5 Weltteilen sehr häufig ist. Mit seinem pelagischen Charakter vereinigt er äusserste Variabilität (vergl. Cyclops strenuus.) Der primäre Charakter äussert sich einmal in der pelagischen Lebensweise, dann in der Rudermembran. Es tritt diese nur an den zwei letzten Segmenten auf, zeigt aber in Folge von Einkerbungen eine schöne Zeichnung (vergl. Fig. 26). Drittens sind zu nennen die langen, das vierte Segment erreichenden Antennen, mit dem kurzen 
Sinneskolben und den auch bei Cyclops fuscus und albidus allerdings mit grösserer Regelmässigkeit auftretenden Dornreihen (vergl. dort.) Bei Cyclops leuckarti verlaufen diese quer oder schräg zur Richtung der Antennen, und zwar :

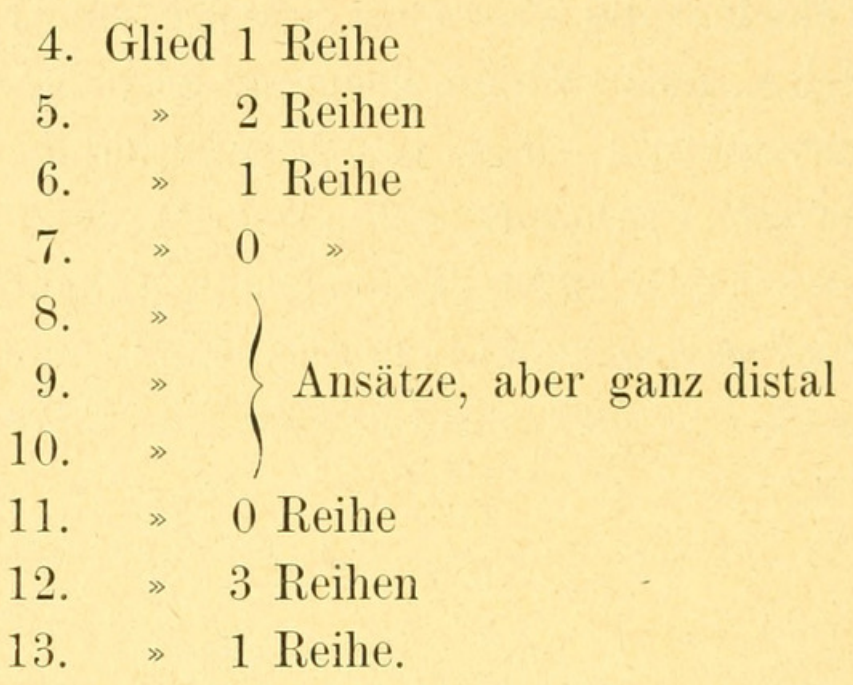

Das Verhältnis der Längsachse des Cephalothorax zur Querachse ist $2: 1$. Es ist dies das Verhältnis der pelagischen Formen. Ebenso ausgesprochen pelagisch ist das Verhältnis der Cephalothoraxlänge zu der des Abdomens, das 1: 1 ist. Da. jeder pelagische Cyclops häufig auch unter ausgesprochen littoralen Bedingungen lebt, so muss man schon a priori Varietäten mit littoralem Habitus erwarten. STINGELin beschreibt eine solche aus Celebes, WiERzeski aus Argentinien. Die letztere, von dem Entdecker und später von RicHARD var. setosa genannt, hat kürzere Antennen, die bloss bis zur Mitte des zweiten Cephalothoraxsegments reichen, eine längere Furka, und der Innenranddorn des rudimentären Füsschens ist kürzer als die Endborste. Die Länge eben dieses Innenranddorns, der im Gegensatz zu allen übrigen Chætophora nicht apikal, sondern auf halber Höhe inseriert ist, bildet selbst ein neues primäres Merkmal. Das Gleiche gilt von den beiden starken Dornen, die den Rand der das vierte Fusspaar verbindenden Basallamelle seitlich schmücken, und ebenfalls das Gleiche gilt von der Furka, 
die kürzer ist als die zwei letzten Abdominalsegmente, und den innersten Apikalborsten, die wie bei Cyclops strenuus lang sind, ungefähr doppelt so lang als die äussersten. Das Vorkommen bei Basel ergibt sich aus den Tabellen. Sein Vorzugsgebiet sind die Rheinsümpfe unterhalb Basel, wo er sehr oft mit Diaptomus gracilis vergesellschaftet ist und aus den meisten Gewässern im Winter verschwindet. Dieser stenotherme Charakter drückt sich auch im Fehlen auf Zschokkes Liste der Hochalpcyclopiden aus, während er doch bis nach Norwegen hinaufgeht. Im Gegensatzzu SchmeıLs Angaben, der bräunliche oder dunkelgelb gefärbte Exemplare konstatierte, waren die meinigen immer hyalin, manchmal mit blauen ventralen Makeln oder rotgefärbten Fettkugeln geschmückt.

Interessant ist sein konstantes Vorkommen im Säckingersee. Ich fand ihn zusammen mit Anurea cochlearis, Notholca longispina, Sida crystallina, Diaptomus gracilis, als eine der fünf Arten, die nach DE Guerne, Richard und ZschokKE allen Seen des Jura gemeinschaftlich sind. Es war dies im Monat März, und zwar muss noch beigefügt werden, dass diese Arten, Sida. ausgenommen, den übrigen Schwarzwaldseen fehlen.

\section{Cyclops oithonoides var. hyalina Rehberg.}

Cyclops hyalimus Rehberg (1884). Lande, Richard, Matile.

Cyclops oilhonoides var. hyalina Rehberg. Schmeil (1892), Richard, Steuer.

Cyclops cabanensis Russki (1889).

Cyclops scourfieldi Brady (1891).

Cyclops oithonoides var. hyalina ist eine, nicht nur Cyclops oithonoides, sondern auch dybouskii äusserst nahe stehende Form. Sie bildet nicht die einzige Varietät; ähnliche Formen sind aus Südamerika und Aegypten beschrieben worden; auch stehen die Arten Mrazers aus Ost-Afrika, emini und schmeilii, ihr sehr nah, und der Streit, ob wir es, wie Renberg meint, mit einer autonomen Art, oder nach SchmeIL bloss mit einer 
Varietät zu tun haben, wird sein Ende erst mit dem methodischen Studium der ganzen Gruppe finden. Ebensowenig lässt sich genaues über die Verbreitung dieses Cyclops sagen, da man nicht immer weiss, ob ein Autor die beiden Formen auseinanderhält, oder nicht etwa gar mit einer dritten verwechselt. Bei Basel fand ich ihn nur im Neudorfer Weiher, einem Altwasser des Rheins, und zwar in den Monaten April bis August. STECK giebt für den Moosseedorfsee Cyclops oithonoides als Winterform an. Es liegt hier vielleicht ein Gegensatz zwischen den beiden Arten vor. Soweit die Angaben, auf die wir uns stützen, richtig sind, findet sich die forma typica im hohen und höchsten Norden und steigt auch ins Gebirge (Lac du Pontet 1800 M.) Die Varietät hyalina hingegen ist den Hochalpen fremd. Ihr nördlichstes Vorkommen bildet die Linie Moskau, Polen, Norddeutschland, und südlich ist sie ganz sicher konstatiert für Kärnthen (STEUER) und Aegypten, wo ich sie selbst, wenn auch nur in wenigen Exemplaren, fischte; sehr wahrscheinlich findet sie sich auch im Senegal bei Rufisque $\left(15^{\circ}\right)$, von wo sie Dr. Richard bestimmt hat.

\section{Cyclops dybowskii Lande.}

Cyclops dybowskii Lande (1890). Schmeil, Matile, Steuer, Amberg.

Cyclops dybowskii, eine weniger bekannte Form, wurde zuerst in Polen gefunden von LANDE, der ihm den Namen seines Landsmannes, des Erforschers des Baikalsees, beilegte. Die Art ist mit oithonoides nahe verwandt und wohl oft mit diesem Cyclops verwechselt worden. Mit blossem Auge kann man sie schon an der charakteristischen Färbung erkennen, die gewöhnlich aus einem ins Braune spielenden Violett besteht. Seite 74 seines Werkes giebt ScHMEIL eine erschöpfende Uebersicht aller Unterschiede, die unsere Art von Cyclops oithonoides trennen. Trotzdem die Species plumper ist als Cyclops oithonoides, besitzt auch sie die Fähigkeit, pelagisch zu leben, und die für Cyclops 
leuckarti betonten Verhältnisse kennzeichnen auch sie in gleichem Masse. Der Umstand, dass Cyclops dybowskii im Schluchsee die littorale Region bevölkerte, während das Plankton sich einzig und allein aus Cyclops strenuus zusammensetzte, beweist, dass, von den fünf pelagischen uns bekannten Cyclopsarten, er den Uebergang zu den nichtpelagischen Formen bildet.

Aus den Tabellen könnte man den Schluss ziehen, er sei ein Kommensale des Cyclops gracilis. Das Gegenteil davon ist der Fall. Cyclops dybowskii trat während der Zeit meiner Untersuchungen erst im Jahre 1899 bẹi Basel auf, und zwar mit einem Schlag an allen von mir bezeichneten Lokalitäten. Bis auf den oben erwähnten Schluchsee waren es nur Gewässer, in denen Sommer für Sommer bisher Cyclops gracilis heimisch gewesen war. Das Merkwürdige ist nun, dass Cyclops gracilis bloss da persistiert hat, wo dybowskii nicht hinkam, sonst aber überall verschwunden ist.

STEuer fand den Cyclops um Triest und ich an mehreren Orten um Cairo. Da er der Hochalp fehlt und auch nicht nach Norden geht, so haben wir es mit einer sehr ausgesprochenen Warmwasserform zu tun.

\section{Cyclops gracilis Lilljeborg.}

Cyclops gracilis Lilljeborg (1853). Lande, SchmeIL (1892), Claus.

Cyclops diaphanus Schmeil (1890).

Von SchmeIL und Claus ist Cyclops gracilis mit andern 11und 12-gliederigen Cyclopsarten in eine Gruppe gestellt worden. Der Bau des Receptaculum seminis, die kurzen Furkalborsten, die langen Antennen und ganz besonders der borstenartige Habitus des medianen Dornes am rudimentären Füsschen, lassen mich Cyclops gracilis der eben besprochenen Gruppe anreihen.

Das eingliederige rudimentäre Füsschen die zweigliederigen Aeste der Ruderfüsse, die geringe Zahl der Antennenglieder 
sind alles Merkmale, die Cyclops gracilis mit diaphanus, bicolor und varicans bloss darum gemein hat, weil diese Formen alle eine konvergente Entwicklung durchgemacht haben.

Die Antennen sind zwar elfgliederig, aber da bloss die Zahl und nicht auch die Grösse ihrer Glieder zurückgegangen ist, so sind sie so lang wie überhaupt die Antennen in der Gruppe der pelagisch lebenden Chatophora. Wie bei Cyclops leuckarti erreichen sie das Ende des vierten Segmentes. Vor seinen Verwandten hat Cyclops gracilis die Länge des Sinneskolbens voraus, die die Länge der zwei folgenden Antennensegmente beträgt; in Uebereinstimmung damit ist das Ende der Antennen nicht verjüngt, ohne Rudermembran und ohne die charakteristische Verlängerung der drei Endsegmente.

Trotz der langen Antennen ist Cyclops qracilis kein pelagisches Tier; es ergiebt sich das aus den Fundorten der Umgebung Basels und aus den Angaben der übrigen Autoren.

Aus den meisten Fundorten wurde, wie oben erwähnt, die Art durch Cyclops dybowskii verdrängt. Die biologische Verwandschaft, die demnach zwischen den beiden Arten besteht, zeigt sich auch in der Stenothermie des Cyclops gracilis. Sie findet ihren Ausdruck weniger in südlichem Vorkommen, wie bei Cyclops dybowskii, als vielmehr in dem äusserst regelmässigen Verschwinden aus allen Gewässern zur Winterszeit und in dem Fehlen auf Zschoкkes Liste der alpinen Arten. Der kleine Allschwyler Weiher ist der erste schweizerische und der südlichste bekannte Fundort. Festgestellt ist die Art bis. jetz für Deutschland, Oesterreich, Polen und Schweden.

\section{Cyclops strenuus Fischer.}

Monoculus quadricornis var. rubens Jurine (1820)?

Cyclops stremuus Fischer (18501). Sars, Brady, Daday, Vosseler, Lande, Schmeil, Richard, Häcker, Claus, Matile, Scourfield, Hartwig, Fuhrmann, Steuer, Burckhardt, ZschokKe. 
C!yclops aurantius Fischer (1831)?

Cyclops quadicornis Lilljeborg (183̈3). SOstarié(1898).

Cyclops brevicaudatus Claus (1857). Lübock, Fric, Ноеск.

Cyclops furcifer Claus (1837).

Cyyclops scutifer Sars (1863).

Cyclops abyssorum Sars (1863).

Cyclops lacustris Sars (1863).

Cyclops Claussii Lubbock (1863).

Cyclops vicimus Ulianin (1873).

Cyclops Fedtschentioi Ulianin (1875).

Cyclops pulchellus Brady (1878).

Cyclops kaufmanni Brady (1878) juv.

Cyclops dentatus Rehberg (1880) juv.

Cyclops claudiopolitanus Daday (1885).

Cyclops hungaricus Daday (1883).

Cyclops paradyi Daday (1885).

Cyclops elongatus Daday (1885)?

Cyclops lucidulus Vosseler (1886), Thallwitz (1890)?

Cyclops bodamicus Vosseler (1886).

Cyclops ulianini Sowinsky (1888) juv.

Cyclops trouchanowi Sowinsky (1888) juv.

Cyclops brevisetosus Sowinsky (1888) juv.

Cyclops bradyi Sostarié (1888).

Cyclops vicinus Lande (1890).

Cyclops stremus ist die bekannteste Art, der klassische Prototyp des Genus. Seine weite Verbreitung, seine Häufigkeit, ganz besonders jedoch seine Eigenschaft als Planktontier grosser und berühmter Seen und das damit verbundene massenhafte Auftreten haben seinen Namen geläufig gemacht. Noch bekannter wurde er als «glaziales Tier», als Bewohner der höchsten Alpenseen, der in der Ebene, wie keine zweite Form, den Sommer hindurch aus den Teichen verschwindet, die er im Winter, selbst unter dem Eise, in so grossen Scharen bevölkert. Auch der Spezialist kennt diese Art vor allen andern besonders gut wegen ihrer übergrossen Variabilität. Cyclops stremuus hat in Folge derselben über zwanzig Synonyma, oft drei von ein und

Rev. Suisse de Zool. T. ^11. 1903. 
demselben Autor. Der Tiergeograph und der Systematiker, die nur mit sicheren Arten operieren können, ständen diesem Cyclops hüflos gegenüber, hätte nicht ScHveIL durch methodisches, noch nach der Publikation seiner Cyclopiden im Jahre 1892 fortgesetztes Studium der Originalexemplare, dem ungeordneten Zustand ein Ende bereitet.

Die komplizierte Synonymie, die Variabilität und die pelagische Lebensweise stehen miteinander in engem Zusammenhange.

Da nirgends im Genus Cyclops die pelagische Lebensweise ausschliesslich ist, mithin, wo sie auftritt, bei der betreffenden Art mannigfaltigere Lebensbedingungen und neue äussere Einflüsse bedeutet, so ist ein Cyclops um so variabler, je ausgeprägter seine pelagische Natur ist. Nun zeigen die quantitativen Planktonmessungen von Jahr zu Jahr deutlicher, wie keine der pelagischen Cyclopsarten die Eigenschaften eines freischwimmenden Seebewohners in so hohem Grade als Cyclops strenuus besitzt.

Die wichtigste, wenn auch nicht die auffallendste der Variationen, in denen sich der pelagische Charakter unserer Art äussert, ist die Verlängerung des Cephalothorax im Verhältnis zum Abdomen und seiner Anhänge und der Verlängerung der Antennen im Verhältnis zum Cephalothorax. Nach den in dieser Arbeit entwickelten Ansichten steht diese Veränderung durchaus im Einklang mit der pelagischen Lebensweise. Es treten damit noch andere Veränderungen auf, wie Kleinheit, Durchsichtigkeit und geringere Fruchtbarkeit, Veränderungen die von jeher den Autoren mehr auffielen, als die oben erwähnten. Am genauesten hat dieses Verhältnis beobachtet G. BurckHARDT, dessen Arbeiten sich durch genaue, ins Detail gehende Messungen auszeichnen. Er sagt pag. 639 seiner faunistischen und systematischen Studien: "Doch waren die Körperproportionen wesentlich andere, als bei den Exemplaren von ScHveIL. 
Der Vorderteil ist bei unseren limnetischen Exemplaren länger, die Furka kürzer, die erste Antenne erreicht oft sogar das Ende des dritten Cephalothoraxsegmentes». BuRckHARDT gibt für jedes einzelne Segment die Längenmasse. Setzt man die Gesamtlänge des Cephalothorax gleich 1, so ergibt die Summe der BunckHARDT'schen Zahlen für Abdomen und längste Furkalborste die Zahl 1,06. Berechnungen an littoralen Exemplaren der Art ergaben im Gegensatz hiezu Verhältnisse bis 1,24 (zu 1). Nun bildet die Messung Burckhardts durchaus keinen extremen Fall. Ich bin oft Exemplaren begegnet, bei denen sich die Länge des Vorderleibs zu der des Hinterleibs verhielt wie $1: 0,95$, und die Fälle sind ganz gewöhnlich, in denen das Verhältnis $1: 1$ beträgt. Wahrscheinlich hat BuRckHaRDT seine Messungen nicht an lebenden, sondern konservierten Tieren vorgenommen, deren Vorderleibsegmente zusammengezogen waren. Solche Veränderungen treten am Abdomen nicht so stark und speziell an seinen längsten Teilen den Furkalästen und Furkalborsten gar nicht auf. Wir stellen die berechneten Verhältnisse noch kurz einmal zusammen.

Vorderleib Hinterleib

$\begin{array}{cccl}1 & : & 0,95 & \text { extreme pelagische Varietät. } \\ 1 & : & 1 & \text { pelagische Varietät. } \\ 1 & : & 1,06 & \text { BuRckHARDT's pelagische Varietät. } \\ 1 & : & 1,24 & \text { littoraler Typus. }\end{array}$

Um die wichtige Frage zu entscheiden, welche von beiden Varietäten dem genetisch primären Verhalten entspricht, sind diese sehr wahrscheinlich noch nicht genügend untersucht worden. Statistisch zusammengestellte Detailuntersuchungen würden vielleicht zeigen, dass die eine der beiden Variationen normal in Verbindung mit unzweideutigen Merkmalen auftritt. Jetzt können wir uns darüber nur in Vermutungen ergehen.

SARS und SCHMEIL berichten von Cyclops scutifer, einer pe- 
lagischen Form unserer Art, dass die Spermatophoren grösser sind als gewöhnlich und, statt an der weiblichen Geschlechtsöffnung transversal angeheftet zu sein, von dieser schräg nach aussen abstehen. Es spricht nun nichts für ein höheres Alter dieser Eigentümlichkeit. Allerdings zeigt sich dieses Verhältnis viel ausgeprägter bei den Diaptomusarten. Die Spermatophoren sind lang, fast schlauchförmig und wie es bei solcher Länge gar nicht anders denkbar ist, auch nicht transversal angeheftet. Dasselbe finden wir bei dem stark stereotropen und nichts weniger als pelagischen Canthocamptus staphylinus: Im Genus Cyclops selbst ist mir die stark reduzierte Form Cyclops bicolor als eine bekannt, deren Spermatophoren auch nicht transversal angeheftet werden, im Gegenteil mit der Längsachse des weiblichen Körpers jeweilen gleichgerichtet sind.

Wie diese, so lässt auch eine andere Eigentümlichkeit der pelagischen Varietät keinen Schluss zu. Es ist dies das Verschwinden der für Cyclops strenus so charakteristischen flügelartigen Verbreiterung der Ecken des vierten und teilweise auch des fünften Cephalothoraxsegments. Fuhrinans in seinen "Recherches sur la faune des lacs alpins du Tessin » und Zsснокке in seiner «Tierwelt der Hochgebirgsseeen » für die Gewässer des Rhätikongebirges betonen übereinstimmend diesen Unterschied mit aller Deutlichkeit.

Die Seitenflügel des vierten Segmentes bei Cyclops stremus sind einer jener äusserst charakteristischen Differentialcharaktere, durch die sich die Anzestralformen des Genus auszeichnen. Das rotgefärbte Receptaculum bei Cyclops fuscus, die Einkerbungen des grossen Maxillarfusses von Cyclops leuckarti, sowie bei derselben Art und ihren nächsten Verwandten die mit Dornen gekrönten beiden Höcker des distalen Randes der Verbindungslamelle des vierten Fusspaares, sind solche Differentialcharaktere, die bei fortschreitender Entwicklung sofort verloren gehen. 
Das Verschwinden der Seitenflügel bei der in Frage kommenden Varietät des Cyclops strenuus würde demnach zeigen, dass die pelagische Lebensweise hier nicht in ununterbrochenem Uebergang von den pelagischen Vorfahren übernommen wurde, sondern dass der Cyclops von einer der pelagischen Lebensweise wenn auch nur leicht entfremdeten littoralen Form abstammt und sekundär in einer neuen Varietät zur früheren Lebensweise zurückkehrte.

Das Verschwinden der Seitenflügel müsste dann in Zusammenhang gebracht werden mit der Reduktion eines zweiten Differentialcharakters unserer Art, der dorsalen Leiste der Furkaläste, einer Reduktion, die sich in verschiedenem Masse bei der pelagischen Varietät geltend macht. Leider sind wir noch nicht weit genug, um überhaupt eine sichere Beziehung zwischen den Flügeln des vierten Cephalothoraxsegments und der pelagischen Lebensweise feststellen zu können. Den Angaben FunRMANN's und ZschokKE's stehen die ebenso zuverlässigen G. BURcKHARDT's gegenüber, der in seinem oben angeführten Werke an der gleichen Stelle von der limnetischen Form sagt: «Die zwei letzten Segmente des Cephalothorax sind zwar in die Länge sehr schwach, in die Breite aber oft äusserst kräftig entwickelt, wodurch die Tiere ein ganz eigenartiges Aussehen erhalten ». - Auch meine eigenen Erfahrungen sprechen gegen eine Generalisation der in den Hochalpen gemachten Erfahrungen. Die littoralen Formen des Cyclops strenuus zeigten die Verbreiterung nur in Ausnahmefällen. Die Rheinebene unterhalb Basel und die Waldweiher des Jura beherbergen braungetärbte Cyclops strenuus, die den für die littorale Varietät postulierten Charakter nicht zeigen. Zwei Weiher, der kleine. Allschwylerweiher und der Bottmingerschlossweiher, beherbergen die breite Form in grossen durchsichtigen Exemplaren mit Diaptomus vulgaris vergesellschaftet, während die schmale Form, so weit meine Erfahrung reicht, diesen Diaptomus mei- 
det. In zwei kleinen Weihern von ähnlichem Habitus, einen halben Meter tief und ohne Pflanzenwuchs, fand ich schmalen und breiten Typus zusammen und durch Uebergänge verbunden; die grösseren Formen waren auch die breiteren, alle Exemplare zeigten strohgelbe Farbe und waren in beiden Weihern mit Cyclocypris lavis vergesellschaftet. Solche Uebergänge begegneten mir auch im Schluchsee, in dem Cyclops strenus der einzige pelagische Copepode ist. Ebenso auffallend wie dieser Umstand war dort die dunkle, ans grünliche streifende Färbung aller Exemplare. Diese Verhältnisse, sowie das Vorkommen der schmalen Form in den qualitativ und quantitativ so reichen Gewässern längs des Rhein-Rhonekanals unterhalb Basel, lassen auch den Gedanken nicht aufkommen, dass der schmaler Typus eine Kümmerform sein könnte.

Wie auch die pelagischen Gewohnheiten des Cyclops strenus in Zukunft gedeutet werden mögen, eines steht für sie heute schon fest : sie finden sich nur bei den. Anzestralformen des Genus und sichern Cyclops strenuus den Charakter einer solchen. Die pelagische Lebensweise wird möglich durch eine Kombination verschiedener ursprünglicher Charaktere. Obschon durch das Fehlen eines einzigen dieser Charaktere bei der ursprünglichsten Form des Genus, bei Cyclops fuscus, die pelagische Natur sich verloren hat, so bleibt eine solche, wo sie auftritt, doch ein untrügliches Zeichen eines genetisch alten Habitus. Sie findet in der Körperform unserer Art ihren Ausdruck in folgenden Verhältnissen primärer Natur :

1) Die noch siebzehngliedrigen Vorderantennen des Weibchens ragen über das erste und manchmal auch über das zweite Cephalothoraxsegment hinaus.

2) An den drei letzten Segmenten der weiblichen Antenne findet sich in Form eines hyalinen Dornensaums ein Ansatz zu einer Rudermembran. Ich habe bei pelagischen Formen beobachtet, wie die hyalinen Dörnchen näher zusammentraten und 
der Saum das Aussehen eines Papierstreifchens erhielt, an dem man mit einer Scheere gleichweit entfernte Schnitte angebracht hätte. Bei dem littoralen Typus stehen im Gegensatz hiezu die Dörnchen weiter auseinander, verbreitern sich gegen die Basis und berühren sich mit ihren Rändern nicht.

3) Der schlanke Cephalothorax. Seine beiden Axen verhalten sich wie $1: 2$.

4) Das kurze Abdomen. Seine Länge beträgt ungefähr die Länge des Cephalothorax. (Vergleiche weiter oben.)

5) Die Furkalborsten. Sie sind stark und bis nahe an die Wurzel befiedert, und die Unterschiede in der Länge sind nicht so gross wie bei den verwandten littoralen Formen. Von innen nach aussen gezählt lauten die Verhältniszahlen der vier Apikalborsten :

$$
\begin{aligned}
72: 125: 117: 36 \text { (nach Richard.) } \\
20: 34: 29: 10 \text { (nach BuRckHardt.) } \\
19: 33: 28: 9 \text { (eigene Messung.) }
\end{aligned}
$$

In dieser Proportion ist die Länge der imnersten Borste zu beachten, die hier noch das Doppelte der äusserstén beträgt, in den einzelnen Gruppen des Genus aber bald so kurz oder sogar kürzer als diese wird.

Wie die hier aufgeführten Charaktere, so sprechen noch einige andere für die primäre Natur dieser Art. So die schon besprochenen Differentialcharaktere, von denen die Rückenleiste der Furkaläste sich bei Cyclops insignis erhalten hat; dann die interne Behaarung der Furka, die sich nicht nur bei Cyclops insignis, sondern auch noch bei viridis vorfindet und für die Anzestralformen der drei grossen Gruppen des Genus besonders charakteristisch ist. Bis jetzt war sie für die Trifida bei Cyclops fuscus bekannt, für die Acanthophora bei Cyclops strenus und in sehr reduzierter Form bei dessen 2 verwandten Arten. In Cairo habe ich nun eine Cyclops leuckarti nahestehende Art 
gefunden die die, interne Behaarung in auffallender Weise zeigt, so dass diese Eigentümlichkeit nun auch für die Gruppe der Chatophora feststeht. Auch das rudimentäre Füsschen spricht für das hohe phylogenetische Alter von Cyclops stremus. Es ist zweigliederig und der innere Dorn des zweiten Gliedes relativ stark entwickelt. SostariÉ zeichnet am Innenrande zwei Dornen. SchmeIL nennt dieses Verhältnis ein abnormales. Für mich steht dies nicht ohne weiteres fest. So zeichnet auch Vosseler proximal neben dem Dorn eine Borste. Eine solche, wenn auch nicht immer in der gleichen Stärke, habe auch ich vorgefunden. (Fig. 15.) Der Vergleich mit dem Füsschen der Trifida liegt nahe, wird aber immer als gewagt erscheinen, so lange keine Uebergangsformen die fragliche Homologie sicherstellen. Zum mindesten haben wir in der Borste, die zusammen mit anderen kleineren auftritt, eines jener Ornamente zu sehen, die nur bei wenig reduzierten, relativ gut ausgebildeten " rudimentären Füsschen » auftreten. Den gleichen Charakter schreibe ich auch den narbenartigen, bei Cyclops fuscus beschriebenen Vertiefungen zu, die bei strenuus besonders häufig sind. Ebenfalls mit Cyclops fuscus hat strenuus die Haarsäume der das vierte Fusspaar verbindenden Lamelle gemein, nur dass diese hier schwach entwickelt und schwierig nachzuweisen sind. Hieraus und aus dem früher Gesagten geht deutlich hervor, dass, verglichen mit dem Ursprünglichsten der Trifida, Cyclops strenuus trotz seines pelagischen Vorkommens eine sekundäre Form darstellt. Es ergiebt sich das auch aus dem Vorkommen eines Sinneskolbens, der bis zur Hälfte des übernächsten Antennensegmentes oder darüber hinausreicht. Ferner ergiebt sich dies aus jener typischen Braunfärbung, die sich bei im Zimmer gehaltenen Tieren nach Monaten verliert.

Die Grösse des Tieres schwankt zwischen weiten Grenzen, wie es bei der variabelsten Cyclopsart nicht anders zu erwarten ist. 
Im Weiher von Vendlincourt fand ich zur selben Zeit reife Weibchen von 3,1 mm Länge und solche von nur 1,7 mm. Der breitere Typus ist gewöhnlich der grössere. Die äussersten Grenzen sind 1, 4 und 3,5 mm. (Vosseler 3,8 mm.)

Das Vorkommen um Basel ist aus den Tabellen ersichtlich. Aus ihnen wird man, in Uebereinstimmung mit andern faunistischen Listen, wie z. B. derjenigen DADAYs aus der hohen Tatra, ersehen, dass Cyclops strenus sehr oft mit viridis zusammen auftritt und, wenn auch in geringerem Masse, mit vernalis.

Cyclops strenuus erfreut sich einer ausserordentlichen Verbreitung. Doch sind, aus den heute bekannten Fundorten zu schliessen, seinem Kosmopolitismus bestimmte Grenzen gezogen. Er ist ein Cyclops der alten Welt und ganz speziell Europas. Sein Vorkommen erstreckt sich von Portugal nach Galizien und Moskau, von Island, Norrland, der Halbinsel Kola nach der Auvergne, den Pyrenäen, Triest und Ungarn. Ueber Europa hinaus findet er sich in Sibirien und Turkestan, in Syrien und Algier. Von besonderem Interesse ist seine vertikale Verbreitung. In seiner « Tierwelt der Hochgebirgsseeen » widmet ihr ZschoкkE eine ausführliche Besprechung. Cyclops strenuus und fimbriatus finden sich im höchsten für Cyclopiden konstatierten Fundort, im untern See von Orny des St. Bernhardgebietes, in einer Höhe von $2686 \mathrm{~m}$.

\section{Cyclops viridis Jurine.}

Monoculus quadricornis var. viridis Jurine (1820).

Cyyclops viridis Fischer (185̈1). Sars, Ulianin, Rehberg, Herrick, Daday, Vosseler, Sostarié, Thallwitz, Lande, Schmeil, Richard, Clads, Steck, Hartwig, Scourfield, Steuer, Matile.

Cyclops crassus Fischer (1851).

Cyclops brevicornis Claus (1857). Lubbock, Heller, Fric, Hoeck, Hartog, HÄCKER.

Cyclops gigas Claus (1857). Fric, Brady.

Cyclops viridis var. vincens Schmankewitsch (1875). 
Cyclops ingens Herrick (1883)?

Cyclops viridis var. b. gigas Herrick (1884).

Cyclops aurantius Daday (1895̈), (Fischer (185̈1) vergl. Cyclops strenuus). Cyclops auratus Daday (1885) juv.

Cyclops viridis var. gigas Sostarié (1888).

Cyclops brevicornis var. gigas Hartog (1888).

Cyclops americanus Marsch (1892). Brewer.

Der interne Dorn des zweiten Giiedes des rudimentären Füsschens bei Cyclops stremuus ist nicht wie der homologe bei Cyclops biscupidatus und den anderen Arten seiner Gruppe am Ende des Gliedes, sondern auf halber Höhe inseriert. Schment legt diesem Umstand keine besondere Bedeutung bei. Er hat beobachtet, dass die Insertionshöhe nicht konstant ist und bald in proximaler, bald in distaler Richtung variert. Ich habe deshalb eine grosse Anzahl, über vierhundert Exemplare verschiedenster Provenienz, daraufhin untersucht und eine gewisse Variabilität konstatiert. Wir haben es mit einer Amplitude zu tun, deren Grenzen nie überschritten werden. Dasselbe gilt von Cyclops viridis. Nie inseriert sich bei den beiden Formen der innere Dorn so weit distal, dass nicht ein deutlicher Abstand die Insertionsstelle trennte von dem Ende des Gliedes, wo sich die äussere Borste inseriert. Die zuerst von ScHveIL bei Cyclops strenuus konstatierten Schwankungen beruhen, so viel ich sehen konnte, hauptsächlich auf Unterschieden in der Länge des zweiten Gliedes des Füsschens. Der Umstand, dass die besprochene mediale Insertion ein konstantes Merkmal und immer leicht festzustellen ist, erlaubt die Aufstellung der Gruppe stremus, viridis, insignis und varicans und erleichtert die Diagnostizierung dieser Arten ungemein. Der Wert des Merkmals ist also nicht nur, wie bei der Besprechung der Systematik des Genus Cyclops hervorgehoben wurde, ein genetischer, sondern auch ein praktischer. Dies zeigt sich am deutlichsten bei Cyclops viridis. Habituell gleicht er durchaus der Art vernalis. Beide nehmen, 
was die Antennen, das rudimentäre Füsschen und grosso modo die Furka anbelangt, die gleiche Entwicklungsstufe ein. Besonders bei schlecht erhaltenen Exemplaren oder, was bei diesen Formen besonders häufig vorkommt, wenn der Körper mit Algen oder Infusorien bewachsen ist, lässt sich nicht so leicht sehen, mit welcher Art man es zu tun hat. Ist das rudimentäre Füsschen sichtbar, so macht die verschieden hohe Insertion des inneren winzigen Dörnchens trotz der grossen Aehnlichkeit und den fast identischen Dimensionen dieses Organes bei den beiden Tieren jede Verwechslung unmöglich. Einige weitere Unterschiede haben ähnliche praktische Bedeutung. So sind die Antennen bei den beiden Arten verschieden lang. Sie erreichen bei Cyclops viridis das Ende des ersten Cephalothoraxsegments, bei vernalis hingegen nicht. Entsprechend der Antennenlänge verhält sich auch der Sinneskolben. Bei Cyclops viridis ist seine Länge gleich der des folgenden Antennensegmentes und der Hälfte des nächstfolgenden, bei vernalis reicht er bis zum distalen Rande des nächstfolgenden Segmentes nach dem Gesetze. dass der Sinneskolben um so länger ist, je kürzer die Antenne. Einen weiteren Unterschied bietet uns die Furka, die bei der Art viridis, wie bei den nah verwandten strenuus und insignis, auf der Innenseite behaart ist, wenn auch nur schwach. Ausgeprägter findet sich ein zweites genetisch altes Merkmal an der Furka von viridis. Die innerste Apikalborste ist noch mehr als doppelt so lang als die äusserste, während bei vernalis in Folge dervorgeschritteneren Differenzierung der inneren Borsten, die innerste nur noch die unbedeutende Länge der äussersten oder vierten erlangt.

ScHмEIL hatte in seiner Einteilung Cyclops viridis in dieselbe Gruppe wie Cyclops vernalis gestellt. Abgesehen von den Merkmalen, die alle Acantophora gemein haben, vereinigen unsere Art mit dieser Gruppe nur solche Merkmale, die von derselben Lebensweise herrühren: Der plumpe Cephalothorax, mit dem. 
das durch seine lange Furka sich auszeichnende Abdomen im Verhältnis 1: 1,3 steht; die trotz ihrer 17 Glieder kurzen Antennen, die an der Spitze weder verjüngt sind, noch eine Membran tragen; die bräunliche Färbung; die ungeheuren Eiballen, bis zu 80 Eier enthaltend, von elliptischer Form, in spitzem Winkel vom Abdomen abgehalten; der gut entwickelte Sinneskolben und das stark reduzierte, wiewohl noch zweigliedrige rudimentäre Füsschen mit auffallend verbreitertem Basalsegment.

Die Lebensweise dieser Cyclopsarten ist eine ausgesprochen littorale. Angaben über pelagisches Vorkommen beruhen auf Ungenauigkeit; wir beobachten im Gegenteil bei diesen Formen Neigung zur kriechenden Lebensweise, da sie sehr oft auf dem Grunde der Gewässer, seien es Teiche, Brunnen oder Seen, vorkommen. Deutlich war dies der Fall bei Cyclops viridis auf den hohen Bergweiden des Jura, wo er in den hölzernen Brunnentrögen mit ziemlicher Regelmässigkeit auftritt (vergl. Tabelle 5). Der Boden und die Wände eines solchen Troges sind mit Algen und Moosen bewachsen; er selbst ist von dem durchsichtigen reinen Wasser erfüllt, das in dünnem Faden aus der Röhre hineinrieselt. Die Sonne dringt bis auf den Grund des Troges und durchdringt den klaren, kleinen See mit solcher Helligkeit, dass man alle Verhältnisse darin, nachdem das Auge sich nur etwas eingewöhnt hat, mit Leichtigkeit beherrscht. Unten am Boden zwischen den Algen erblickt man die grossen über $4 \mathrm{~mm}$ langen Körper der Cyclops viridis, das eine Mal mit den kleineren, schlankeren und hastigeren Cyclops fimbriatus, das andere Mal mit grossen roten Cypris incongruens. Die Brunnentröge der Städte und Dörfer beherbergen keine Copepoden. Entweder fliesst das Wasser zu rasch hindurch, oder dieses ist verunreinigt, wenn nicht allzugrosse Reinheit, die keine Vegetation aufkommen lässt, Schuld daran trägt. Das Vorkommen in kaltem Brunnenwasser ist für Cyclops viridis bezeichnend; in den 
Teichen links und rechts vom Rheine unterhalb Basel, wo er im ersten Frühjahr der häufigste Copepode ist, wird er im Sommer und Herbste seltener. Hiemit stimmt überein sein Vordringen in die Hochalpen und sein Vorkommen in den nördlichsten Gewässern, die untersucht worden sind. Der südlichste Fundort unserer Art sind die Azoren; er zeugt, wie auch die Häufigkeit in den Vereinigten Staaten, von grosser Verbreitung. Und überall, von wo Cyclops viridis gemeldet wird, gilt er, im Gegensatz zu den Kümmerformen unter den Bifida, als gemein.

\section{Cyclops insignis Claus.}

Cyclops insignis Claus (1857). Sars, Fric, Rehberg, Herrick, Schmeil, Richard, Matile.

Die Form Cyclops insignis steht zu strenuus in einem ähnlichen Verhältnis wie Cyclops fimbriatus zu poppei (vergl. $\mathrm{Cy}$ clops fimbriatus).

Die Antennen sind 14 gliederig und erreichen nicht den Saum des 2. Cephalothoraxsegments.

Das rudimentäre Füsschen ist dem von strenuus, wie SCHVEIL. berichtet, identisch.

Ich fand diese Form etwa zehn Stunden von Basel an der Grenze von Frankreich, Deutschland und der Schweiz in der Nähe des bernischen Dorfes Bonfol am 16. April 1896.

Ich fand bloss zwei mit Pilzen und Epistylis überwachsene Exemplare, die ich ihrer Grösse wegen $(4,2 \mathrm{~mm})$ zuerst für $\mathrm{Cy}$ clops viridis hielt. Soviel ich weiss, ist Bonfol nicht nur der erste schweizerische, sondern zugleich der südlichste bekannte Fundort dieser Art, deren Gebiet sich von Moskau nach Nordfrankreich erstreckt und in der Richtung des Meridians bis. nach Norwegen geht. 


\section{Cyclops varicans Sars.}

Cyclops varicans Sars (1862). Lande, Schmeil, Claus, Richard (1893). Cyclops orientalis Ulianin (1875).

Cyclops minutus var. Schmankevitsch (187ว̈).

Wie Cyclops gracilis ist auch varicans eine Kümmerform. Die Antennen sind zwölfgliederig, die Schwimmfussäste zweigliederig und das rudimentäre Füsschen eingliederig. Die Aehnlichkeit des Receptaculums (vergl. Fig. 22) und die mediale Insertion des winzigen, manchmal fehlenden inneren Dorns des rudimentären Füsschens (vergl. Fig. 25) sichern dieser Art eine Stelle in der Gruppe des Cyclops strenuus (vergl. Cyclops viridis).

Die Form war bis jetzt bekannt für Norwegen, Deutschland, Polen, Oesterreich und Turkestan; Barrois fand sie beim See Tiberias und ich selbst sehr häufig in Aegypten.

Durch die Fundorte um Basel werden die Faunenlisten des Elsass, der Schweiz und von Frankreich zugleich um eine neue Art bereichert.

\section{Cyclops bicuspidatus Claus.}

Cyclops biscuspidatus Claus (185̈7). Heller, Hoeck, Fric, Schmeil, Richard, STECK, SCOURFIELD.

Cyelops pulchellus Sars (1863). Rehberg, Vejdowsky, Daday, Vosseler, Sostarié, Thallwitz, Lande.

Cyclops pectinatus Herrick (1883).

Ciyclops Thomasi Forbes (nach Herrick) (1884).

Cyclops navus Herrick (1884), Brewer (1898).

Ciyclops entzii Daday (1885).

Cyclops roseus Daday (1885̈).

Das rudimentäre Füsschen, dessen Dorn, im Gegensatz zur Cyclops strenuus-Gruppe, apikal inseriert ist, zeigt bei bicuspidatus relativ starke Dimenisionen und teilt mit dem von strenuus 
die Besonderheit, dass unter dem medialen Stachel ein kleines Dörnchen inseriert ist. Dieser Umstand, sowie die Näpfchen der Cuticula, sind noch primäre Charaktere; habituell ist Cyclops bicuspidatus ganz littoral, ja fast zur abyssalen Grundform geworden.

Die Antennen erreichen nur ausnahmsweise die Grenze des ersten Cephalothoraxsegmentes. Bei 12 von 173 untersuchten Exemplaren ragten sie schwach über das Segment hinaus. Wie der Typus einer kurzen Antenne es verlangt, besitzt sie:

1) einen langen Sinneskolben, der die Länge der zwei folgenden Segmente erreicht,

2) auffallend kurze Beborstung,

3) kein verjüngtes Ende und in Uebereinstimmung damit

4) keine hyaline Rudermembran.

Die Färbung ist das typische Dunkelbraun.

Die Eiballen gehören zu den grössten des Genus, und der Umstand, dass sie stets in einem vorgerückten Stadium der Reife erscheinen, lässt mich vermuten, dass wir es hier, wie bei Cyclops strenuus, mit einer abgekürzten Ovogenese zu tun haben könnten (vergl. Häcker: Die Eibildung bei Cyclops und Canthocamptus. Zool. Jahrb., Abteilung für Anat. und Ontog. Bd. 5, 1892).

Cyclops bicuspidatus ist, wie die Tabellen zeigen, um Basel herum häufig; doch kommt er immer nur in wenigen Exemplaren vor. Er hat eine Neigung zur Stenothermie und verschwindet im Sommer aus kleineren Gewässern.

Im Säckinger See fand ich ihn bei 10 Meter Tiefe im Schlamm, zusammen mit den verwandten, aber kriechenden Formen Cyclops bisetosus und languidus. Den freien See bevölkerten Cyclops leuckarti und Diaptomus gracilis.

Nicht nur die Körperbeschaffenheit, auch das Vorkommen spricht gegen eine pelagische Lebensweise.

Zwar nennt der Amerikaner ForBes Cyclops bicuspidatus 
eine gemeine pelagische Art der Seen seiner Heimat. (ZschokkE: Die Tierwelt der Hochgebirgseen, pag. 143.) Doch nach allem, was wir über den fraglichen Cyclops wissen, klingt die Angabe sehr unwahrscheinlich. Zu den schon aufgezählten kommen noch folgende Gründe, die a priori unbedingt gegen eine pelagische Lebensweise unserer Art sprechen.

Der Widerstand, den Flüssigkeiten und Gase gegen die Bewegung fester Körper ausüben, nimmt zu :

1) Mit der Grösse des Querschnitts des bewegten Körpers.

2) Mit der 4. Potenz seiner Geschwindigkeit.

Bei gleichbleibendem Querschnitt sind die Vorteile besserer Lokomotionsapparate verschwindend, da ja die gewonnene Geschwindigkeit bloss den Widerstand ins Ungemessene steigert. Ein Tier kann seine Geschwindigkeit nur erhöhen, wenn sich sein Querschnitt verringert. Bei Diaptomus verhält sich die Länge des Thorax zur Breite wie $3: 1$ oder $2,5: 1$. Bei den pelagischen Cyclopiden finden wir ohne Ausnahme das Verhältnis $2: 1$. Und wenn wir dieses auch bei nicht pelagischen Arten treffen, so bleibt es doch die äusserste conditio sine qua non des pelagischen Lebens. Denn diejenigen Formen, die sich zwar durch lange Antennen und an diesen durch breite Membranen und lange Fiedern auszeichnen, aber infolge der Präponderanz der produktiven Organe einen umfangreichen Cephalothorax haben, sind nicht im Stande, ein pelagisches Leben zu führen. Die längsten Antennen des Genus finden sich bei Cyclops fuscus und albidus, deren Thoraxlänge sich zur Breite verhält wie 1,75:1 bei Cycl.fuscus, 1,7: 1 bei Cycl. albidus.

Cyclops bicuspidatus steht den beiden Formen in ihrer Korpulenz keineswegs nach; auch bei ihm beträgt das Verhältnis $1,7: 1$.

Deshalb dürfen wir annehmen, dass, wenn geeignete Formen wie die beiden genannten Arten einer Eigentümlichkeit wegen mit den pelagischen Arten nicht konkurrieren können, der in 
jeder Weise hiezu ungeeignete Cyclops bicuspidatus wegen der gleichen Eigentümlichkeit es auch nicht wird können.

\section{Cyclops vernalis Fischer.}

Cyclops vernalis Fischer (1833). Richand, Schment (1882), Claus, Zschokke, Scourfield, Matile.

Cyclops lucidulus Sars (1863). Daday, Rehberg, Herrick, Sostarié.

Cyclops robustus Sars (1863).

Cyclops elongatus Claus (1863). Heller, Rehberg, Herrick, Schíeil (1891).

Cyclops uniangulatus Cragin (1883).

Cyclops brevispinosus Herrick (1883).

Cyclops parcus Herrick (1883)?

SchmeIL stellt wie Clads Cyclops vernalis mit bicuspidatus und bisetosus zusammen. Ich tue dasselbe; aber nicht wie die beiden Autoren wegen der habituellen Aehnlichkeit, die diese Formen ja auch mit Cyclops viridis verbindet, sondern aus den bei der Beschreibung dieser Art angeführten Gründen. Dem dort gesagten habe ich noch beizufügen, dass das mediale Dörnchen des rudimentären Fusses schwach behaart ist im Gegensatz zu Cyclops viridis, und dass die Fruchtbarkeit, so viel ich gesehen, bei vernalis ihre höchste Grenze erreicht. Ich habe Eiballen von 98 Eiern gesehen, so dass das betreffende Tier gegen 200 Eier allein aussen am Leibe trug. Das Receptaculum ähnelt dem von Cyclops albidus in seiner oberen Hälfte.

In seinem Vorkommen spricht sich sein schwach stenothermer Charakter aus. Am häufigsten ist er im Frühjahr; auch findet er sich oft in den zurückgelassenen Lachen zurückgetretener oder abgestellter Flüsse. Sein Vorzugsgebiet ist der Schwarzwald. In meinen Tabellen finden sich auch schweizerische Fundorte, deren bis jetzt erst einer durch ZschokkE konstatiert worden war, in dem Seengebiet des Rhätikon mit dem höchsten Vorkommen der Art im Gafiensee (2313 m).

Rev. Suisse DE Zool. T. 11. 1903. 


\section{Cyclops bisetosus Rehberg.}

Cigclops biscuspidatus Sars (1862).

Cyclops bisetosus Rehberg (1880). Schmeil, Claus, Scolrfield.

Cyclops pulchellus (bicuspidatus var. bisetosus, Herrick (1884). Brewer.

Ein merkwürdiger Differentialcharakter unterscheidet $C y$ clops bisetosus von allen übrigen Formen. Das ist sein Receptaculum, das mit dem von Cyclops bicuspidatus grosse Aehnlichkeit hat, aber seine oberen Ecken spitz auslaufen lässt. ScHMEIL spricht von 2 Hörnchen. Vielleicht sind es Drüsengänge. (vergl. Fig. 20 und 21.)

Die Antenne gleicht Punkt für Punkt der von Cyclops vernalis und bicuspidatus, und dieselbe überraschende Aehnlichkeit finden wir im Bau der Furka.

Das Füsschen gleicht ganz dem von bicuspidatus, nur dass es schmächtiger ist.

Die kurzen Schwimmfüsse und die dorsoventrale Abplattung des Körpers ermöglichen eine kriechende Lebensweise. Mit ihr tritt eine schöne Rosa- oder Blaufärbung auf, doch nicht in dem Masse, wie bei den kriechenden Formen der Trifida.

Ich kenne bei Basel bloss 2 Fundorte dieser Art.

Der erste war von Interesse, weil dic Art dort mit ihren nächsten Verwandten vergesellschaftet war, ein speziell für das Genus Cyclops sehr bezeichnendes Verhalten. Es war dies im Säckingersee, wo die Mitbewohner der Tiefe, in der Cyclops bisetosus sich aufhielt, die Arten biscuspidatus und languidus waren.

Der zweite Fundort ist der im Sommer jeweilen steintrockene Mönchensteiner Feuerweiher. Er ist der erste schweizerische Fundort dieser Art und zeigt, dass die Art ein Eintrocknen überdauern kann. 
Cyclops languidus Sars.

Cyclops languidus Sars (1862). Herrick, Schmeit, Richard, Daday.

Cyclops languidus ist die einzige Cyclopsart mit 16 gliederigen Antennen. Es ist hier die beginnende Verkümmerung der elfgliederigen Formen angedeutet; die Art übernimmt von bisetosus die kriechende Bewegungsart, aber in äusserst schwächlicher Weise. Das Verhältnis zwischen Thorax- und Abdomenlänge nähert sich wieder dem der pelagischen Arten; bei Cyclops bisetosus hatten wir noch $1: 1,37$, hier finden wir $1: 1,26$.

Bemerkenswert ist die Bildung der Schwimmfüsse, die unsern Cyclops auch als Uebergangsform dokumentieren. Cyclops languidus ist die einzige Art, die Schwimmfussäste mit drei und solche mit zwei Segmenten besitzt. Zwei Segmente bloss besitzen die beiden Aeste des ersten Paares und jeweilen der Innenast des zweiten Paares.

Die geringe Grösse zeigt auch die Kümmerform an. Meine Exemplare betrugen nie viel mehr als $1 \mathrm{~mm}$. SchmeIL fand im «Süssen See» Tiere, die nur 0,86 mm. Länge zählten.

Ich beobachtete das Tier hauptsächlich in moorigen Gewässern des Schwarzwalds, dann im Säckingersee und auch auf Schweizerboden, in einem moorigen Tümpel beim Dorfe Allschwyl. Ich fand ihn zu jeder Jahreszeit. Nichtsdestoweniger fehlt er dem Hochgebirge, zeichnet sich aber durch weite horizontale Verbreitung aus. So konstatierte ihn SARS in Norwegen und DADAY auf der Insel Ceylon.

\section{Cyclops bicolor Sars.}

Cyclops bicolor Sars (1862). Schmeil, Zschoкke, Scourfield.

Cyclops diaphamus Rehberg (1880). Daday, Lande, Richard.

? Cyclops longicaudatus Poggenpol (1871). 
? Cyclops ignceus Poggenpol (1874).

Cyclops brevisetosus Daday (188ว).

Cyclops tenuicaudis Daday.

SaRs und SchmeIL betonen beide die grosse Aehnlichkeit zwischen Cyclops varicans und bicolor. Diese Aehnlichkeit beruht auf einer konvergenten Entwicklung. Ich verweise hier auf das bei Cyclops gracilis Gesagte.

Hier verdienen nur noch die Verhältnisse der Furka eine Besprechung. Die Verhältnisse der Apikalborsten der Furkaläste unterliegen in den verschiedenen Reihen des Genus einer bestimmten Entwicklungstendenz, die darin besteht, dass bei kürzer werdender Antenne die beiden mittleren Borsten an Länge zunehmen, die beiden äussersten abnehmen und zwar so, dass die externe rascher reduziert wird als die interne. Primäre Formen (vergl. z. B. Cyclops stremus) haben darum die erste Borste (von innen gezählt) länger (etwa doppelt so lang) als die vierte. Hier bei Cyclops bicolor finden wir gerade umgekehrte Verhältnisse. Er, dessen Reduktion am weitesten gediehen, zeichnet sich dadurch aus, dass seine längste Borste, die Borste Nr. 2, nicht wie bei den anderen Formen die Länge des Abdomens, sondern bloss die der beiden letzten Abdominalsegmente erreicht. Die interne Borste, die erste, ist nicht ganz dreimal so lang als die externe, ein Verhältnis, wie wir es nicht einmal bei Cyclops stremuus vorfinden. Es lässt dieser Umstand mit Sicherheit auf besondere biologische Verhältnisse bei den Kümmerformen schliessen.

Cyclops bicolor wird seiner Kleinheit wegen oft übersehen, meine Exemplare massen von 0,8 bis 1,4 mm.

Ich fand ihn bloss in einem einzigen Gebiete, in den Rheinsümpfen nördlich von Basel. Aus manchen verschwand er im Winter und zeigte sich als schwach stenotherme Warmwasserform. Auf schweizerischem Gebiet haben sich nirgends Exemplare dieser Art vorgefunden. Der einzige Fundort der Schweiz. 
bleibt demnach noch der Lac des Brenets, wo er von ZschokKE nachgewiesen wurde. Seine Verbreitung ist nicht gross; soviel wir heute wissen, ist es eine spezifisch europäische Art.

\section{Cyclops diaphanus nov. var. diaphanoides.}

Cyclops diaphamus Fischer (185̈3). Schmell, Claus, Sostarié. (?)

Cyclops minutus Claus (1863). Heller (?)

Cyclops Frivaldszliyi Daday (1883)

Nachdem schon frühere Autoren den Cyclops diaphanus mit den durch konvergente Reduktion ähnlichen Arten, besonders mit Cyclops gracilis zusammengestellt hatten, ist Cuaus, in seinem Irrtum befangen, sogar so weit gegangen, in dem Receptaculum der beiden Arten eine auf Verwandtschaft schliessen lassende Aehnlichkeit herauszulesen. Claus, der diese SchNeIL leider nicht vorliegende Art im Jahre 1894 genau beschrieben, betrachtete nur die Vorder- und nicht auch die Seitenansicht des Organs. In dieser springt die Aehnlichkeit mit Cyclops bicolor sofort in die Augen. Bei gracilis verliert sich der untere Teil der Samentasche als langer Schlauch im Innern des betreffenden Segments; bei den andern Arten ragen oberer und unterer Teil in sehr charakteristischer Weise hervor. (Vergl. Fig. 11-14, 29 und 34-36.) Der nächste Verwandte unserer Form ist Cyclops languidus. Abgesehen von den ähnlichen Grössenverhältnissen, ergibt sich dies vor allem aus der Gestalt des zweiten Gliedes des rudimentären Füsschens und ganz besonders aus dem Vorkommen einer Varietät, die unbedingt eine Zwischenform der beiden Arten ist. Diese Varietät besitzt von Cyclops languidus die Schwimmfüsse und das Receptaculum, während sie mit dem typischen Cyclops diaphanus die Zahl der Antennenglieder, den Bau des rudimentären Füsschens (vergl. Fig. 28) und der Furka (vergl. Fig. 24) gemein hat. Hiezu kommt, dass die Varietät wie Cyclops languidus die Fähigkeit besitzt, wenigstens schwach 
auf fester Unterlage zu kriechen, und dass ihre Antennen etwas länger sind als bei Cyclops diaphanus, d. h. das erste Cephalothoraxsegment überragen.

Wie Cyclops languidus, so findet sich diese Varietät von diaphanus in Torfmooren. Ich fand sie am 12. Juli 1895 im Torfstich von Jungholz und 5 Jahre später an einer ganz anderen Oertlichkeit des Schwarzwaldes, im Nonnenmattweiher, der sich aber auch durch ausgeprägten torfmoorigen Charakter auszeichnet. Da die Varietät noch nie beschrieben worden ist, dürfte sie dem Schwarzwalde eigentümlich sein. 


\section{LITTERATURVERZEICHNIS}

Amberg, 0. Beiträge zur Bioloyie des Katzensees. Vierteljahrsschrift. Naturf. Gesellschaft Zürich, Jahrg. 4ö, 1900.

AsPer, G. Wenig bekannte Gesellschaften kleiner Tiere unserer Schweizerseen. Neujahrsblatt der Zürcher Naturf. Gesellschaft, 1880.

Asper, G. und Heuscher, J. Zur Naturgeschichte der Alpenseen. Bericht über die Tätigkeit der St. Galler naturw. Gesellschaft (188ə/86), 1887.

- Neue Zusammensetzung der pelayischen Organismenwelt. Zool. Anz. Jahrgang IX, Seite 448, 1886.

BAIRD, W. The natural history of the British Entomostraca. Ray Society, 1849, London, 1850.

Blanchard, R. et Richard, J. Sur la faune des lacs élevés des Hautes-Alpes. Mémoires de la Soc. zool. de France, T. X, p. 43, 1879.

Brady, G. S. A monograph of the fiee and semi-parasitic Copepoda of the British Islands. 3 Bände. Ray Society, 1878-1880.

- A revision of the british species of fresh-water Cyclopidae and balanidae. Nat. Hist. Transact. of North., Durh. and Neweastle, vol. VI, 1891.

Brewer, Albert-D. A study of the Copepoda found in the vicinity of Lincoln Nebraska. Journ. Cin. Soc. Nat. Hist., vol. XIX, Nr. 4, 1898.

Burckhardt, G. Faunistische und systematische Studien über das Zooplankton der grösseren Seen der Schweiz und ihrer Grenzgebiete. Rev. suisse de Zool., T. 7, 1900.

- Quantitative Studien über das Zooplankton des Vierwaldstättersees. Mitteilungen der Naturf. Gesellschaft Luzern, 1900.

Claus, C. Pas Genus Ciyclops und seine einheimischen Arlen. Archiv für Naturgeschichte. Jahrg. XXIII, 1. Band, 1857.

- Die einheimischen Copepoden. Eine kurze Notiz zur Lokalfauna Giessens. Sechster Bericht der Oberhessischen Gesellsch., Giessen, 1857.

- Zur Anatomie und Enlwicklungsgeschichte der Copepoden. Archiv für Naturgeschichte. 24. Jahrg., Band I, 1858. 
Claus, C. Zur Morphologie der Copepoden. Würzburger naturw. Zeitschrift, Band I, 1860.

- Ueber die blassen Kolben und Cylinder an den Antennen der Copepoden und Ostracoden. Ebenda, 1860.

- Ueber die Antennen der Cyclopiden und die Auflösung der Galtung Cyclops in Gattungen und Untergattungen. Anz. der Kaiserl. Akad. der Wissensch., Wien, Nr. IX, Sitzung vom 16. März 1893.

- Ueber die Bildung der Greifantennen der Cyclopiden und ihre Zurückführung auf die weiblichen Antennen und auf die Calaniden. Zool. Anz., 1893.

- Ueber die sogenannten Bauchwirbel am integumentalen Skelett der Copepoden und die medianen Zwischenplatten der Ruderfusspaare. Arbeiten aus dem zool. Institut zu Wien, T. X, Heft 3, 1893.

- Neue Beobachtungen über die Organisation und Entwicklung von Cyclops. Ein Beitrag zur Systematil der Cyclopiden. Ebenda, 1893.

-- Ueber die Wiederbelebung im Schlamm eingetrockneter Copepoden und Copeporden-Eier. Zugleich ein Beilrag zur Kenntnis von Mikrocyclops diaphanus (Fisch.)-minutus (Claus). Ebenda, T. XI, 1894.

Cragin, F. W. A contribution to the history of the fresh-water-copepoda. Kansas akad. of science, Bd. VIII, 1883.

Daday, E. v. Catalogus Crustaceorum, faunce Transsylvanice. In : Kolozs. orv. term. tud. Ertasitö, Jahrgang IX, 161, 1884.

- Conspectus Diaptomorum faune hungarice. In: Math. naturw. Berichte a. Ungarn, Band XIII, p. 114-143, Taf. IV-VI, 1890.

- Uebersicht der Diaptomusurten Ungarns. Ebenda, Band XIV, p. $177-180,1890$.

- Ujabb adatok a Balaton Mikrofaunájanak ismeretéhez. 'Nematoda, Rotatoria, Entomostraca). In : Math. term. tud. Ertesitö, Bd. XII, p. 122-14.ั, 1894 .

- Mikroskopische Süswassertiere aus Ceylon. In : Termeszetrajzi Füzetek, vol. 20, 1897.

van Douwe, C. Die freilebenden Süsswassercopepoden Deutschlands: Diaptomus denticornis Wierz. Zool. Anz., Band 22, 1899.

- Zur Morphologie des rudimentären Copepodenfusses. Zool. Anz., Bd. 22, 1899.

Fischer, S. Beiträge zur Kenntnis der in der Umgegend von St. Petersburg sich findenden Cyclopiden. In: Bull. de la soc. imp. des naturalistes 
de Moscou, Tome XXIV, seconde partie, p. 409-438, Taf. IX und $\mathrm{X}, 1851$.

Fischer, S. Beiträge zur Kennlnis der in der Umgegend von St. Petershurg sich findenden Cyclopiden. (Fortsetzung). Ebenda, Tome XXVI, Nr. 1, p. 74-100, Tafel II und III, 1833.

Fric, (Ant. -) Jos. Al. Note préliminaire sur l'ontogénie de nos Copépodes d'eau douce. In : Zool. Anz., V. Jahrg., Nr. 121, 1882

Fuhrmann, 0. Recherches sur la faune des lacs alpins du Tessin. Revue suisse de Zoologie, T. 4, 1897.

Giesbrecht, W. Systematik und Faunistik der pelagischen Copepoden des Golfs von Neapel und der angrenzenden Meeresabschnitte. 19. Monographie der Fauna und Flora des Golfs von Neapel, Berlin, 1892.

Gruber, Aug. Beiträge zur Kenntnis der Generationsorgane der freilebenden Copepoden. In : Zeitschr. für wissenschaftl. Zoologie, Band XXXII, p. 407-442, Taf. XXIV-XXVII, 1879.

Greter, A. Les Harpacticides du Val Piora. In : Rev. suisse de Zool., T. 6 , 1889 .

Guenne, Jul. de. La faune des eanx douces des Azores et le transport des animanx à grande distunce par l'intermédiaire des oiseaux. In : C. R. Soc. Biologie, 22. 0kt. 1887.

Guerne, Jul. de, et Richard, J. Sur la distribution géographique du genre Diaphtomus. In: Comptes rendus de l'académie des sciences, 2 juillet 1888.

- Revision des Calanides d'eau douce. In : Mém. de la Soc. zool. de France, T. II, p. 53 $3-181$ mit 4 Taf., 1889.

HaRTog, M. The relations of the Copepoda and the morphologie of Cyclops. In : Journ. Lin. Soc. London, vol. XVIII, 188 s.

Hantwig, W. Die Krebstiere der Provinz Brandenbourg. In: Naturwissenschaftliche Wochenschrift. Bd. X, 1895.

Імноғ, 0.-E. Ueber die pelagische Fauna einiger Seen des Schwarzwaldes. Zool. Anz., Band 14, 1891.

Jurine, L. Histoire des Monocles qui se trouvent aux environs de Genève. 22 Tafeln, Genève et Paris, 1820.

Lewander, K. M. Zur Kenntniss der Fauna und Flor a Finnischer Binnenseen. In : Acta Societatis Pro Fauna et Flora Fennica. XIX. No 2, 1900. Lilljeborg, W. Description de deux espéces nouvelles de Diaptomus du nord de l'Europe (Diapt. graciloides u. serricornis). In : Bull. de la soc. zool. de France, T. XIII, p. $156,1888$. 
Mrazer, Al. Beitrag zur Kenntnis der Harpacticiden Fauna des Süsswassers. Zool. Jahrb. f. Systematik, etc. Band VII, 1892.

- Ueber abnorme Vermehrung der Sinneskolben an dem Vorderfühler des Weibchens bei Cyclopiden, etc. Zool. Anz., XVI, 1893.

- Ueber die Systematik der Cyclopiden und die Segmenlation der Antennen.

- Zur Morphologie der Antennen der Ćyclopiden.

- Copepoden. Deutsch-Ost-Afrika, wissensch. Forschungsresultate, etc. Band IV, Die Tierwelt Ostafrikas, 189.

Matile, Paul. Contribution à la faune des Copépodes des environs de Moscou. Bull. de Moscou, 1897.

Poppe, S.-A. u. Mrazek, A. Eutomostraken des Naturh. Museums in Hamburg. Beiheft zu den Jahrb. d. Hamburgischen wissenschaftlichen Anstalten, XII, 1895.

Richard, Jules. Entomostracés d'eau douce de Sumatra el de Celèbes. Ergebnisse einer Reise in Niederl. Ostindien, herausgegeben von Max Weber. Bd. II, Leiden, 1891.

- Recherches sur le système glandulaire et sur le système nerveux des Copépodes libres d'eau douce, suivies d'une revision des espèces de ce groupe qui vivent en France. Ann. scienc. nat. zool., T. XII, 1891.

- Entomastraces recueillis par M. Steindachner dans les lacs de Janina et de Scutciri. Ann. nat. Hofmus., Wien, Bd. 21, 1897.

SARs, G.-0. Oversigt af den indenlanske Fersvandscopepoden. Forhandlinger i Videnskabs - Selskabet i Christiania, Aar, 1862.

SchmeIt, O. Die Copepoden des Rhätikongebirges. Abh. Naturf. Gesellsch., Halle, Bd. 19, 1893.

- Deutschlands freilebende Süsswasser-Copepoden. Teil 1, 3 u. Nachtrag. Bibl. Zool., 1892-1897.

- Einige neur Harpacticidenformen des Süsswassers. Zeitschr. für Naturw., Bd. 67.

Scourfield, J.-D. A preliminary account of the Entomostraca of North Wales. Journ. Queckett Microscop. Club, vol. 6, 1893 .̈.

STECK, Th. Beilräge zur Biologie des grossen Moosseedorfsees. Mitt. der naturf. Gesellsch. Bern, Jahrg. 1893.

Steuer, Adolf. Bemerkungen über die männlichen Geschlechtsorgane von Cyclops viridis und anderer Copepoden. Verh. der k. k. zool. bot. Gesellsch., Bd. XLVI, 1896. 
Steuer, Adolf. Copepoden und Cladoceren des süssen Wasser's aus der Umgebung von Triest. Ebenda, XLVII, 1897.

- Ein Beitrag zur Kenntnis der Cladoceren und Copepodenfauna Kärntens. Ebenda, XLVII, 1897.

- Die Diaptomiden des Ballan, zugleich ein Beitrag zur Kenntnis des Diaptomus vulgaris Schmeil. Sitzungsberichte d. kaiserlichen Akad. d. Wissensch. in Wien, Bd. CIX, Abt. 1, März 1900.

Stingelin, Th. Beitrag zur Kenntniss der Entomostrakenfauna von Celebès. In : Rev. suisse de Zool., t. 7, 1900.

VERNET, J. Observations anatomiques et physiologiques sur le genre Cyclops. Genève, 1871.

Vosseler, J. Die freilebenden Copepoden Würtembergs und d. angrenzenden Gebiete. Jahreshefte d. Vereins für vaterl. Naturk. in Würtemberg. 22. Jahrg., 1886.

Znmer, C. Das tierische Plankton der Oder. In : Zool. Anz., Bd. XVII, 1898.

Zsснокке, F. Faunistische Studien an Gebirgsseen. Verhandl. der Naturf. Gesellsch. in Basel, Bd. IX, 1890.

- Beitrag zur Kenntnis der Fauna von Gebirgsseen. Zool. Anz., Jahrg. XIII, 1890.

- Weiterer Beitrag zur Kenntnis der Fauna von Gebirgsseen. Zool. Anz., Jahrg. XIV, 1891.

- Die zweite zool. Excursion an die Seen des Rhätikon. Verhandl. der Naturf. Gesellschaft in Basel, Bd. IX, 1891.

- Die Tierwelt der Juraseen. Revue Suisse der zool., 1894.

- Die Fauna hochgelegener Gebirgsseen. Verhandl. der naturf. Gesellsch. in Basel, Bd. XI, 1894.

- Die Tierwelt der Hochgebirgsseen : Neue Denkschriften der Schweizer. Naturf. Gesellsch., Bd. XXXVII, 1900. 


\section{$2 \mathrm{BHL}$ Biodiversity Heritage Library}

1903. "Die Copepoden der Umgebung Basels." Revue suisse de zoologie 11, 419-541. https://doi.org/10.5962/bhl.part.22186.

View This Item Online: https://www.biodiversitylibrary.org/item/37620

DOI: https://doi.org/10.5962/bhl.part.22186

Permalink: https://www.biodiversitylibrary.org/partpdf/22186

\section{Holding Institution}

MBLWHOI Library

Sponsored by

MBLWHOI Library

\section{Copyright \& Reuse}

Copyright Status: NOT_IN_COPYRIGHT

This document was created from content at the Biodiversity Heritage Library, the world's largest open access digital library for biodiversity literature and archives. Visit BHL at https://www.biodiversitylibrary.org. 